\title{
From Stagnation to Growth: Unified Growth Theory*
}

\author{
Oded Galor ${ }^{\dagger}$
}

August 11, 2004

\begin{abstract}
This chapter examines the process of development from an epoch of Malthusian stagnation to a state of sustained economic growth. The analysis focuses on recently advanced unified growth theories that capture the intricate evolution of income per capita, technology, and population over the course of human history. Deciphering the underlying forces that triggered the transition from stagnation to growth and the associated phenomenon of the great divergence in income per capita across countries has been widely viewed as one of the most significant challenges facing researchers in the field of growth and development. The inconsistency of non-unified growth models with the main characteristics of the process of development across most of human history induced growth theorists to advance an alternative theory that captures in a single unified framework the epoch of Malthusian stagnation, the modern era of sustained economic growth, and the recent transition between these distinct regimes. Unified growth theory reveals the underlying micro foundations that are consistent with the growth process over the entire history of the human species, enhancing the confidence in the viability of the theory, its predictions and policy implications for the growth process of less developed economies.
\end{abstract}

Keywords: Growth, Technological Progress, Demographic Transition, Income Distribution, Human Capital, Evolution, Natural Selection, Malthusian Stagnation, Class Structure.

JEL classification Numbers: O11, O14, O33, O40, J11, J13.

\footnotetext{
${ }^{*}$ Forthcoming in the Handbook of Economic Growth (P. Aghion and S. Durlauf eds.), North-Holland, 2004.

${ }^{\dagger}$ The author wishes to thank Philippe Aghion, Graziella Bertocchi, Carl Johan Dalgaard, Matthias Doepke, Hagai Etkes, Moshe Hazan, Nils-Petter Lagerloef, Sebnem Kalemli-Ozcan, Daniel Mejia, Joel Mokyr, Omer Moav, Andrew Mountford, Nathan Sussman, and David Weil for valuable discussions and detailed comments, and Tamar Roth for excellent research assistance. This research is supported by NSF Grant SES-0004304.
} 


\section{Table of Content}

1. Introduction

2. Historical Evidence

2.1. The Malthusian Epoch

2.1.1. Income per capita

2.1.2. Income and Population Growth

2.2. The Post-Malthusian Regime

2.2.1. Income Per Capita

2.2.2. Income and Population Growth

2.2.3. Industrialization and Urbanization

2.2.4. Early Stages of Human Capital Formation

2.3. The Sustained Growth Regime

2.3.1. Growth of Income Per Capita

2.3.2. The Demographic Transition

2.3.3. Industrial Development and Human Capital Formation

2.3.4. Industrialization and International Trade

2.4. The Great Divergence

3. The Fundamental Challenges

3.1. Unresolved Mysteries of the Growth Process

3.2. The Incompatibility of Non-Unified Growth Theories

3.2.1. Malthusian and Post-Malthusian Theories

3.2.3. Theories of Modern Growth

3.3. Theories of the Demographic Transition and their Empirical Assessment

3.3.1. The Decline in Infant and Child Mortality

3.3.2. The Rise in Income Per Capita

3.3.3. The Rise in the Demand for Human Capital

3.4.4. The Decline in the Gender Gap

3.3.5. Other Theories

4. Unified Growth Theories:

4.1. From Stagnation to Growth

4.2. Complementary Mechanisms

4.2.1. Alternative Mechanisms for the Emergence of Human Capital Formation

4.2.2. Alternative Triggers for the Demographic Transition

4.2.3. Alternative Modeling of the Transition from Agricultural to Industrial Economy

5. Unified Evolutionary Growth Theory

5.1. Human Evolution and Economic Development

5.2. Natural Selection and the Origin of Economic Growth

5.3. Complementary Mechanisms

5.3.1. The Evolution of Ability and Economic Growth

5.3.2. The Evolution of Life Expectancy and Economic Growth

5.4. Assessment of the Various Mechanisms

6. Differential Takeoffs and the Great Divergence

6.1. Non-Unified Theories

6.2. A Unified Theory: Globalization and the Great Divergence

7. Concluding Remarks

References 
"A complete, consistent, unified theory...would be the ultimate triumph of human reason" Stephen W. Hawking - A Brief History of Time.

\section{Introduction}

This chapter examines the recent advance of a unified growth theory that is designed to capture the process of development over the entire course of human history.

The inconsistency of exogenous and endogenous neoclassical growth models with some of the most fundamental features of process of development, has led recently to a search for a unified theory that would unveil the underlying micro-foundations of the growth process in its entirety, capturing the epoch of Malthusian stagnation that characterized most of human history, the contemporary era of modern economic growth, and the underlying driving forces that triggered the recent transition between these regimes and the associated phenomenon of the Great Divergence in income per capita across countries.

The evolution of economies over the major portion of human history was marked by Malthusian Stagnation. Technological progress and population growth were miniscule by modern standards and the average growth rate of income per capita in various regions of the world was even slower due to the offsetting effect of population growth on the expansion of resources per capita. In the past two centuries, in contrast, the pace of technological progress increased significantly in association with the process of industrialization. Various regions of the world economy departed from the Malthusian trap and experienced initially a considerable rise in the growth rates of income per capita and population. Unlike episodes of technological progress in the pre-Industrial Revolution era that failed to generate sustained economic growth, the increasing role of human capital in the production process in the second phase of the Industrial Revolution ultimately prompted a demographic transition, liberating the gains in productivity from the counterbalancing effects of population growth. The decline in population growth and the associated enhancement in technological progress and human capital formation paved the way for the emergence of the modern state of sustained economic growth.

The fundamental factors that generated the remarkable escape from the Malthusian trap have been shrouded in mystery until recently and their significance for the understanding of the contemporary growth process have been under-explored.

- What accounts for the epoch of stagnation that characterized most of human history?

- What is the origin of the sudden spurt in growth rates of output per capita and population?

- Why had episodes of technological progress in the pre-industrialization era failed to generate sustained economic growth?

- What was the source of the dramatic reversal in the positive relationship between income per capita and population that existed throughout most of human history?

- What triggered the demographic transition?

- Would the transition to a state of sustained economic growth have been feasible without the demographic transition?

- What are the underlying behavioral and technological structures that can simultaneously account for these distinct phases of development and what are their implications for the contemporary growth process of developed and underdeveloped countries? 
The perplexing phenomenon of the Great Divergence in income per capita across regions of the world in the past two centuries presents an additional mystery about the growth process.

- What accounts for the sudden take-off from stagnation to growth in some countries in the world and the persistent stagnation in others?

- Why has the positive link between income per capita and population growth reversed its course in some economies but not in others?

- Why have the differences in per capita incomes across countries increased so markedly in the last two centuries?

- Has the transition to a state of sustained economic growth in advanced economies adversely affected the process of development in less-developed economies?

Deciphering the fundamental determinants of the transition from stagnation to growth and the great divergence has been widely viewed as one of the most significant research challenges facing researchers in the field of growth and development.

The transitions from a Malthusian epoch to a state of sustained economic growth and the related phenomenon of the Great Divergence, as depicted in Figure 2.1, have significantly shaped the contemporary world economy. ${ }^{1}$ Nevertheless, the distinct qualitative aspects of the growth process during most of human history were virtually ignored in the shaping of neoclassical growth models, resulting in a growth theory that is only consistent with a small fragment of human history.

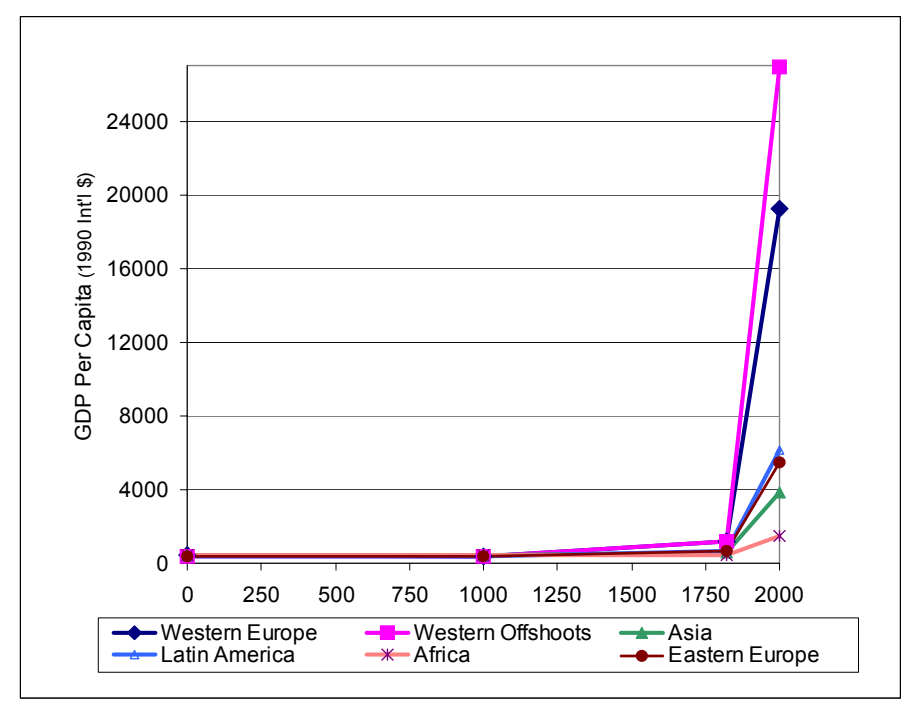

Figure 2.1. The Evolution of Regional Income per Capita over the Years 1 - 2001

Sources: Maddison $(2003)^{2}$

\footnotetext{
${ }^{1}$ The ratio of GDP per capita between the richest region and the poorest region in the world was only 1.1:1 in the year 1000, a 2:1 in the year 1500 and 3:1 in the year 1820. In the course of the 'Great Divergence' the ratio of GDP per capita between the richest region (Western offshoots) and the poorest region (Africa) has widened considerably from a modest $3: 1$ ratio in 1820 , to a 5:1 ratio in 1870, a 9:1 ratio in 1913, a 15:1 in 1950, and a huge 18:1 ratio in 2001.

${ }^{2}$ According to Maddison's classification, "Western Offshoots" consists of United States, Canada, Australia and New Zealand.
} 
The preoccupation of growth theory with the empirical regularities that have characterized the growth process of developed economies in the past century and of less developed economies in the last few decades, has become harder to justify from a scientific viewpoint in light of the existence of vast evidence about qualitatively different empirical regularities that characterized the growth process over most of human existence. Is there a scientific justification for the use of selective observations, only about the contemporary growth process, in formulating theory about the current growth process? Could we be confident about the predictions of a theory that is not based on micro foundations that are consistent with the main elements of the entire growth process? As argued by Copernicus, "it is as thuoght an artist were to gather the hands, feet, head and other members for his images from diverse models, each part perfectly drawn, buut not related to a single body, and since they in no way match each other, the result would be monster rather than man". ${ }^{3}$ The evolution of theories in older scientific disciplines suggests that theories that are founded on the basis of a subset of the existing observations and their driving forces, may be attractive in the short run, but non-robust and ultimately non-durable in the long run. ${ }^{4}$ The attempts to develop unified theories in physics have been based on the conviction that all physical phenomena should ultimately be explainable by some underlying unity. ${ }^{5}$ Similarly, the entire process of development and its basic causes ought to be captured by a unified growth theory.

In recent years, it has been increasingly recognized that the understanding of the contemporary growth process would be fragile and incomplete unless growth theory could be based on proper microfoundations that reflect the qualitative aspects of the growth process and their central driving forces. Moreover, it has become apparent that a comprehensive understanding of the hurdles faced by less developed economies in reaching a state of sustained economic growth would be futile unless the factors that prompted the transition of the currently developed economies into a state of sustained economic growth could be identified and their implications would be modified to account for the differences in the growth structure of less developed economies in an interdependent world.

The transition from stagnation to growth and the associated phenomenon of the great divergence have been the subject of an intensive research in the growth literature in recent years. ${ }^{6}$ The inconsistency of exogenous and endogenous neoclassical growth models with the process of development along most of human history, induced growth theorists to search for an alternative theory that could capture in a single unified framework the contemporary era of sustained economic growth, the epoch of Malthusian stagnation that had characterized most of human history, and the driving forces that brought about the recent transition between these distinct regimes.

Imposing the constraint that a single theory should account for the entire intricate process of development and its prime causes in the last thousands of years is a discipline that would enhance the viability of growth theory. A unified theory of economic growth reveals the fundamental microfoundations that are consistent with the process of economic development over the entire course of human history, rather that with the last century only, boosting the confidence in growth theory, its predictions and policy implications. Moreover, it improves the understanding of the underlying factors

\footnotetext{
${ }^{3}$ Quoted in Kuhn (1957).

${ }^{4}$ For instance, Classical Thermodynamics that lacked micro-foundations was ultimately superseded by the micro-based Statistical Mechanics.

${ }^{5}$ Unified Field Theory, for instance, proposes to unify by a set of general laws the four distinct forces that are known to control all the observed interactions in matter: electromagnetism, gravitation, the weak force, and the strong force. The term unified field theory was coined by Einstein, whose research on relativity had led him to the hypothesis that it should be possible to find a unifying theory for the electromagnetic and gravitational forces.

${ }^{6}$ The transition from Malthusian stagnation to sustained economic growth was explored by Galor and Weil (1999, 2000), Lucas (2002), Galor and Moav (2002), Hansen and Prescott (2002), Jones (2001), Stokey (2002), as well as others, and the association of Great Divergence with the transition was analyzed by Galor and Mountford (2003).
} 
that led to the transition from stagnation to growth of the currently developed countries, shedding light on the growth process of the less developed economies.

\section{Historical Evidence}

This section examines the historical evidence about the evolution of the relationship between income per capita, population growth, technological change and human capital formation along three distinct regimes that have characterized the process of economic development: The Malthusian Epoch, The Post-Malthusian Regime, and the Sustained Growth Regime.

During the Malthusian Epoch that characterized most of human history, technological progress and population growth were insignificant by modern standards. The level of income per capita had a positive effect on population and the average growth rate of income per capita in the long-run, as depicted in Figure 2.2, was negligible due to the slow pace of technological progress as well as the counterbalancing effect of population growth on the expansion of resources per capita. During the Post Malthusian Regime, the pace of technological progress markedly increased in association with the process of industrialization, triggering a take-off from the Malthusian trap. The growth rate of income per capita increased significantly, as depicted in Figures 2.1 and 2.2, but the positive Malthusian effect of income per capita on population growth was still maintained, generating a sizeable increase in population growth that offset some of the potential gains in income per capita. The acceleration in the rate of technological progress in the second phase of the Industrial Revolution, and its interaction with human capital formation ultimately prompted the demographic transition. The rise in aggregate income was not counterbalanced by population growth, enabling technological progress to bring about sustained increase in income per capita.

\subsection{The Malthusian Epoch}

For thousand of years, humans were subjected to persistent struggle for existence. Survival, argued Malthus (1798), necessitated a "perpetual struggle for room and food." Resources generated by technological progress and land expansion were channeled primarily towards an increase in the size of the population, with a minor long-run effect on income per capita. Thus, as reflected in the viewpoint of a prominent observer of the period, "the most decisive mark of the prosperity of any country is the increase in the number of its inhabitants" (Smith 1776).

The evolution of population and output per capita across most of human history was consistent with the Malthusian paradigm. The positive effect of the standard of living on population growth along with diminishing labor productivity kept income per capita in the proximity of a subsistence level. ${ }^{7}$ Periods marked by the absence of changes in the level of technology or in the availability of land, were characterized by a stable population size as well as a constant income per capita, whereas periods characterized by improvements in the technological environment or in the availability of land generated temporary gains in income per capita, leading ultimately to a larger but not richer population. Technologically superior countries had eventually denser populations but their standard of living did not reflect the degree of their technological advancement.

\footnotetext{
${ }^{7}$ This subsistence level of consumption may be well above the minimal physiological requirements that are necessary in order to sustain an active human being.
} 


\subsubsection{Income per capita}

During the Malthusian epoch the average growth rate of output per capita was negligible and the standard of living did not differ greatly across countries. As depicted in Figure 2.2 the average level of income per capita during the first millennium fluctuated around $\$ 450$ per year, and the average growth rate of output per capita in the world was nearly zero. ${ }^{8}$ This state of Malthusian stagnation persisted until the end of the 18th century. The average level of income per capita in the world economy remained below $\$ 670$ per year in the years 1000-1820 and the average growth rate of the world income per capita was miniscule, creeping at a rate of about $0.05 \%$ per year (Maddison 2001).

Average Annual growth of GDP Per Capita

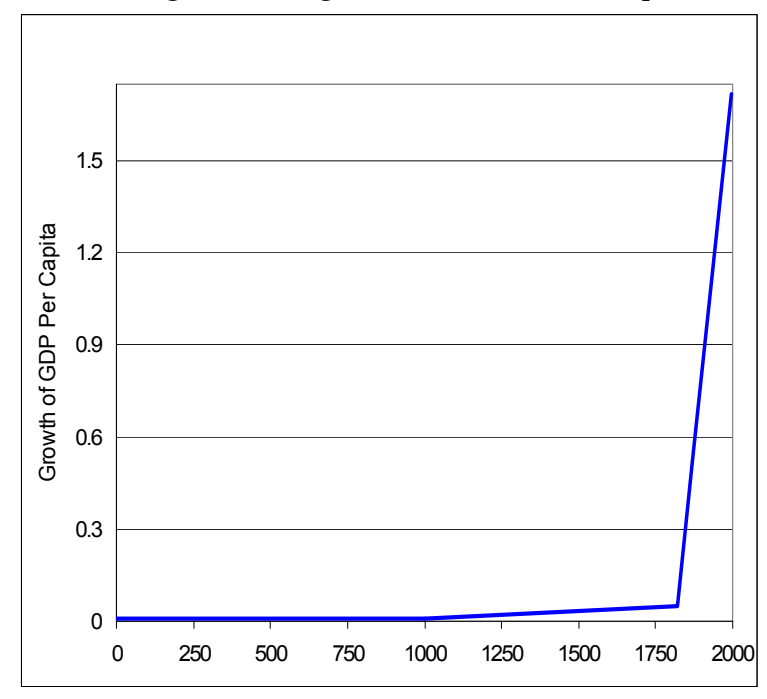

GDP Per Capita

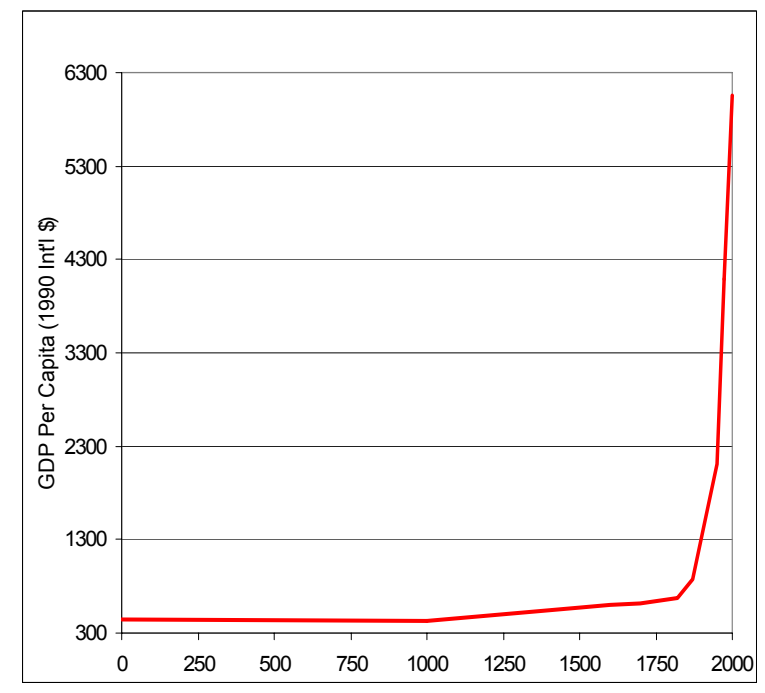

Figure 2.2. The Evolution of the World Income Per Capita over the Years 1-2001

Source: Maddison $(2001,2003)$

This pattern of stagnation was observed across all regions of the world. As depicted in Figure 2.1, the average level of income per capita in Western and Eastern Europe, the Western Offshoots, Asia, Africa, and Latin America was in the range of $\$ 400-450$ per year in the first millennium and the average growth rates in each of these regions was nearly zero. This state of stagnation persisted until the end of the 18th century across all regions and the average level of income per capita in the years 1000-1820 ranged from $\$ 418$ per year in Africa, $\$ 581$ in Asia, $\$ 692$ in Latin America, and $\$ 683$ in Eastern Europe, to $\$ 1202$ in the Western Offshoots, and $\$ 1204$ in Western Europe. Furthermore, the average growth rate of output per capita over this period ranged from $0 \%$ in the impoverish region of Africa to a sluggish rate of $0.14 \%$ in the prosperous region of Western Europe.

Despite the stability in the evolution of the world income per capita in the Malthusian epoch, from a perspective of a millennium, wages and income per capita had fluctuated significantly within regions deviating from their sluggish long-run trend over decades and sometimes over few centuries. In particular, as depicted in Figure 2.3, real GDP per capita in England fluctuated drastically over most of the past millennium. It declined during the 13th century, and increased sharply during the 14th and the 15th century in response to the catastrophic population decline in the aftermath of the Black Death. This two-century rise in per capita real income stimulated population growth and brought about a decline in income per capita in the 16th century back to its level in the first half of the 14th century.

\footnotetext{
${ }^{8}$ Maddison's estimates of income per capita are evaluated in terms of 1990 international dollars.
} 
Real income per capita increased once again in the 17th century and remained stable during the 18th century, prior to its rise during the take-off from the Malthusian epoch in the 19th century.

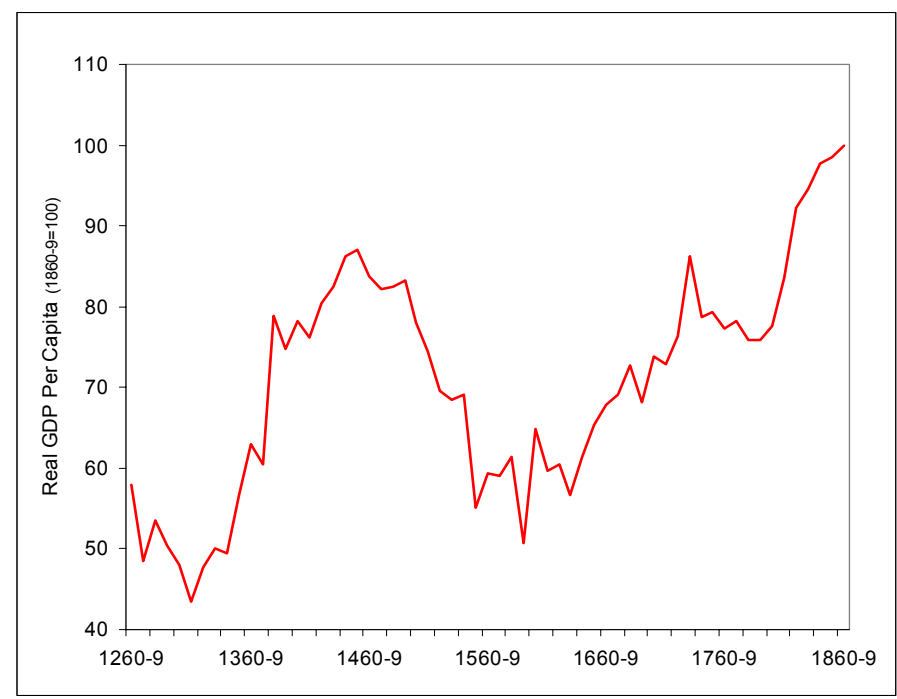

Figure 2.3. Fluctuations in Real GDP Per Capita: England, 1260-1870

Source: Clark (2001)

\subsubsection{Income and Population Growth}

\section{Population Growth and Income level}

Population growth over this Malthusian era followed the Malthusian pattern as well. As depicted in Figures 2.4 and 2.5, the slow pace of resource expansion in the first millennium was reflected in a modest increase in the population of the world from 231 million people in the year 1 to 268 million in the year 1000; a miniscule average growth rate of $0.02 \%$ per year. ${ }^{9}$ The more rapid (but still very slow) expansion of resources in the period 1000-1500, permitted the world population to increase by $63 \%$ over this period, from 268 million in the year 1000 to 438 million in the year 1500; a slow $0.1 \%$ average growth rate per year. Resource expansion over the period 1500-1820 had a more significant impact on the world population, that grew 138\% from 438 million in the year 1500 to 1041 million in the year 1820; an average pace of $0.27 \%$ per year. ${ }^{10}$ This positive effect of income per capita on the size of the population was maintained in the last two centuries as well, as world population reached a remarkable level of nearly 6 billion people.

\footnotetext{
${ }^{9}$ Since output per capita grew at an average rate of $0 \%$ per year over the period $0-1000$, the pace of resource expansion was approximately equal to the pace of population growth, namely, $0.02 \%$ per year.

${ }^{10}$ Since output per capita in the world grew at an average rate of $0.05 \%$ per year in the time period $1000-1500$ as well as in the period 1500-1820, the pace of resource expansion was approximately equal to the sum of the pace of population growth and the growth of output per capita. Namely, $0.15 \%$ per year in the period, $1000-1500$ and $0.32 \%$ per year in the period 1500-1820.
} 


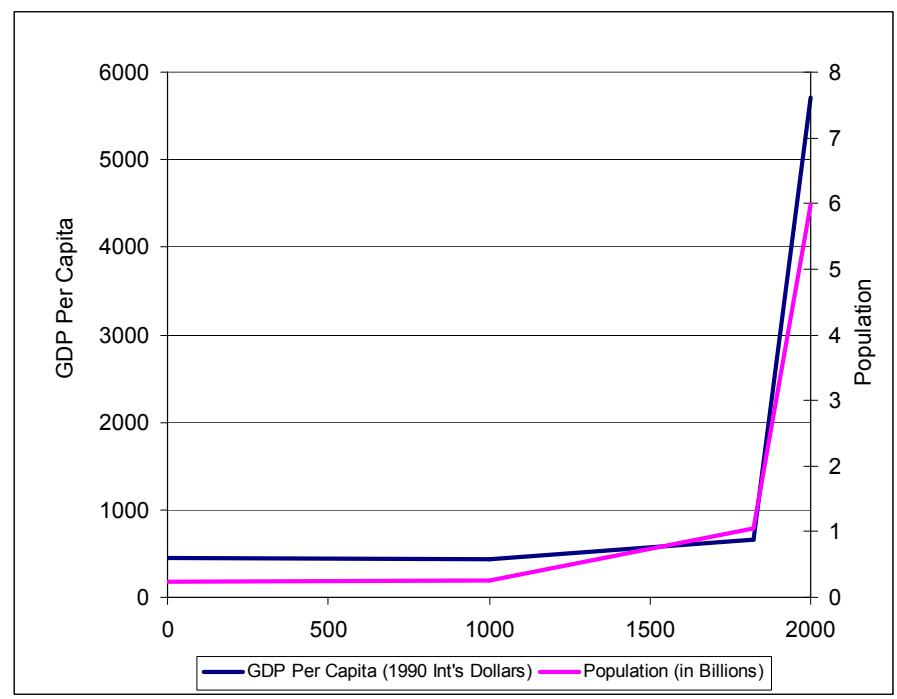

Figure 2.4. The Evolution of World Population and Income Per Capita over the Years 1 - 2000 Source: Maddison (2001)

Moreover, the gradual increase in income per capita during the Malthusian epoch was associated with a monotonic increase in the average rate of growth of world population, as depicted in Figure 2.5. ${ }^{11}$

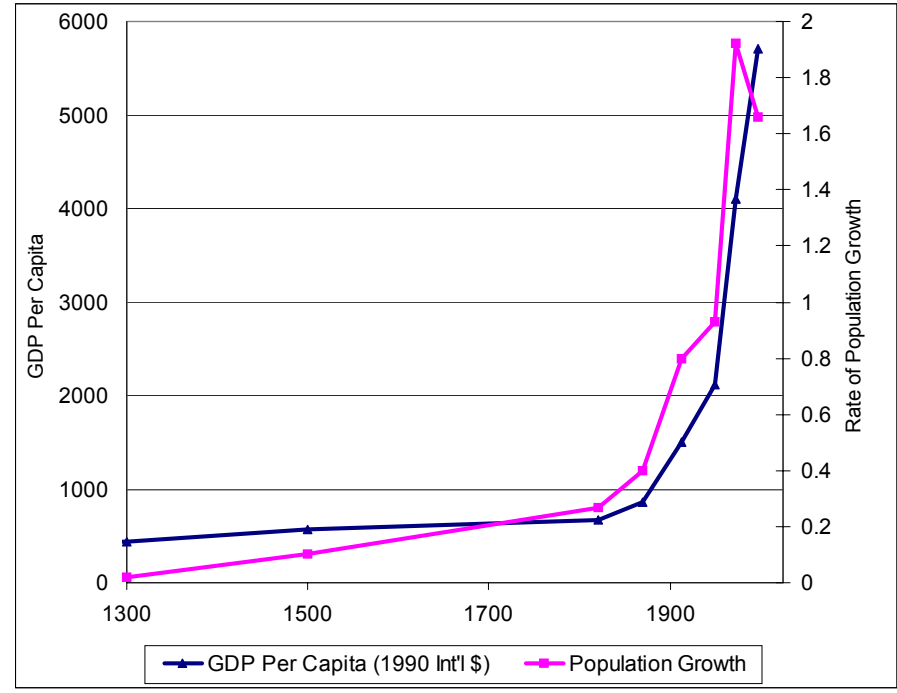

Figure 2.5. Population Growth and Income Per Capita in the World Economy

Source: Maddison (2001)

\section{Fluctuations in Income and Population}

Fluctuations in population and wages exhibited the Malthusian pattern as well. Episodes of technological progress, land expansion, favorable climatic conditions, or major epidemics (that resulted in a decline of the adult population), brought about a temporary increase in real wages and income per

\footnotetext{
${ }^{11}$ Lee (1997) reports positive income elasticity of fertility and negative income elasticity of mortality from studies examining a wide range of pre-industrial countries. Similarly, Wrigley and Schofield (1981) find a strong positive correlation between real wages and marriage rates in England over the period 1551-1801. Clark (2003) finds that in England, at the beginning of the 17th century, the number of surviving offspring is higher among households with higher level of income and literacy rates, suggesting that the positive effect of income on fertility is present cross-sectionally, as well.
} 
capita. In particular, as depicted in Figure 2.6, the catastrophic decline in the population of England during the Black Death (1348-1349), from about 6 millions to about 3.5 millions people, increased significantly the land-labor ratio, tripling real wages in the subsequent 150 years. Ultimately, however, most of this increase in real resources per capita was channelled towards increased fertility rates, increasing the size of the population, and bringing the real wage rate in the 1560 s back to the proximity of its pre-plague level. ${ }^{12}$

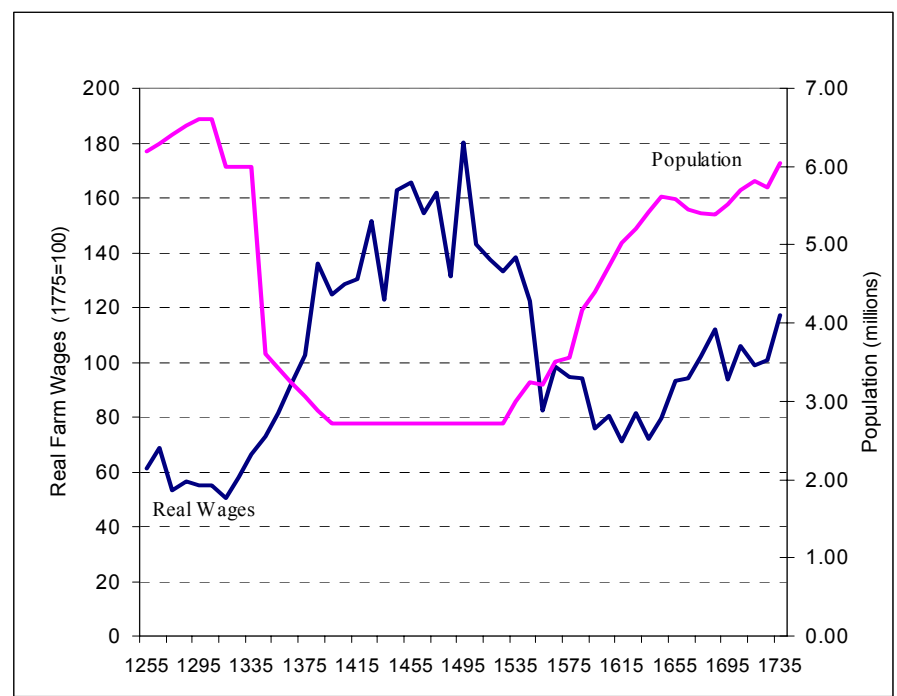

Figure 2.6. Population and Real Wages: England, 1250-1750

Source: Clark $(2001,2002)$

\section{Population Density}

Variations in population density across countries during the Malthusian epoch reflected primarily cross country differences in technologies and land productivity. Due to the positive adjustment of population to an increase in income per capita, differences in technologies or in land productivity across countries resulted in variations in population density rather than in the standard of living. ${ }^{13}$ For instance, China's technological advancement in the period 1500-1820 permitted its share of world population to increase from $23.5 \%$ to $36.6 \%$, while its income per capita in the beginning and the end of this time interval remained constant at roughly $\$ 600$ per year. ${ }^{14}$

This pattern of increased population density persisted until the demographic transition, namely, as long as the positive relationship between income per capita and population growth was maintained. In the period 1600-1870, United Kingdom's technological advancement relative to the rest of the world more than doubled its share of world population from $1.1 \%$ to $2.5 \%$. Similarly, in the period 1820-1870, the land abundant, technologically advanced, economy of the US. experienced a $220 \%$ increased in its share of world population from $1 \%$ to $3.2 \% .^{15}$

\footnotetext{
${ }^{12}$ Reliable population data is not available for the period 1405-1525 and figure 2.6 is depicted under the assumption maintained by Clark (2001) that population was rather stable over this period.

${ }^{13}$ Consistent with the Malthusian paradigm, China's sophisticated agricultural technologies, for example, allowed high per-acre yields, but failed to raise the standard of living above subsistence. Similarly, the introduction of the potato in Ireland in the middle of the 17th century generated a large increase in population over two centuries without a significant improvements in the standard of living. Furthermore, the destruction of potatoes by fungus in the middle of the 19th century, generated a massive decline in population due to the Great Famine and mass migration [Mokyr 1985].

${ }^{14}$ The Chinese population more than tripled over this period, increasing from 103 million in the year 1500 to 381 million in the year 1820 .

${ }^{15}$ The population of the United Kingdom nearly quadrupled over the period 1700-1870, increasing from 8.6 million in
} 


\section{Mortality and Fertility}

The Malthusian demographic regime was characterized by fluctuations in fertility rates, reflecting variability in income per capita as well as changes in mortality rates. Periods of rising income per capita permitted a raise the number of surviving offspring, inducing an increase in fertility rates along with a reduction in mortality rates, due to improved nourishment, and health infrastructure. Periods of rising mortality rates (e.g., the black death) induced an increase in fertility rates so as to maintain the number of surviving offspring that can be supported by existing resources.

The relationship between fertility and mortality during the Malthusian epoch was complex. Demographic patterns in England during the 14th and 15th centuries, as depicted in Figure 2.6, suggest that an (exogenous) increase in mortality rates was associated with a significant rise in fertility rates. However, the period 1540-1820 in England, vividly demonstrates a negative relationship between mortality rates and fertility rates. As depicted in Figure 2.7, an increase in mortality rates over the period 1560-1650 was associated with a decline in fertility rates, whereas a decline in mortality rates in the time period 1680-1820 was associated with increasing fertility rates.

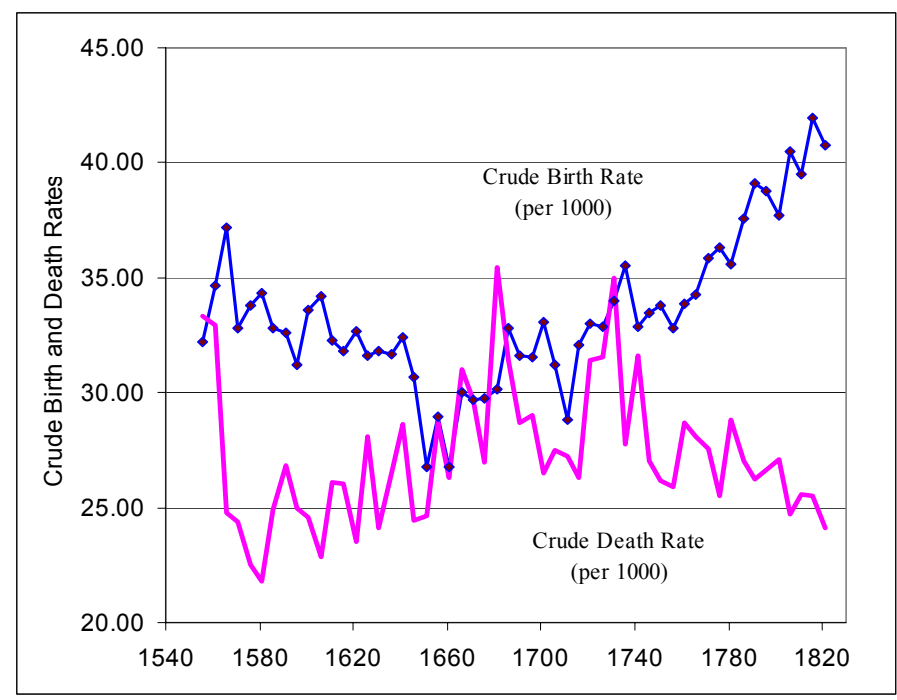

Figure 2.7. Fertility and Mortality: England 1540-1870 Source: Wrigley and Schofield (1981)

\section{Life Expectancy}

Life expectancy at birth fluctuated in the Malthusian epoch, ranging from 24 in Egypt in the time period 33 - $258 \mathrm{AD}$, to 42 in England at the end 16th century. In the initial process of European urbanization, the percentage of urban population increased six-fold from about $3 \%$ in 1520 to nearly 18\% in 1750 (de Vries (1984) and Bairoch (1988)). This rapid increase in population density, without significant changes in health infrastructure, generated a rise in mortality rates and a decline in life expectancy. As depicted in Figures 2.7 and 2.8, over the period 1580-1740 mortality rates increased by $50 \%$ from 0.022 to 0.032 , and life expectancy at birth fell from 42 to 28 (Wrigley and Schofield, 1981). A decline in mortality along with a rise in life expectancy began in the 1740s. Life expectancy at birth rose from 28 to 41 in England and from 25 to 40 in France over the period 1740-1830 (Livi-Bacci 1997).

the year 1700 to 31.4 million in the year 1870. Similarly, the population of the United states increased 40 -fold, from 1.0 million in the year 1700 to 40.2 million in the year 1870, due to a significant labor migration, as well as high fertility rates. 


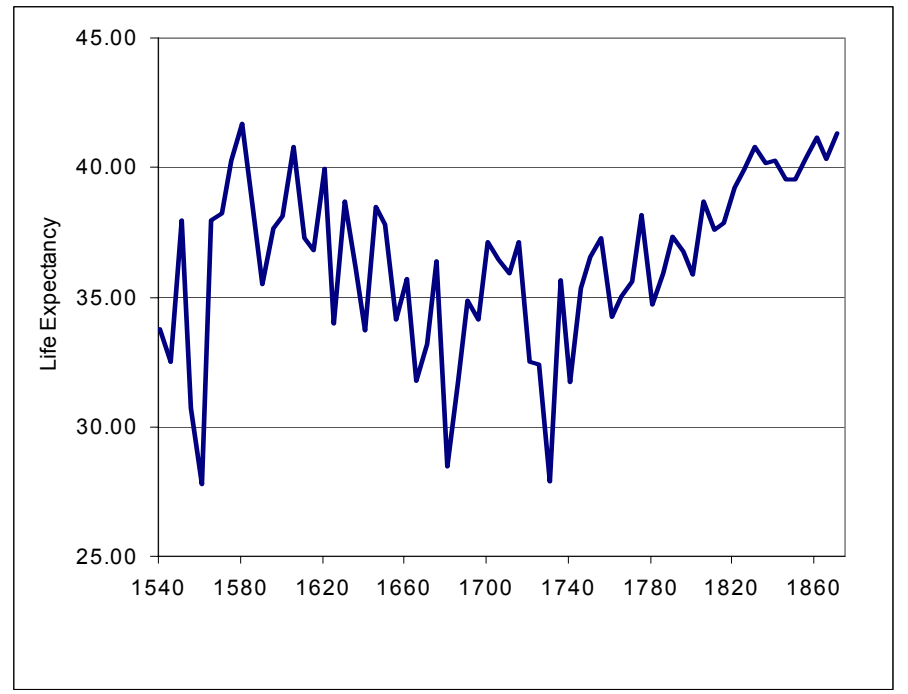

Figure 2.8. Life Expectancy: England, 1540-1870

Source: Wrigley and Schofield (1981)

\subsection{The Post-Malthusian Regime}

The pace of technological progress markedly increased along with the process of industrialization, instigating a take-off from the Malthusian epoch. ${ }^{16}$ The growth rate of output per capita increased significantly, as depicted in Figures 2.1-2.3, but the positive Malthusian effect of income per capita on population growth was still maintained, generating a sizeable increase in population growth, as depicted in Figure 2.4 and 2.5, offsetting some of the gains in income.

The take-off of developed regions from the Malthusian regime was associated with the Industrial Revolution and occurred in the beginning of the 19th century, whereas the take-off of less developed regions occurred towards the beginning of the 20th century and was delayed in some countries well into the 20th century. The Post-Malthusian Regime ended with the decline in population growth in Western Europe and the Western Offshoots towards the end of the 19th century and in less developed regions in the second half of the 20th century.

\subsubsection{Income Per Capita}

During the Post-Malthusian Regime the average growth rate of output per capita increased significantly and the standard of living started to differ considerably across countries. As depicted in Figure 2.2, the average growth rate of output per capita in the world increased from $0.05 \%$ per year in the time period $1500-1820$ to $0.53 \%$ per year in $1820-1870$, and $1.3 \%$ per year in $1870-1913$. The timing of the take-off and its magnitude differed across regions. As depicted in Figure 2.9, the take-off from the Malthusian Epoch and the transition to the Post-Malthusian Regime occurred in Western Europe, the Western Offshoots, and Eastern Europe at the beginning of the 19th century, whereas in Latin America, Asia (excluding China) and Africa it took place at the end of the 19th century.

\footnotetext{
${ }^{16}$ Ironically, it was only shortly before the time that Malthus wrote, that some regions in the world began to emerge from the trap that he described.
} 

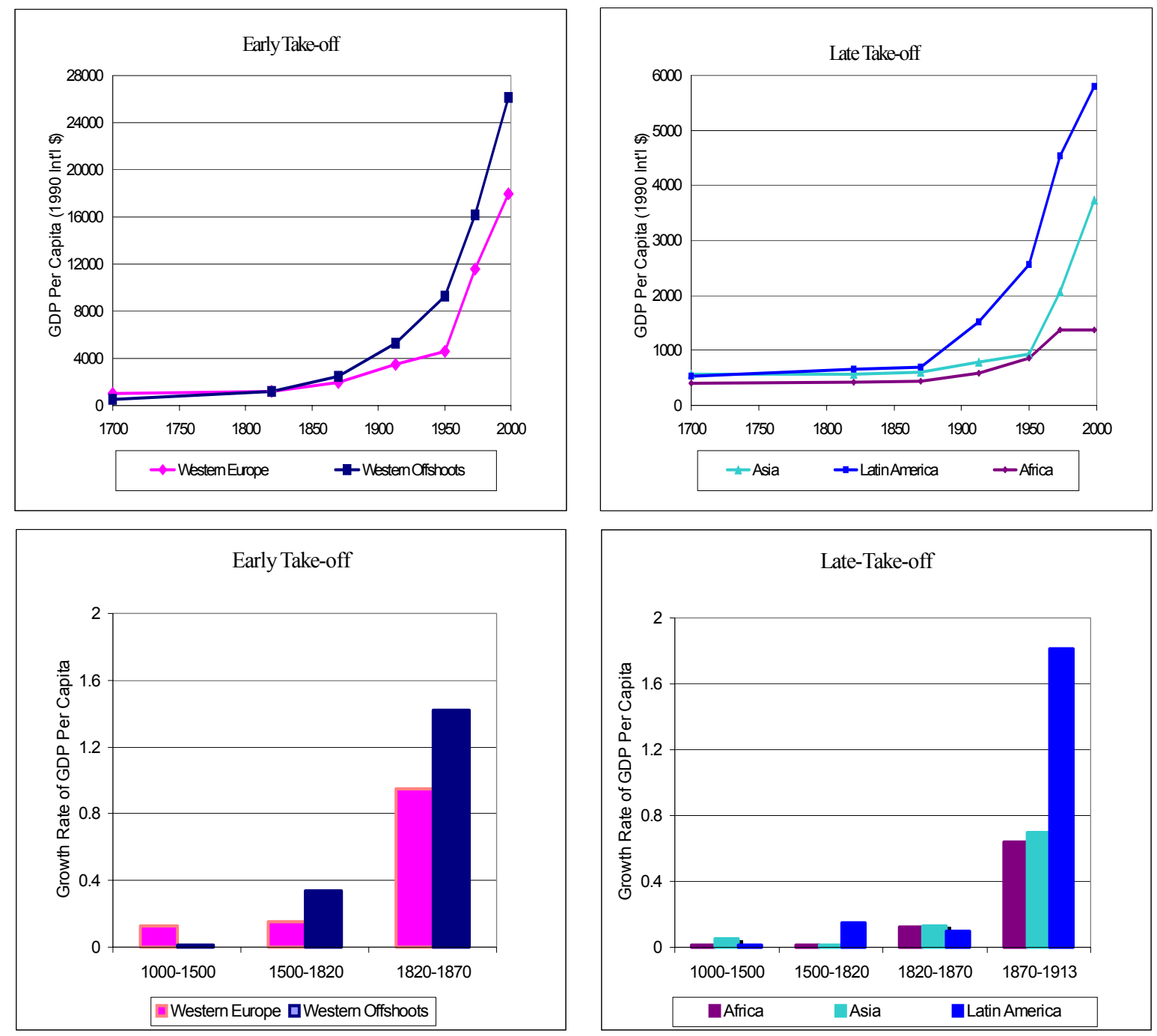

Figure 2.9. The Differential Timing of the Take-off Across Regions.

Source: Maddison (2001)

Among the regions that took off at the beginning of the 19th century, the growth rate of income per capita in Western Europe increased from $0.15 \%$ per year in the years $1500-1820$ to $0.95 \%$ per year in the time period 1820-1870, and the growth rates of income per capita of the Western Offshoots increased over this period from $0.34 \%$ per year to $1.42 \%$ per year. In contrast, the take-off in Eastern Europe was more modest, and its growth rate increased from $0.1 \%$ per year in the period $1500-1820$ to $0.63 \%$ per year in the time interval 1820-1870. Among the regions that took-off towards the end of the 19th century, the average growth rate of income per capita in Latin America jumped from a sluggish rate of $0.11 \%$ per year in the years $1820-1870$ to a considerable $1.81 \%$ per year in the time period $1870-1913$, whereas Africa's growth rates increased more modestly from $0.12 \%$ per year in the years $1820-1870$ to $0.64 \%$ per year in time interval 1870-1913 and 1.02\% per year in the period 1913-1950. Asia's (excluding Japan, China and India) take-off was modest as well, increasing from $0.13 \%$ per year in the years $1820-1870$ to $0.64 \%$ per year in the $1870-1913$ period. ${ }^{17}$

\footnotetext{
${ }^{17}$ Japan's average growth rate increased from $0.19 \%$ per year in the period $1820-1870$, to $1.48 \%$ per year in the period
} 
The level of income per capita in the various regions of the world, as depicted in Figure 2.1, ranged in the year 1870 from $\$ 444$ in Africa, $\$ 543$ in Asia, \$698 in Latin America, and \$871 in Eastern Europe, to $\$ 1974$ in Western Europe and $\$ 2431$ in the Western Offshoots. Thus, the differential timing of the take-off from the Malthusian epoch, increased the gap between the richest regions of Western Europe and the Western Offshoots to the impoverished region of Africa from about 3:1 in 1820 to approximately 5:1 in 1870 .

The acceleration in technological progress and the accumulation of physical capital and to a lesser extent human capital, generated a gradual rise in real wages in the urban sector and (partly due to labor mobility) in the rural sector as well. As depicted in Figure 2.10, the take-off from the Malthusian epoch in the aftermath of the Industrial Revolution was associated in England with a modest rise in real wages in the first decades of the 19th century and a very significant rise in real wages after $1870 .{ }^{18} \mathrm{~A}$ very significant rise in real wages was experienced by France, as well, after 1860.
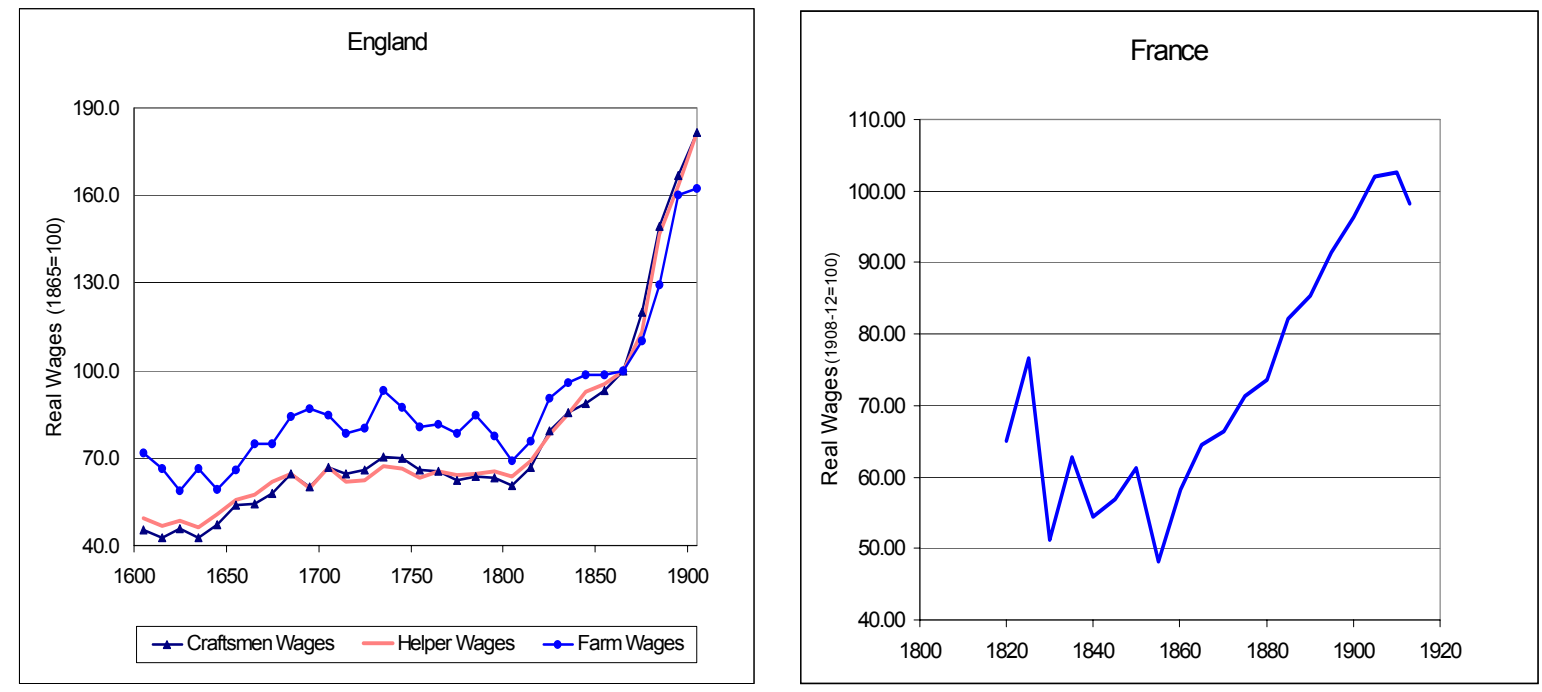

Figure 2.10. Real Wages in England and France During the take-off from the Malthusian Epoch Sources: Clark (2002) for England, and Levy-Leboyer and Bourguignon (1990) for France

\subsubsection{Income and Population Growth}

The rapid increase in income per capita in the Post-Malthusian Regime was channeled partly towards an increase in the size of the population. During this Regime, the Malthusian mechanism linking higher income to higher population growth continued to function, but the effect of higher population on diluting resources per capita, and thus lowering income per capita, was counteracted by the acceleration in technological progress and capital accumulation, allowing income per capita to rise despite the offsetting effects of population growth.

The Western European take-off along with that of the Western Offshoots brought about a sharp increase in population growth in these regions and consequently a modest rise in population growth in the world as a whole. The subsequent take-off of less developed regions and the associated increase in their population growth brought about a significant rise in the population growth in the world. The 1870-1913. India's growth rate increased from $0 \%$ per year to $0.54 \%$ per year over this period, whereas China's take-off was delayed till the 1950s.

${ }^{18}$ Stokey (2001)'s quantitative study attributes about half of the rise in real wage over the period $1780-1850$ to the forces of international trade. Moreover, technological change in manufacturing was 3 times as important as technological change in the energy sector in contributing to output growth. 
rate of population growth in the world increased from an average rate of $0.27 \%$ per year in the period $1500-1820$ to $0.4 \%$ per year in the years $1820-1870$, and to $0.8 \%$ per year in the time interval $1870-1913$. Furthermore, despite the decline in population growth in Western Europe and the Western Offshoots towards the end of the 19th century and the beginning of the 20th century, the delayed take-off of less developed regions and the significant increase in their income per capita prior to their demographic transitions generated a further increase in the rate of population growth in the world to $0.93 \%$ per year in the years 1913-1950 and a sharp rise to a high rate $1.92 \%$ per year in the period 1950-1973. Ultimately, the onset of the demographic transition in less developed economies in the second half of the 20th century, gradually reduced population growth rates to $1.66 \%$ per year in the $1973-1998$ period (Maddison 2001).

\section{Growth in Income Per Capita and Population Growth}

As depicted in Figure 2.11, the take-off in the growth rate of income per capita in all regions of the world was associated with a take-off in population growth. In particular, the average growth rates of income per capita in Western Europe over the time period 1820-1870 rose to an annual rate of 0.95\% (from $0.15 \%$ in the earlier period) along with a significant increase in population growth to an annual rate of about $0.7 \%$ (from $0.26 \%$ in the earlier period). Similarly, the average growth rates of income per capita in the Western Offshoots over the years 1820-1870 rose to an annual rate of $1.42 \%$ (from $0.34 \%$ in the earlier period) along with a significant increase in population growth to an annual rate of about $2.87 \%$ (from $0.43 \%$ in the earlier period).

A similar pattern is observed in Asia, and as depicted in Figure 2.11 in Africa and Latin America as well. The average growth rates of income per capita in Latin America over the years 1870-1913 rose to an annual rate of $1.81 \%$ (from $0.1 \%$ in the period $1820-1870$ ) and subsequently by $1.43 \%$ in time interval 1913-1950 and 2.52\% in the time period 1950-1973 along with a significant increase in population growth to an annual rate of $1.64 \%$ in the period $1870-1913,1.97 \%$ in the years $1913-1950$, and $2.73 \%$ in the period $1950-1973$, prior to the decline in the context of the demographic transition. Similarly, the average growth rates of income per capita in Africa over the 1870-1913 period rose to an annual rate of $0.64 \%$, (from $0.12 \%$ in the period $1820-1870$ ) and subsequently by $1.02 \%$ in the years 1913-1950 and 2.07\% in the period 1950-1973 along with a monotonic increase in population growth from a modest average annual rate of $0.4 \%$ in the years $1820-1870$, to a $0.75 \%$ in the years $1870-1913$, $1.65 \%$ in the years $1913-1950,2.33 \%$ in the time interval $1950-1973$, and a rapid average annual rate of $2.73 \%$ in the $1973-1998$ period . 

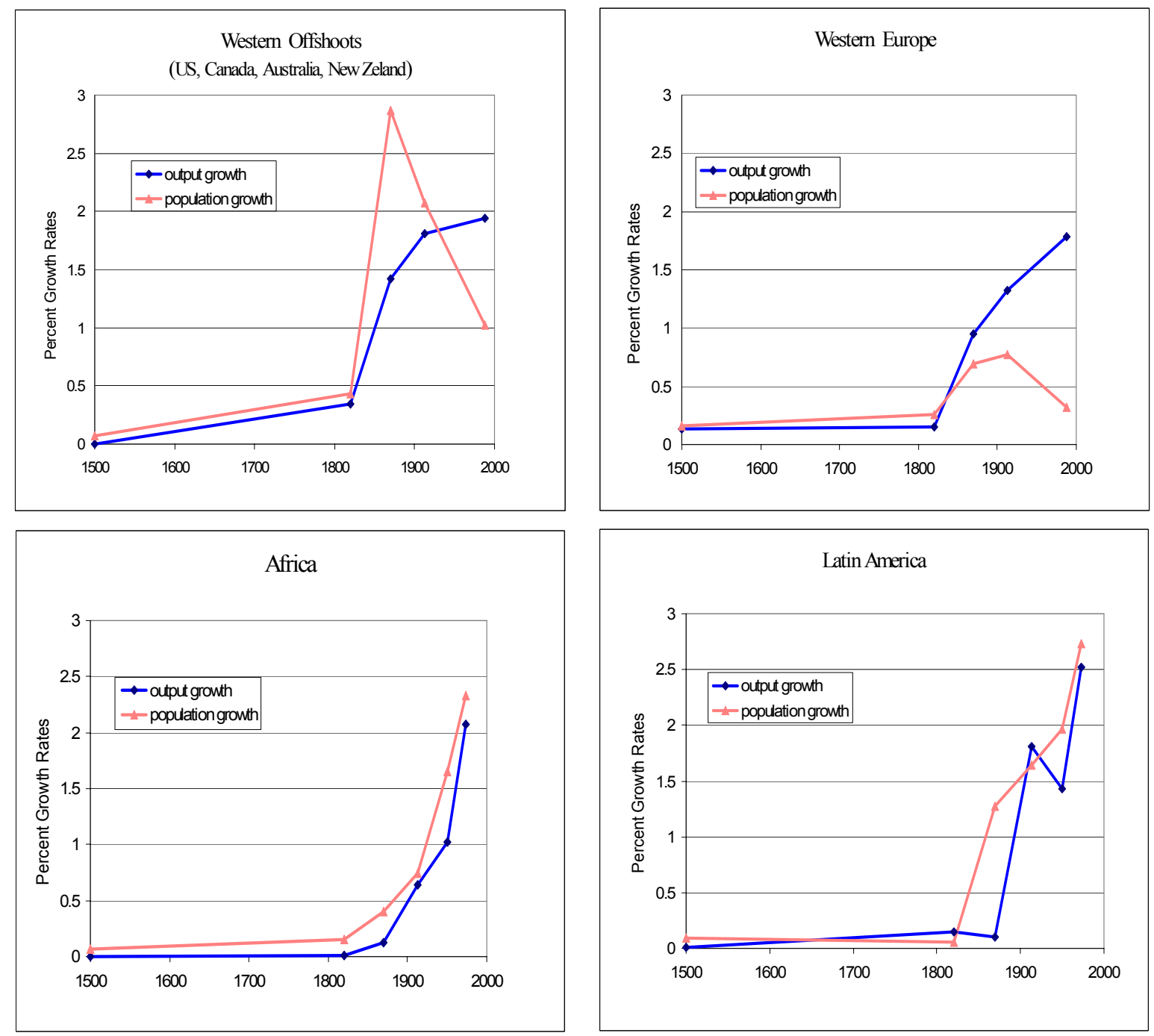

Figure 2.11. Regional Growth of GDP Per Capita and Population: 1500-2000

Source: Maddison (2001)

Ultimately, however, most regions experienced a demographic transition and thereby a transition to a state of sustained economic growth that enabled economies to convert a larger share of the fruits of factor accumulation and technological progress into the growth of output per capita.

Technological leaders and land-abundant regions during the Post-Malthusian era improved their relative position in the world in terms of their level of income per capita as well as their population size. The increase in population density of technological leaders persisted as long as the positive relationship between income per capita and population growth was maintained. Western Europe's technological advancement relative to the rest of the world increased its share of world population by $16 \%$ from $12.8 \%$ in 1820 to $14.8 \%$ in 1870 , where the regional technological leader, the United Kingdom, increased its share of world population by $25 \%$ (from $2 \%$ to $2.5 \%$ ) over this fifty year period. Moreover, land abundance and technological advancement in the Western Offshoots (US, Australia, New Zealand and Canada) increased their share of world population by $227 \%$ over a fifty year period, from $1.1 \%$ in 1820 to $3.6 \%$ in 1870 .

The rate of population growth relative to the growth rate of aggregate income declined gradually over the period. For instance, the growth rate of total output in Europe was 0.3\% per year between 1500 
and 1700 , and $0.6 \%$ per year between 1700 and 1820 . In both periods, two thirds of the increase in total output was matched by increased population growth, and the growth of income per capita was only $0.1 \%$ per year in the earlier period and $0.2 \%$ in the later one. In the United Kingdom, where growth was the fastest, the same rough division between total output growth and population growth can be observed: total output grew at an annual rate of $1.1 \%$ in the 120 years after 1700 , while population grew at an annual rate of $0.7 \%$. Population and income per capita continued to grow after 1820, but increasingly the growth of total output was expressed as growth of income per capita. Population growth was $40 \%$ as large as total output growth over the time period 1820-1870, dropping further after the demographic transition to about $20 \%$ of output growth over the 1929-1990 period.

\section{Fertility and Mortality}

The relaxation in the households' budget constraints in the Post-Malthusian Regime permitted an increase in fertility rates along with an increase in literacy rates and years of schooling. Despite the decline in mortality rates, fertility rates (as well as population growth) increased in most of Western Europe until the second half of the 19th century (Coale and Treadway (1986)). ${ }^{19}$ In particular, as depicted in Figure 2.12, in spite of a century of a decline in mortality rates, the crude birth rates in England increased over the 18th century and the beginning of the 19th century. Thus, the Net Reproduction Rate (i.e., the number of daughters per woman who reach the reproduction age) increased for about the replacement level of 1 surviving daughters per women in 1740 to about 1.5 surviving daughters per woman in the eve of the demographic transition in 1870.
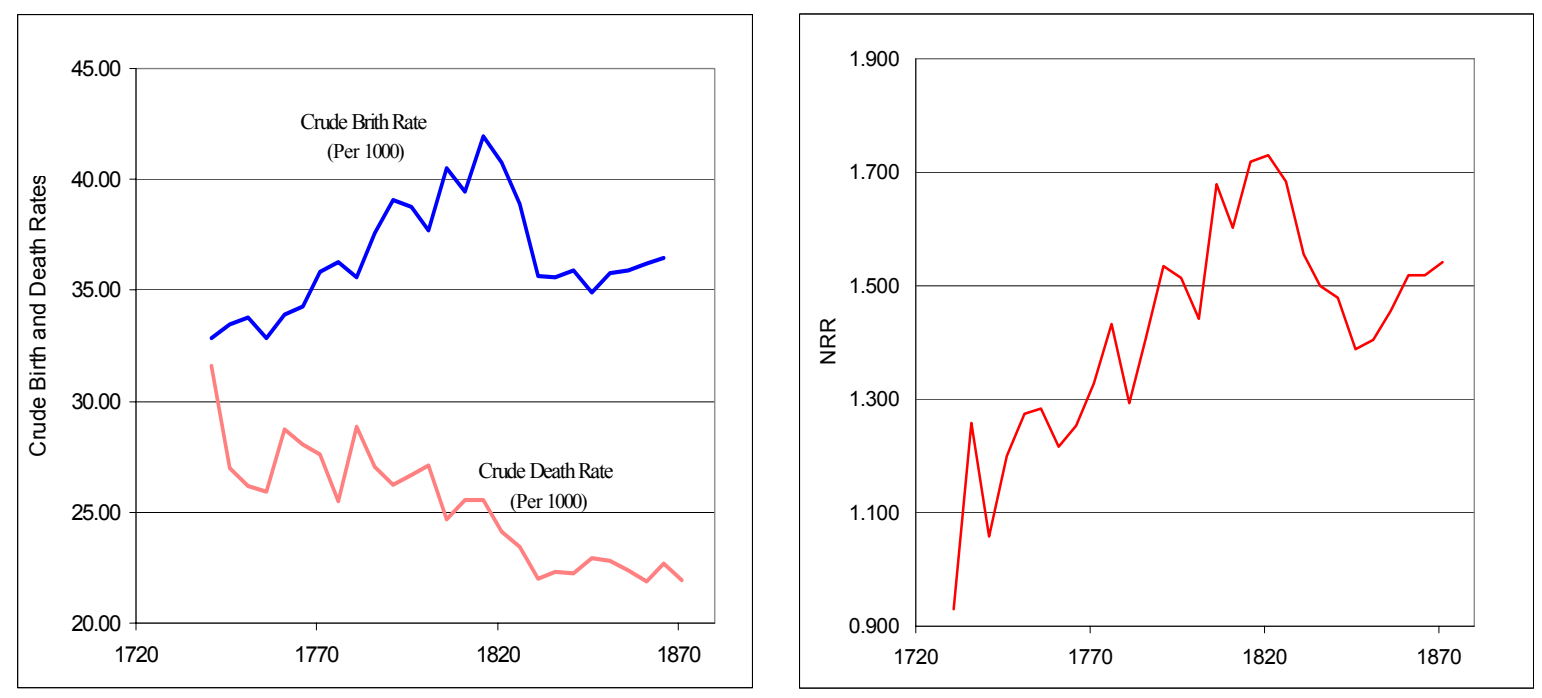

Figure 2.12. Fertility, Mortality and Net Reproduction Rate: England, 1730-1871 Source: Wrigley and Schofield (1981)

It appears that the significant rise in income per capita in the Post-Malthusian Regime increased the desirable number of surviving offspring and thus, despite the decline in mortality rates, fertility increased significantly so as to enable households to reach this higher desirable level of surviving offspring.

\section{Fertility Rates and Marriage Age}

Fertility was controlled during this period, despite the absence of modern contraceptive methods,

\footnotetext{
${ }^{19}$ See Dyson and Murphy (1985) as well.
} 
partly via adjustment in marriage rates. ${ }^{20}$ As depicted in Figure 2.13, increased fertility was achieved by earlier female's age of marriages and a decline in fertility by a delay in the marriage age. The same pattern is observed in the relationship between Crude Birth Rates and Female's age of marriages, or alternatively Crude Marriage Rates (per 1000).

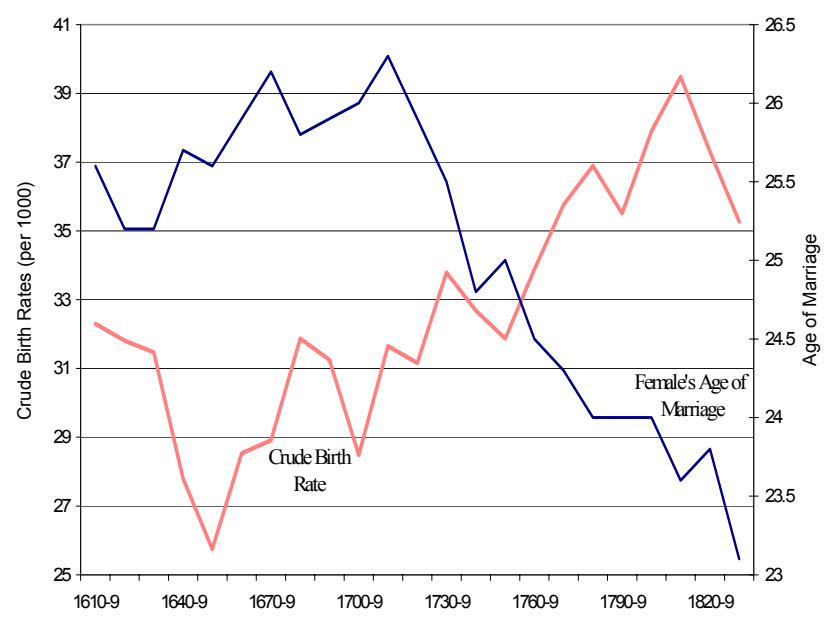

Figure 2.13. Fertility Rates and Female's Age of Marriage Source: Wrigley and Schofield (1983)

\subsubsection{Industrialization and Urbanization}

The take-off of developed and less developed regions from the Malthusian epoch was associated with the acceleration in the process of industrialization as well as with a significant rise in urbanization.

\section{Industrialization}

The take-off in the developed regions was accompanied by a rapid process of industrialization. As depicted in Figure 2.14, Per-Capita Level of Industrialization (measuring per capita volume of industrial production) increased significantly in the United Kingdom since 1750, rising 50\% over the 1750-1800 period, quadrupling in the years 1800-1860, and nearly doubling in the time period 1860-1913. Similarly per-capita level of industrialization accelerated in the United States, doubling in the 1750-1800 as well as 1800-1860 periods, and increasing six-fold in the years 1860-1913. A similar pattern was experienced by Germany, France, Sweden, Switzerland, Belgium, and Canada as of 1800, and industrialization nearly doubled in the 1800-1860 period, further accelerating in the time interval 1860-1913.

The take-off of less developed economies in the 20th century was associated with increased industrialization as well. However, as depicted in Figure 2.14, during the 19th century these economies experienced a decline in per capita industrialization (i.e., per capita volume of industrial production), reflecting the adverse effect of the sizable increase in population on the level of industrial production per capita (even in the absence of an absolute decline in industrial production) as well as the forces of globalization and colonialism, that induced less developed economies to specialize in the production of raw materials. ${ }^{21}$

\footnotetext{
${ }^{20}$ This mechanism is reflected in the assertion of William Cobbett (1763 - 1835) - a leader of the campaign against the changes brought by the Industrial Revolution - “... men, who are able and willing to work, cannot support their families, and ought... to be compelled to lead a life of celibacy, for fear of having children to be starved."

${ }^{21}$ The sources of the decline in the industrialization of less developed economies is explored by Galor and Mountford (2003). The effect of colonialism on the patterns of production and thus trade is examined by Acemoglu, Johnson and
} 

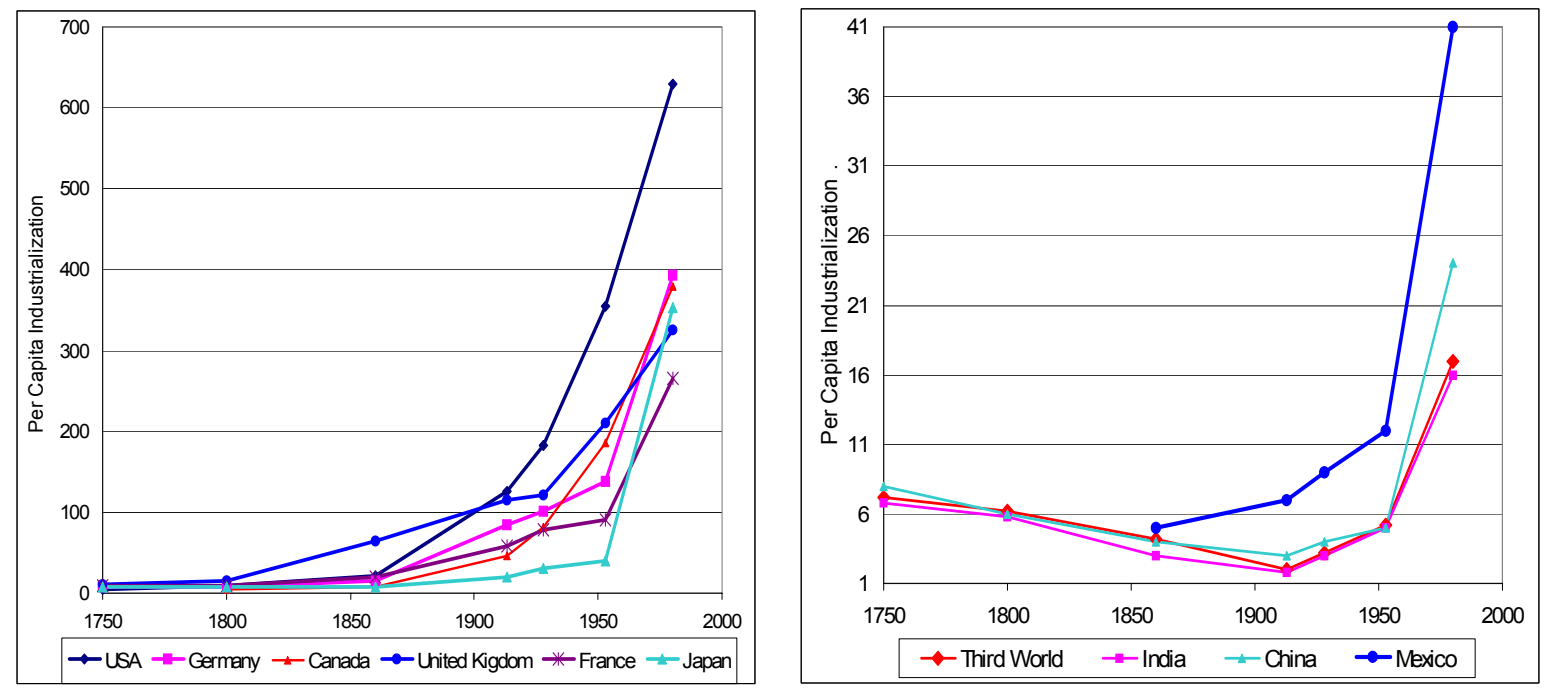

Figure 2.14. Per Capita Levels of Industrialization: (UK in 1900=100)

Source: Bairoch $(1982)^{22}$

\section{Urbanization}

The take-off from Malthusian stagnation and the acceleration in the process of industrialization increased significantly the process of urbanization. As depicted in Figure 2.15, the percentage of the population that lived in European cities with a population larger than 10,000 people nearly tripled over the years $1750-1870$, from $17 \%$ to $54 \%$. Similarly, the percentage of the population in England that lived in cities with population larger than 5,000 quadrupled over the $1750-1910$ period, from $18 \%$ to $75 \%$ (Bairoch 1988)).

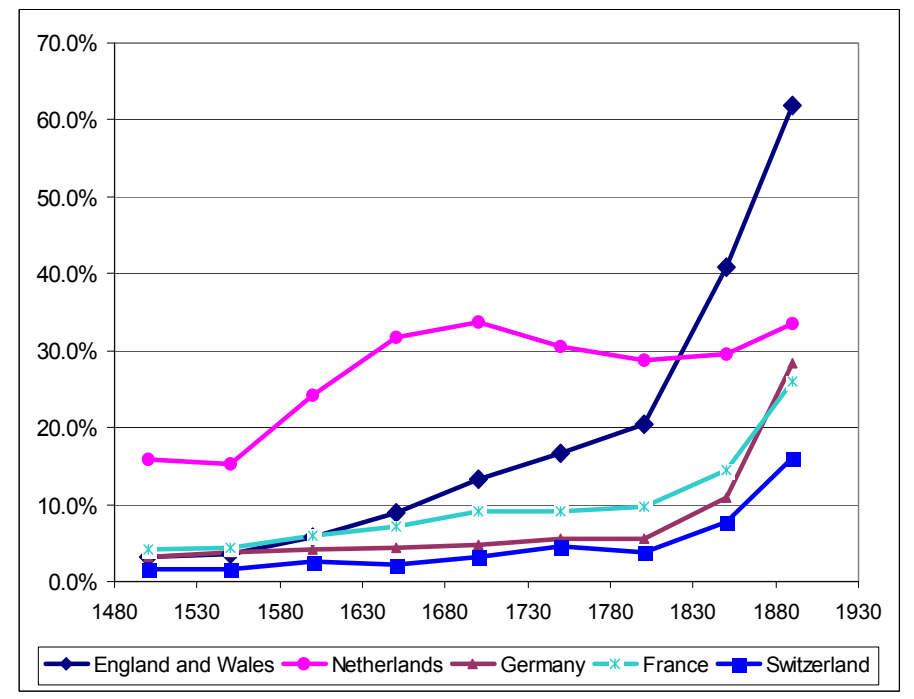

Figure 2.15. Percentage of the Population in Cities with Population larger than 10,000

Sources: Bairoch (1988) and de Vries (1984)

Robinson (2001) and Bertocchi and Canova (2002).

${ }^{22}$ Notes: Countries are defined according to their 1913 boundaries. Germany from 1953 is defined as East and West Germany. India after 1928 includes Pakistan. 
This rapid processes of industrialization and urbanization was accompanied by a rapid decline in the share of agricultural production in total output, as depicted in Figure 2.16. For instance, this share declined in England from 40\% in 1790 to $7 \%$ in 1910.

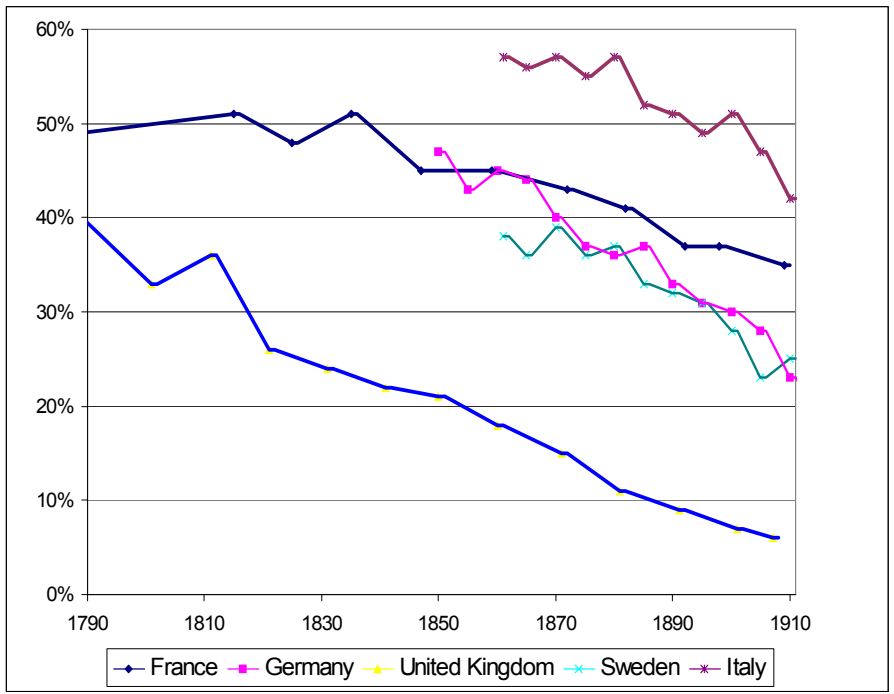

Figure 2.16. The Decline in the Percentage of Agricultural Production in Total Output: Europe: 1790-1910 Source: Mitchell (1981)

\subsubsection{Early Stages of Human Capital Formation}

The acceleration in technological progress during the Post-Malthusian Regime and the associated increase in income per capita stimulated the accumulation of human capital in the form of literacy rates, schooling, and health. The increase in the investment in human capital was induced by the gradual relaxation in the households budget constraints (as reflected by the rise in real wages and income per capita), as well as by qualitative changes in the economic environment that increased the demand for human capital and induced households to invest in the education of their offspring.

In the first phase of the Industrial Revolution, human capital had a limited role in the production process. Education was motivated by a variety of reasons, such as religion, enlightenment, social control, moral conformity, sociopolitical stability, social and national cohesion, and military efficiency. The extensiveness of public education was therefore not necessarily correlated with industrial development and it differed across countries due to political, cultural, social, historical and institutional factors. In the second phase of the Industrial Revolution, however, the demand for education increased, reflecting the increasing skill requirements in the process of industrialization. ${ }^{23}$

During the post-Malthusian regime, the average number of years of schooling in England and Wales rose from 2.3 for the cohort born between 1801 and 1805 to 5.2 for the cohort born in the year 1852-1856 (Matthews et al., 1982). Furthermore, human capital as reflected by the level of health of the labor force increased over this period. In particular, between 1740 and 1840 life expectancy at birth rose from 33 to 40 in England (Figure 2.8), and from 25 to 40 in France.

The process of industrialization was ultimately characterized by a gradual increase in the relative importance of human capital in less developed economies as well. As documented by Barro and

\footnotetext{
${ }^{23}$ Evidence suggests that in Western Europe, the economic interests of capitalists were a significant driving force behind the implementation of educational reforms, reflecting the interest of capitalists in human capital formation and thus in the provision of public education [Galor and Moav (2004)].
} 
Lee (2000) educational attainment increased significantly across all less developed regions in the PostMalthusian Regime (that ended with the decline in population growth in the 1970s in Latin America and Asia, and was still in motion in Africa at the end of the 20th century). In particular, the average years of schooling increased from 3.5 in 1960 to 4.4 in 1975, in Latin America, from 1.6 in 1960 to 3.4 in 2000 in Sub-Saharan Africa, and from 1.4 in 1960 to 1.9 in 1975 in South Asia.

\subsection{The Sustained Growth Regime}

The acceleration in technological progress and industrialization in the Post-Malthusian Regime and its interaction with the accumulation of human capital brought about a demographic transition, paving the way to a transition to an era of sustained economic growth. In the post demographic-transition period, the rise in aggregate income due to technological progress and factor accumulation has no longer been counterbalanced by population growth, permitting sustained growth in income per capita in regions that have experienced sustained technological progress and factor accumulation.

The transition of the developed regions of Western Europe and the Western Offshoots to the state of sustained economic growth occurred towards the end of the 19th century, whereas the transition of the less developed regions of Asia and Latin America occurred towards the end of the 20th century. Africa, in contrast, is still struggling to make this transition.

\subsubsection{Growth of Income Per Capita}

During the Sustained Growth Regime the average growth rate of output per capita increased significantly in association with the decline in population growth. As depicted in Figure 2.11, the decline in population growth in Western Europe as well as the Western Offshoots was followed by a significant increase in income per capita and in many of the less advanced economies a significant increase in income per capita was followed by a demographic transition.

Income per capita in the last century has advanced at a stable rate of about $2 \%$ per year in Western Europe and the Western Offshoots, as depicted in Figure 2.17.

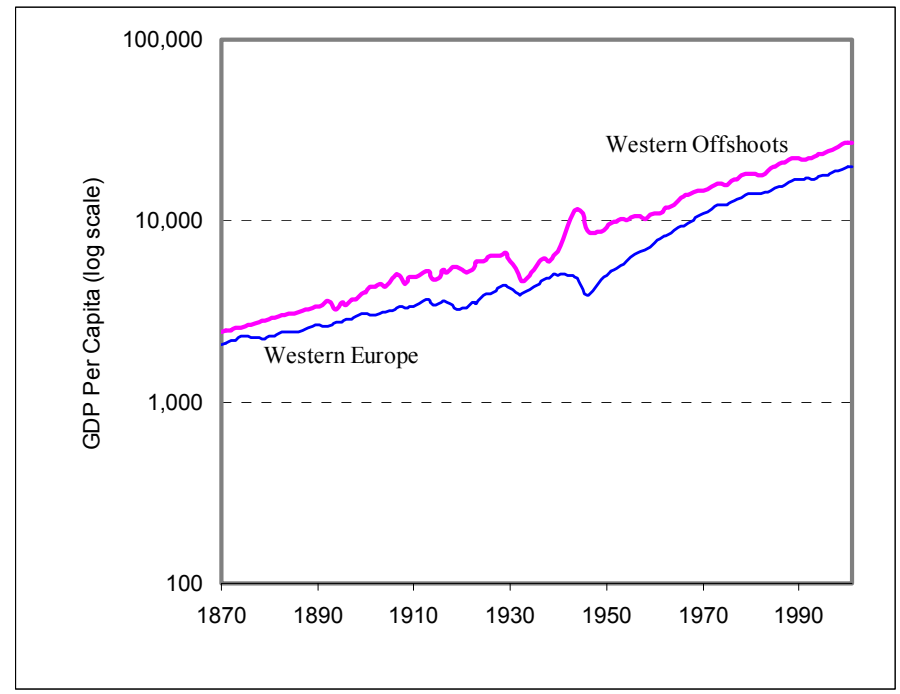

Figure 2.17. Sustained Economic Growth: Western Europe and the Western Offshoots, 1870-2001 Source: Maddison (2003) 
In contrast, less developed regions experienced a sustained growth rate of output per capita only in the last decades. As depicted in Figure 2.18, the growth rate of output per capita in Asia has been stable in the last 50 years, the growth rate in Latin America has been declining over this period, and the growth of Africa vanished in the last few decades. ${ }^{24}$

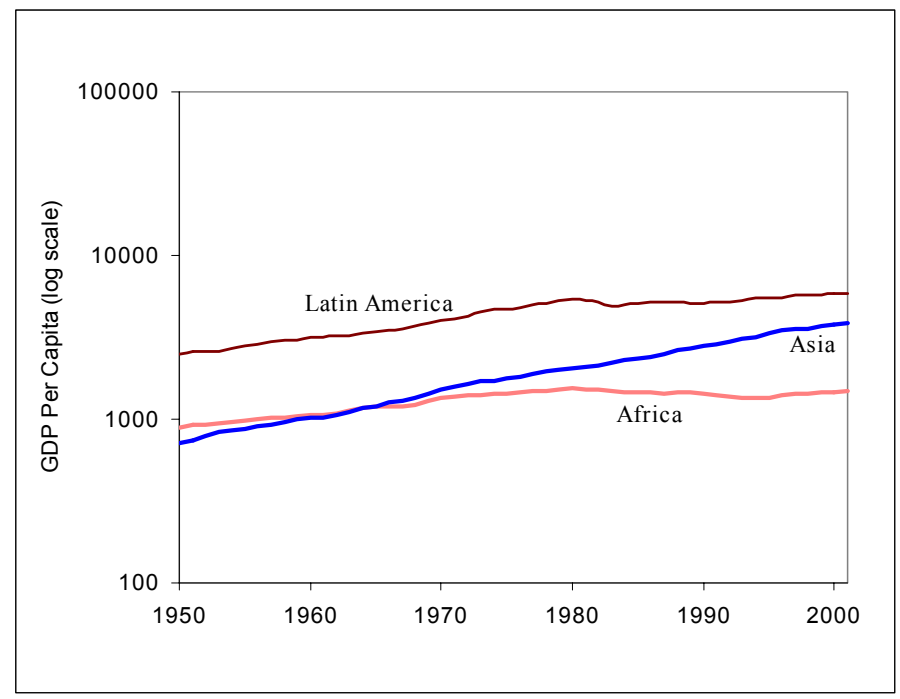

Figure 2.18. Income Per Capita in Africa, Asia and Latin America, 1950-2001 Source: Maddison (2003)

The transition to a state of sustained economic growth in developed as well as less developed regions was accompanied by a rapid process of industrialization. As depicted in Figure 2.14, the Per Capita Level of Industrialization (measuring per capita volume of industrial production) doubled in the time period 1860-1913 and tripled in the course of the 20th century. Similarly the per capita level of industrialization in the United States, increased six-fold over the years 1860-1913, and tripled along the 20th century. A similar pattern was experienced by Germany, France, Sweden, Switzerland, Belgium, and Canada where industrialization increased significantly in the time interval 1860-1913 as well as over the rest of the 20th century. Moreover, less developed economies that made the transition to a state of sustained economic growth in recent decades have experienced a significant increase in industrialization.

The transition to a state of sustained economic growth was characterized by a gradual increase in the importance of the accumulation of human capital relative to physical capital as well as with a sharp decline in fertility rates. In the first phase of the Industrial Revolution (1760-1830), capital accumulation as a fraction of GDP increased significantly whereas literacy rates remained largely unchanged. Skills and literacy requirements were minimal, the state devoted virtually no resources to raise the level of literacy of the masses, and workers developed skills primarily through on-the-job training (Green 1990, and Mokyr 1990, 1993). Consequently, literacy rates did not increase during the period 1750-1830 (Sanderson 1995)). As argued by Landes (1969, p. 340) "although certain workers - supervisory and office personal in particular - must be able to read and do the elementary arithmetical operations in order to perform their duties, large share of the work of industry can be performed by illiterates as indeed it was especially in the early days of the Industrial Revolution."

In the second phase of the Industrial Revolution, however, capital accumulation subsided, the education of the labor force markedly increased and skills became necessary for production. The investment ratio which increased from $6 \%$ in 1760 to $11.7 \%$ in the year 1831, remained at around $11 \%$

\footnotetext{
${ }^{24}$ Extensive evidence about the growth process in the last four decades is surveyed by Barro and Sala-i-Martin (2003).
} 
on average in the years 1856-1913 (Crafts 1985 and Matthews et al. 1982). In contrast, the average years of schooling of the male labor force which did not change significantly until the 1830s, tripled by the beginning of the 20th century (Matthews et al. 1982, p 573). The significant rise in the level of income per capita in England as of 1865, as depicted in Figure 2.19, was associated with an increase in the standard of living (Voth (2004), and an increase in school enrollment of 10-year olds from 40\% in 1870 to $100 \%$ in 1900. Moreover, Total fertility Rates in England sharply declined over this period from about 5 in 1875 , to nearly 2 in 1925 .

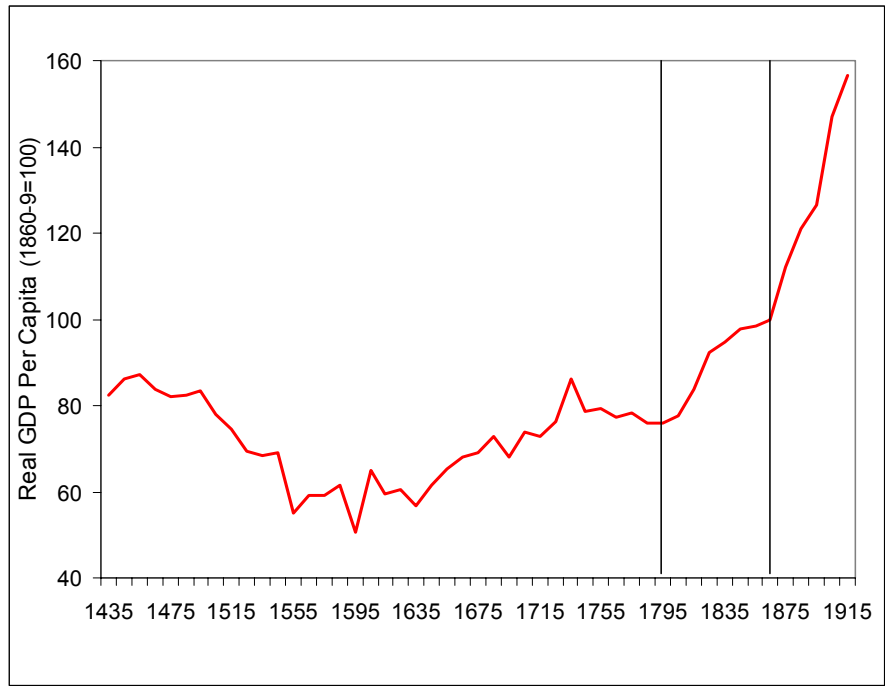

Figure 2.19. The Sharp Rise in Real GDP Per Capita in the transition to Sustained Economic Growth: England 1870-1915

Source: Clark (2001) and Feinstein (1972)

The transition to a state of sustained economic growth in the US, as well, was characterized by a gradual increase in the importance of the accumulation of human capital relative to physical capital. Over the time period 1890-1999 the contribution of human capital accumulation to the growth process in the US nearly doubled whereas the contribution of physical capital declined significantly. Goldin and Katz (2001) show that the rate of growth of educational productivity was $0.29 \%$ per year over the 1890 1915 period, accounting for about $11 \%$ of the annual growth rate of output per capita over this period. ${ }^{25}$ In the period 1915-1999, the rate of growth of educational productivity was $0.53 \%$ per year accounting for about $20 \%$ of the annual growth rate of output per capita over this period. Abramovitz and David (2000) report that the fraction of the growth rate of output per capita that is directly attributed to physical capital accumulation declined from an average of $56 \%$ in the years $1800-1890$ to $31 \%$ in the period 1890-1927 and 21\% in the time interval 1929-1966.

\subsubsection{The Demographic Transition}

The demographic transitions swept the world in the course of the last century. The unprecedented increase in population growth during the Post-Malthusian regime was ultimately reversed and the demographic transition brought about a significant reduction in fertility rates and population growth in various regions of the world, enabling economies to convert a larger share of the fruits of factor accumulation and technological progress into growth of income per capita. The demographic transition enhanced the growth process via three channels: (a) Reduction of the dilution of the stock of capital

\footnotetext{
${ }^{25}$ They measure educational productivity by the contribution of education the educational wage differentials.
} 
and land. (b) Enhancement of the investment in the human capital of the population. (c) Alteration of the age distribution of the population which temporarily increased the size of the labor force relative to the population as a whole.

\section{The Decline in Population Growth}

The evolution of population growth in the world economy, as depicted in Figure 2.5, has been non-monotonic. The growth of world population was sluggish during the Malthusian epoch, creeping at an average annual rate of about $0.1 \%$ over the years 0-1820. The Western European take-off along with that of the Western Offshoots brought about a sharp increase in population growth in these regions and consequently in the world as a whole. The annual average rate of population growth in the world increased gradually reaching $0.8 \%$ in the years $1870-1913$. The delayed take-off of less developed regions and the significant increase in their income per capita generated a further gradual increase in the rate of population growth in the world, despite the decline in population growth in Western Europe and the Western Offshoots, reaching a high level of $1.92 \%$ per year in the period 1950-1973, . Ultimately, however, the onset of the demographic transition in less developed economies in the second half of the 20th century, reduced population growth to an average rate of about 1.63\% per year in the 1973-1998 period.

The timing of the demographic transition differed significantly across regions. As depicted in Figure 2.20, the reduction in population growth occurred in Western Europe, the Western Offshoots, and Eastern Europe towards the end of the 19th century and in the beginning of the 20th century, whereas Latin America and Asia experienced a decline in the rate of population growth only in the last decades of the 20th century. Africa's population growth, in contrast, has been rising steadily, although this pattern is likely to reverse in the near future due to the decline in total fertility rate in this region since the 1980s.

The Western Offshoots experienced the earliest decline in population growth, from an average annual rate of $2.87 \%$ in the period $1820-1870$ to an annual average rate of $2.07 \%$ in the time interval 1870-1913 and 1.25\% in the years 1913-1950. ${ }^{26}$ In Western Europe population growth declined from a significantly lower average level of $0.77 \%$ per year in the period $1870-1913$ to an average rate of $0.42 \%$

\footnotetext{
${ }^{26}$ Migration played a significant role in the rate of population growth of these land-abundant countries.
} 
per year in the 1913-1950 period. A similar reduction occurred in Eastern Europe as well. ${ }^{27}$
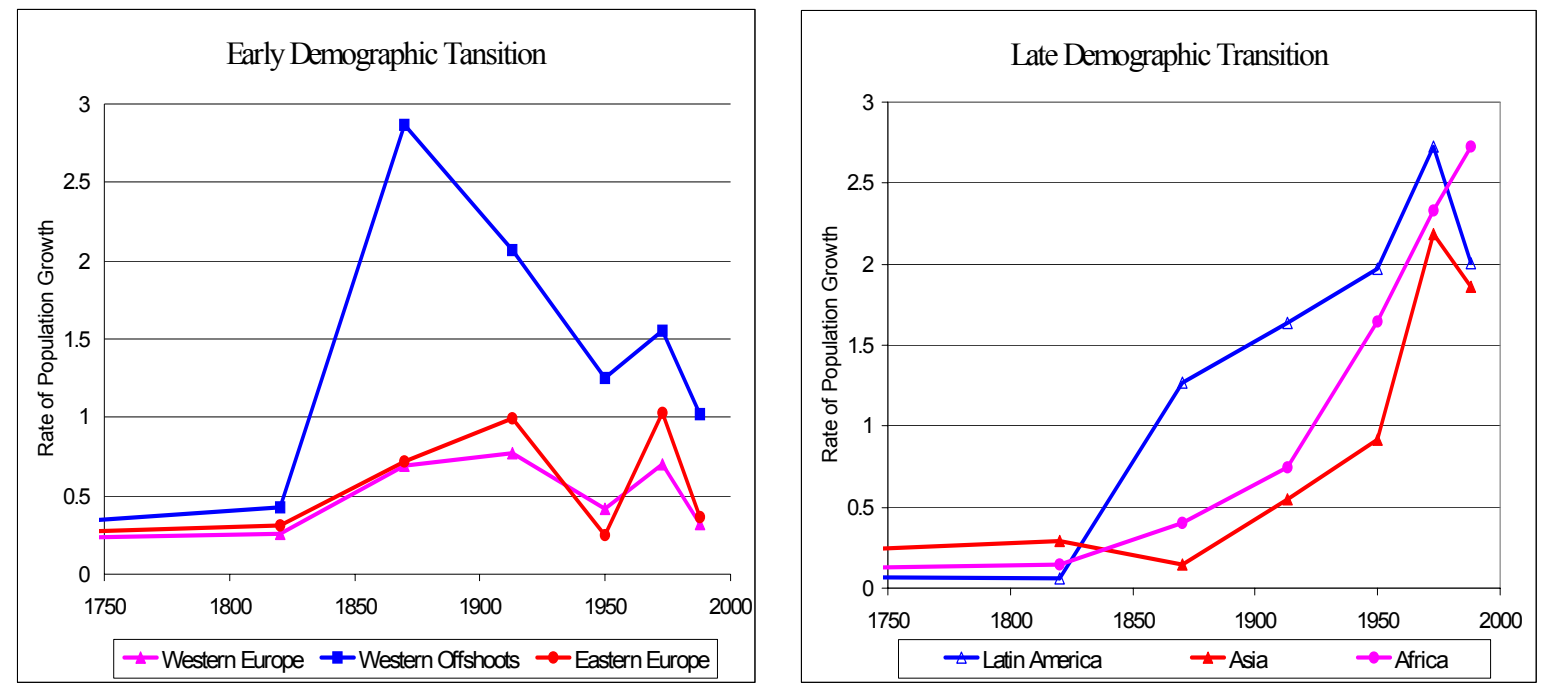

Figure 2.20. The Differential Timing of the Demographic Transition Across Regions Source: Maddison (2001)

In contrast, in Latin America and Asia the reduction in population growth started to take place in the 1970s, whereas the average population growth in Africa has been rising, despite a modest decline in fertility rates. ${ }^{28}$ Latin America experienced a decline in population growth from an average annual rate of $2.73 \%$ in the years $1950-1973$ to an annual average rate of $2.01 \%$ in the period $1973-1998$ Similarly, Asia (excluding Japan) experienced a decline in population growth from an average annual rate of $2.21 \%$ in the time period $1950-1973$ to an average annual rate of $1.86 \%$ in the $1973-1998$ period. Africa's increased resources in the Post-Malthusian Regime, however, has been channeled primarily towards population growth.

Africa's population growth rate has increased monotonically from a modest average annual rate of $0.4 \%$ over the years $1820-1870$, to a $0.75 \%$ in the time interval $1870-1913,1.65 \%$ in the period $1913-1950$, $2.33 \%$ in $1950-1973$, and a rapid average annual rate of $2.73 \%$ in the $1973-1998$ period . Consequently, the share of the African population in the world increased by $41 \%$ in the 60 year period, 1913-1973 (from $7 \%$ in 1913 to $9.9 \%$ in 1973), and an additional $30 \%$ in the last 25 years, from $9.9 \%$ in 1973 to $12.9 \%$ in 1998. The decline in fertility in less developed regions, however, has been more significant, indicating a sharp forthcoming decline in population growth in the next decades.

\section{Fertility Decline}

The decline in population growth stem from a decline in fertility rates. As depicted in Figure 2.21, Total Fertility Rate over the period 1960-1999 plummeted from 6 to 2.7 in Latin America and declined sharply from 6.14 to 3.14 in Asia. ${ }^{29}$ Furthermore, Total Fertility Rate in Western Europe and the Western Offshoots declined over this period below the replacement level: from 2.8 in 1960 to 1.5 in 1999 in Western Europe and from 3.84 in 1960 to 1.83 in 1999 in the Western Offshoots. (World

\footnotetext{
${ }^{27} \mathrm{~A}$ sharper reduction in population growth occurred in the United Kingdom, from $0.87 \%$ per year in the period $1870-$ 1913 to $0.27 \%$ per year in the period $1913-1950$.

${ }^{28} \mathrm{As}$ depicted in Figure 2.18, the decline in Total Fertility Rate in these countries started earlier. The delay in the decline in population growth could be attributed to an increase in life expectancy as well as an increase in the relative size of cohorts of women in a reproduction age.

${ }^{29}$ For a comprehensive discussion of the virtues and drawbacks of the various measures of fertility: TFR, NNR, and $C B R$, see Weil (2004).
} 
Development Indicators, 2001). Even in Africa the Total Fertility Rate declined moderately from 6.55 in 1960 to 5.0 in 1999.

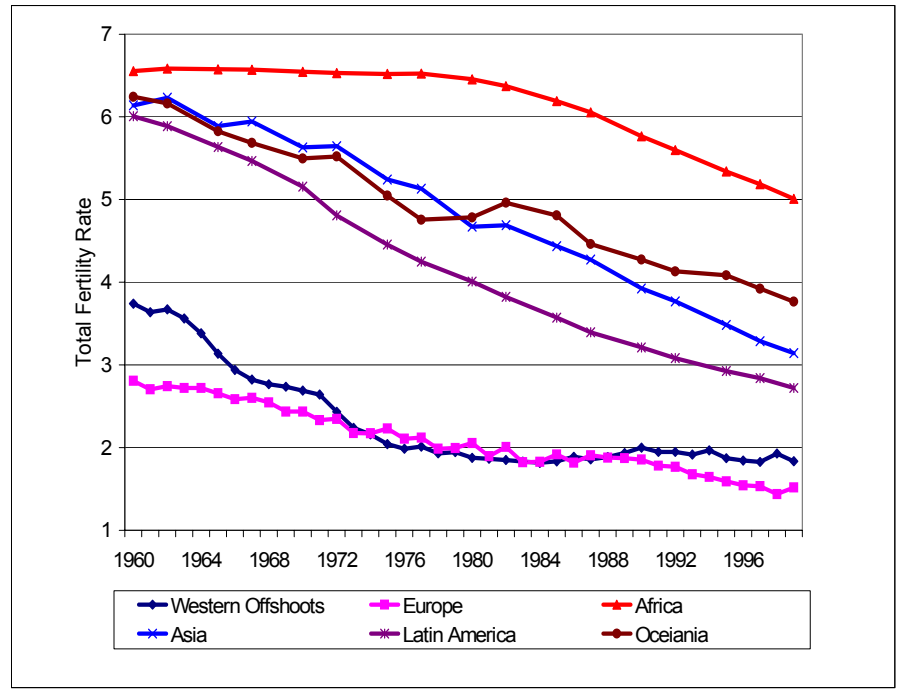

Figure 2.21. The Evolution of Total Fertility Rate Across Regions, 1960-1999

Source: World Development Indicators (2001).

The demographic transition in Western Europe occurred towards the turn of the 19th century. A sharp reduction in fertility took place simultaneously in several countries in the 1870s, and resulted in a decline of about $1 / 3$ in fertility rates in various states within a 50 year period. ${ }^{30}$
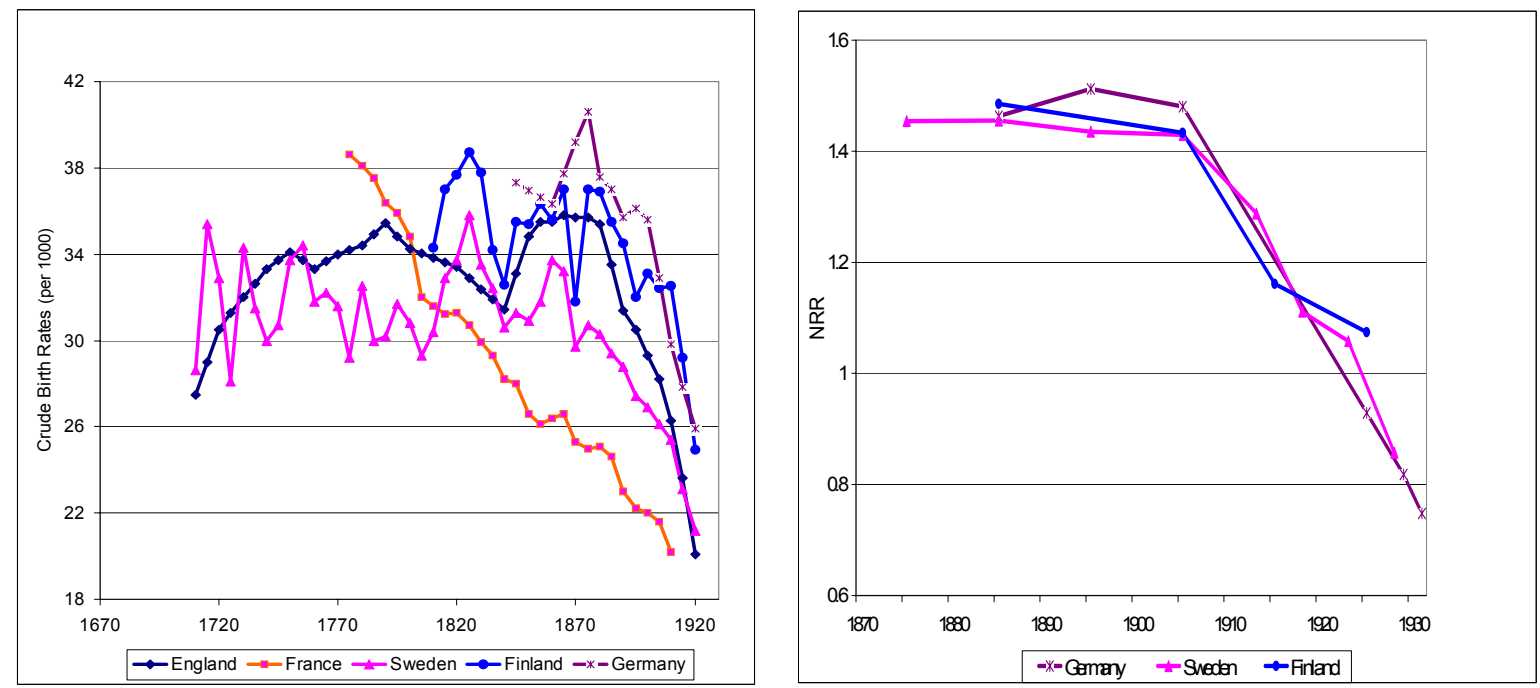

Figure 2.22. The Demographic Transition in Western Europe:

Crude Birth Rates and Net Reproduction Rates

Source: Andorka (1978) and Kuzynski (1969)

As depicted in Figure 2.22, Crude Birth Rates in England declined by 44\%, from 36 (per 1000) in 1875 , to 20 (per 1000) in 1920. Similarly, live births per 1000 women aged 15-44 fell from 153.6 in

\footnotetext{
${ }^{30}$ Coale and Treadway (1986) find that a $10 \%$ decline in fertility rates was completed in $59 \%$ of all European countries in the time period 1890-1920. In particular, a 10\% decline was completed in Belgium in 1881, Switzerland in 1887, Germany in 1888, England and Wales in 1892, Scotland in 1894, Netherlands in 1897, Denmark in 1898, Sweden in 1902, Norway in 1903, Austria in 1907, Hungary in 1910, Finland in 1912, Greece and Italy in 1913, Portugal in 1916, Spain 1920, and Ireland in 1922.
} 
1871-80 to 109.0 in 1901-10 (Wrigley, 1969). In Germany, Crude Birth Rates declined 37\%, from 41 (per 1000) in 1875 to 26 (per 1000) in 1920. Sweden's Crude Birth Rates declined 32\%, from 31 (per 1000 ) in 1875 to 21 (per 1000) in 1920, and in Finland they declined 32\%, from 37 in 1875 to 25 (per 1000) in 1920. Finally, although the timing of demographic transition in France represents an anomaly, starting in the second half of the 18th century, France experienced an additional significant reduction in fertility in the time period 1865-1910, where Crude Birth Rates declined by 26\%, from 27 (per 1000) in 1965 to 20 (per 1000) in 1910.

The decline in the crude birth rates in the course of the demographic transition was accompanied by a significant decline in the Net Reproduction Rate (i.e., the number of daughters per woman who reach the reproduction age), as depicted in Figure 2.22. Namely, the decline in fertility during the demographic transition outpaced the decline in mortality rates, and brought about a decline in the number of children who survived to their reproduction age.

Similar patterns are observed in the evolution of Total Fertility Rates in Western Europe, as depicted in Figure 2.23. Total Fertility Rates (TFR) peaked in the 1870s and then decline sharply and simultaneously across Western European States. In England, TFR declined by 51\%, from 4.94 children in 1875 , to 2.4 in 1920. In Germany, TFR declined 57\%, from 5.29 in 1885 to 2.26 in 1920 . Sweden's TFR declined 61\%, from 4.51 in 1876 to 1.77 in 1931, in Finland they declined 52\%, from 4.96 in 1876 to 2.4 in 1931 and in France where a major decline occurred in the years 1750-1850, additional decline took place in the same time period from 3.45 in 1980 to 1.65 in 1920.

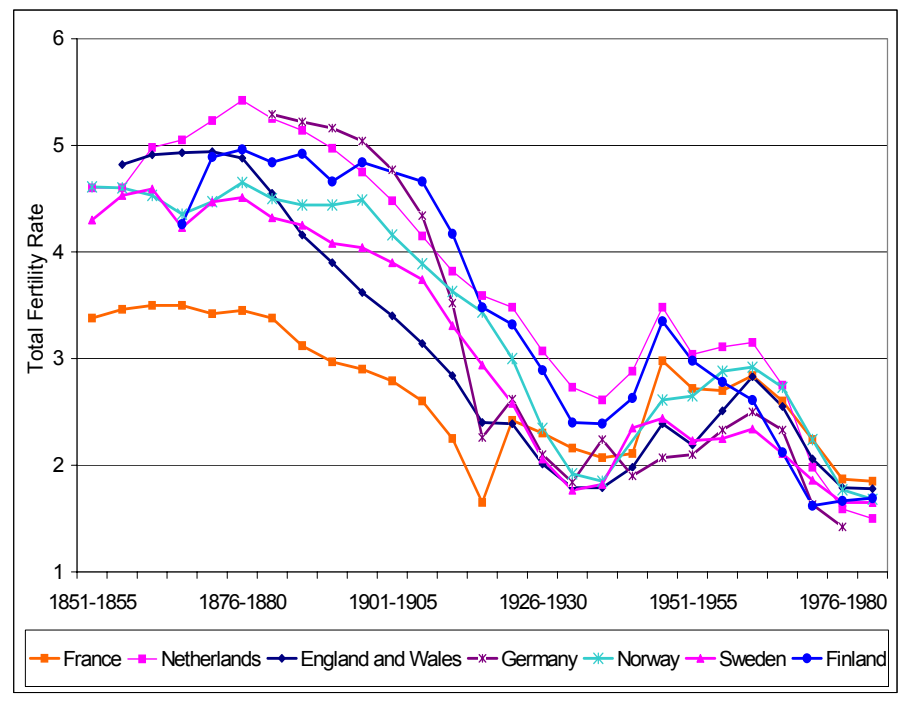

Figure 2.23. The Demographic Transition in Western Europe: Total Fertility Rates Source: Chesnais (1992)

\section{Mortality Decline}

The mortality decline which preceded the decline in fertility rates in most countries in the world, with the notable exceptions of France and the United States, has been, unjustifiably, viewed by demographers as the prime force behind the demographic transition. The evidence provided in section 3.3.1, suggests that this viewpoint is inconsistent with historical evidence. 


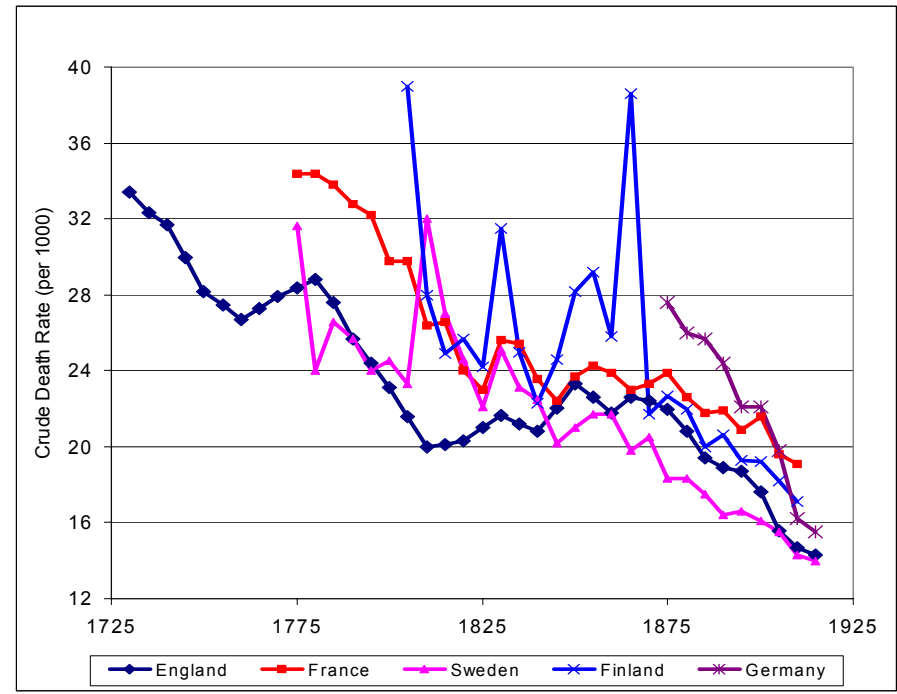

Figure 2.24. The Mortality Decline in Western Europe, 1730-1920

Source: Andorka (1978)

The decline in mortality rates preceded the decline in fertility rates in Western European countries in the 1730-1920 period, as depicted in Figures 2.22 and 2.24. The decline in mortality rates began in England 140 years prior to the decline in fertility and in Sweden and Finland nearly 100 years prior to the decline in fertility.

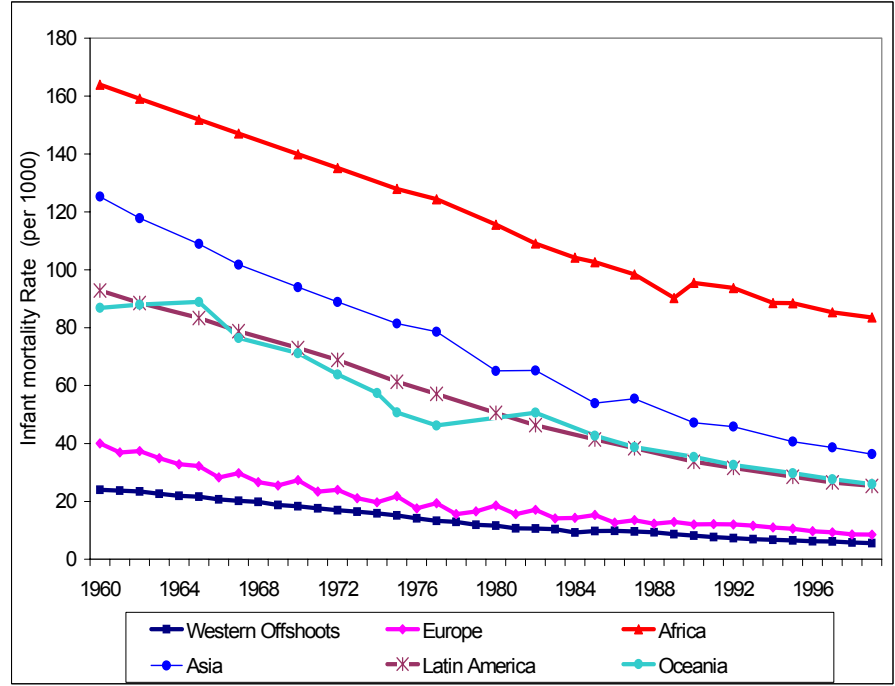

Figure 2.25. The Decline in Infant Mortality Rates Across Regions, 1960-1999 Source: World Development Indicators (2001).

A similar sequence of events emerges from the pattern of mortality and fertility decline in less developed regions. As depicted in Figures 2.21 and 2.25, a sharp decline in infant mortality rates as of 1960 preceded the decline in fertility rates in Africa that took place in 1980. Moreover, the existing evidence shows a simultaneous reduction in mortality and fertility in the 1960-2000 period in all other regions. ${ }^{31}$

\footnotetext{
${ }^{31}$ Extrapolation about mortality rates prior to 1960 suggests that a similar pattern appears in Asia and Latin America.
} 


\section{Life Expectancy}

The decline in mortality rates in developed countries since the 18th century, as depicted in Figure 2.24, corresponded to a gradual increase in life expectancy generating a further inducement for investment in human capital. As depicted in Figure 2.26, life expectancy at birth in England increased at a stable pace from 32 years in the 1720 s to about 41 years in the 1870 s. This pace of the rise in life expectancy increased towards the end of the 19th century and life expectancy reached the levels of 50 years in the year 1906, 60 years in the year 1930 and 77 years in the year 1996.

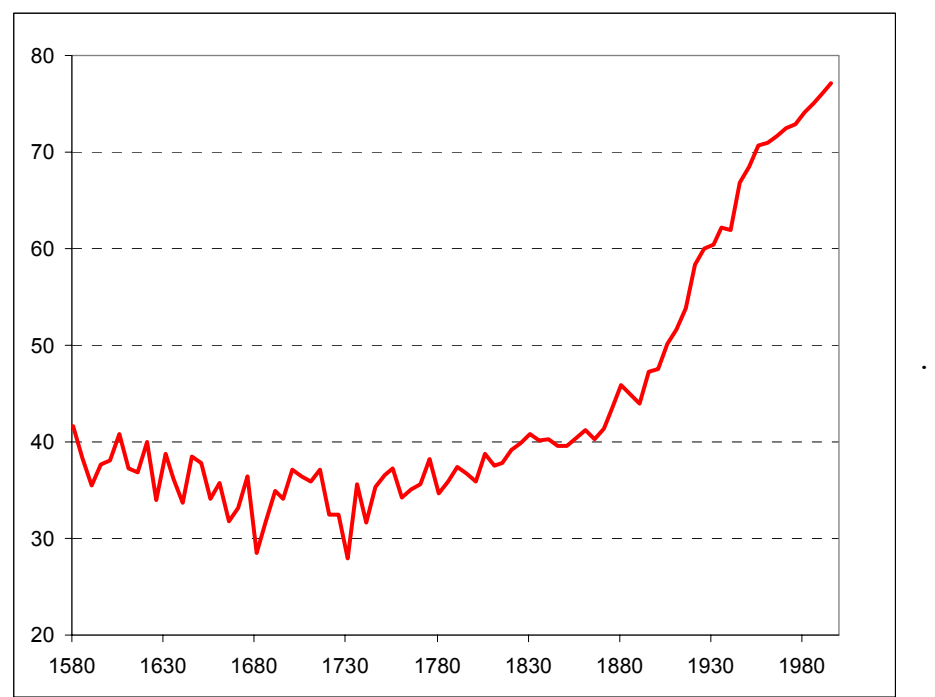

Figure 2.26. The Evolution of Life Expectancy: England 1726-1996

Source: Wrigley and Schofield (1981) for 1726-1871 and Human Mortality Database (2003) for 1876-1996

Similarly, the significant decline in mortality rates across the developed regions in the last two centuries and across less developed regions in the past century, corresponded to an increase in life expectancy. As depicted in Figure 2.27, life expectancy increased significantly in developed regions in the 19th century, whereas the rise in life expectancy in less developed regions occurred throughout the 20th century, stimulating further human capital formation.

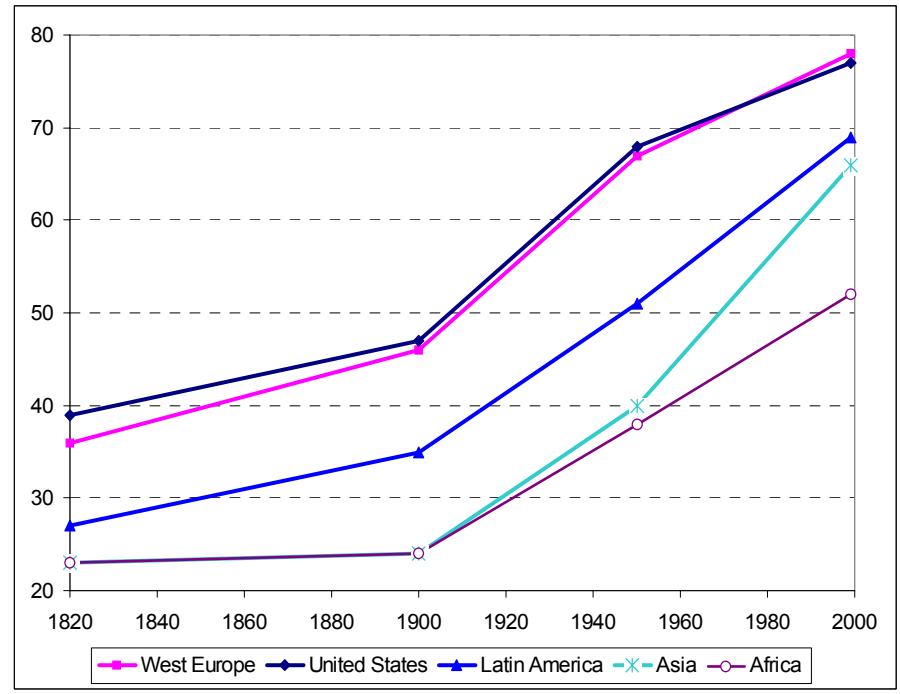

Figure 2.27. The Evolution of Life Expectancy Across Regions, 1820-1999

Source: Maddison (2001). 
In particular, life expectancy nearly tripled in the course of the 20th century in Asia, rising from a level of 24 years in 1960 to 66 years in 1999, reflecting the rise in income per capita as well as the diffusion of medical technology. Similarly, life expectancy in Africa doubled from 24 years in 1900 to 52 years in 1999. The more rapid advancement in income per capita in Latin America generated an earlier rise in life expectancy, and life expectancy increased modestly during the 19th century and more significantly in the course of the 20th century, from 35 years in 1900 to 69 years in 1999.

\subsubsection{Industrial Development and Human Capital Formation}

The process of industrialization was characterized by a gradual increase in the relative importance of human capital for the production process. The acceleration in the rate of technological progress increased gradually the demand for human capital, inducing individuals to invest in education, and stimulating further technological advancement. Moreover, in developed as well as less developed regions the onset of the process of human capital accumulation preceded the onset of the demographic transition, suggesting that the rise in the demand for human capital in the process of industrialization and the subsequent accumulation of human capital played a significant role in the demographic transition and the transition to a state of sustained economic growth.

\section{Developed Economies ${ }^{32}$}

As observed by Abramowitz (1993 p. 224), "In the nineteenth century, technological progress was heavily biased in a physical capital-using direction...the bias shifted in an intangible (human and knowledge) capital-using direction and produced the substantial contribution of education and other intangible capital accumulation to this century productivity growth." Furthermore, as argued by Goldin (2001), "The modern concept of the wealth of nations emerged by the early twentieth century. It was that capital embodied in the people - human capital - mattered."

In the first phase of the Industrial Revolution, the extent of public education was not correlated with industrial development and it differed across countries due to political, cultural, social, historical and institutional factors. Human capital had a limited role in the production process and education served religious, social, and national goals. In contrast, in the second phase of the Industrial Revolution the demand for skilled labor in the growing industrial sector markedly increased, human capital formation was designed primarily to satisfy the increasing skill requirements in the process of industrialization, and industrialists became involved in shaping the education system.

Notably, the reversal of the Malthusian relation between income and population growth during the demographic transition, corresponded to an increase in the level of resources invested in each child. For example, the literacy rate among men, which was stable at around $65 \%$ in the first phase of the Industrial Revolution, increased significantly during the second phase, reaching nearly $100 \%$ at the end of the 19th century (Clark 2003), and the proportion of children aged 5 to 14 in primary schools increased significantly in the second half of the 19 th century, from $11 \%$ in 1855 to $74 \%$ in 1900 . A similar pattern is observed in other European societies (Flora et al. 1983). In particular, as depicted in Figure 2.28, the proportion of children aged 5 to 14 in primary schools in France increased significantly in the second half of the 19th century, from $30 \%$ in 1832 to $86 \%$ in 1901 .

${ }^{32}$ This section is closely based on the research of Galor and Moav (2004b). 


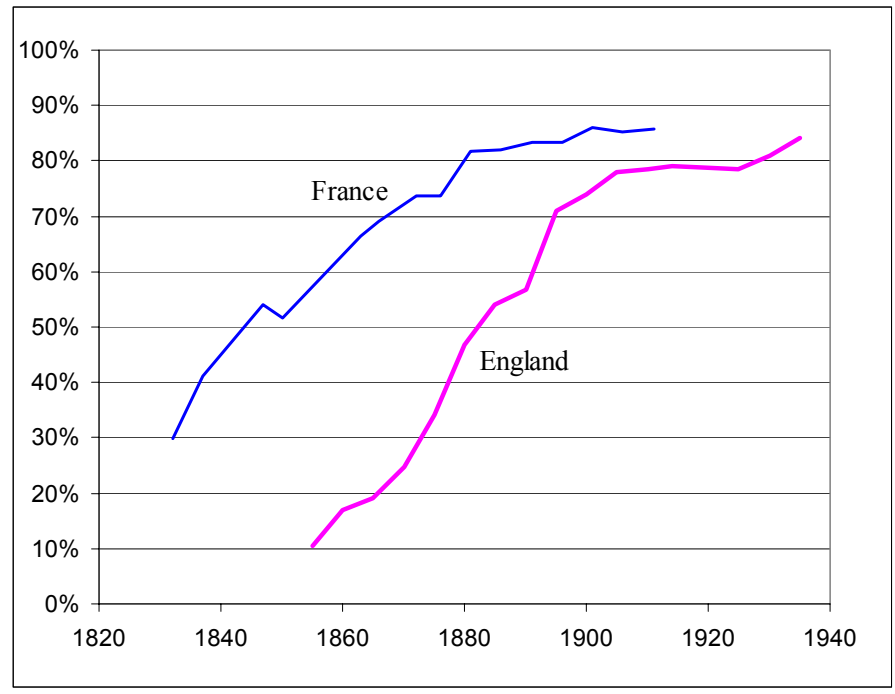

Figure 2.28. The Fraction of Children Age 5-14 in Public Primary Schools, 1820-1940 Source: Flora et al. (1983)

Evidence about the evolution of the return to human capital over this period are scarce and controversial. They do not indicate that the skill premium increased markedly in Europe over the course of the 19th century (Clark 2003). One can argue that the lack of clear evidence about the increase in the return to human capital over this period is an indication for the absence of a significant increase in the demand for human capital. This partial equilibrium argument, however is flawed. The return to human capital is an equilibrium price that is affected both by the demand and the supply of human capital. Technological progress in the second phase of the Industrial Revolution brought about an increase in the demand for human capital, and indeed, in the absence of a supply response, one would have expected an increase in the return to human capital. However, the significant increase in schooling that took place in the 19th century, and in particular the introduction of public education that lowered the cost of education, generated a significant increase in the supply of educated workers. Some of this supply response was a direct reaction of the increase in the demand for human capital, and thus may only operate to partially offset the increase in the return to human capital. However, the removal of the adverse effect of credit constraints on the acquisition of human capital (as reflected by the introduction of public education) generated an additional force that increased the supply of educated labor and operated towards a reduction in the return to human capital. ${ }^{33}$

\section{A. The Industrial Base for Education Reforms in the 19th Century}

Education reforms in developed countries in the 18th and the 19th century provide a profound insight about the significance of industrial development in the formation of human capital (and thus in the onset of the demographic transition) in the second half of the 19th century. In particular, the variation in the timing of the establishment of a national system of public education between England and Continental Europe is instrumental in isolating the role of industrial forces in human capital formation from other forces such as social control, moral conformity, enlightenment, sociopolitical stability, social and national cohesion, and military efficiency.

\footnotetext{
${ }^{33}$ This argument is supported indirectly by contemporary evidence about a higher rate of returns to human capital in less developed economies than in developed economies (Psacharopoulos and Patrinos 2002). The greater prevalence of credit markets imperfections and other barriers for the acquisition of skills in less developed economies generated only a partial supply response to industrial demand for human capital, contributing to this differential in the skill premium.
} 
England In the first phase of the Industrial Revolution (1760-1830), capital accumulation increased significantly without a corresponding increase in the supply of skilled labor. The investment ratio increased from $6 \%$ in 1760 to $11.7 \%$ in the year 1831 (Crafts 1985, p. 73). In contrast, literacy rates remained largely unchanged and the state devoted virtually no resources to raising the level of literacy of the masses. During the first stages of the Industrial Revolution, literacy was largely a cultural skill or a hierarchical symbol and had limited demand in the production process. ${ }^{34}$ For instance, in 1841 only $4.9 \%$ of male workers and only $2.2 \%$ of female workers were in occupations in which literacy was strictly required (Mitch 1992, pp. 14-15). During this period, an illiterate labor force could operate the existing technology, and economic growth was not impeded by educational retardation. ${ }^{35}$ Workers developed skills primarily through on-the-job training, and child labor was highly valuable.

The development of a national public system of education in England lagged behind the continental countries by nearly half a century and the literacy rate hardly increased in the period 1750-1830 (Sanderson 1995, pp. 2-10). ${ }^{36}$ As argued by Green (1990, pp. 293-294), "Britain's early industrialization had occurred without direct state intervention and developed successfully, at least in its early stages, within a laissez-faire framework. Firstly, state intervention was thought unnecessary for developing technical skills, where the initial requirements were slight and adequately met by traditional means. Secondly, the very success of Britain's early industrial expansion encouraged a complacency about the importance of scientific skills and theoretical knowledge which became a liability in a later period when empirical knowledge, inventiveness and thumb methods were no longer adequate." Furthermore, as argued by Landes (1969, p. 340) "although certain workers - supervisory and office personnel in particular - must be able to read and do the elementary arithmetical operations in order to perform their duties, large share of the work of industry can be performed by illiterates as indeed it was especially in the early days of the industrial revolution."

England initiated a sequence of reforms in its education system since the 1830s and literacy rates gradually increased. The process was initially motivated by a non-industrial reasons such as religion, social control, moral conformity, enlightenment, and military efficiency, as was the case in other European countries (e.g., Germany, France, Holland, Switzerland) that had supported public education much earlier. ${ }^{37}$ However, in light of the modest demand for skills and literacy by the capitalists, the level of governmental support was rather small. ${ }^{38}$

In the second phase of the Industrial Revolution, the demand for skilled labor in the growing industrial sector markedly increased and the proportion of children aged 5 to 14 in primary schools increased from $11 \%$ in 1855 to $25 \%$ in 1870 (Flora et al. 1983). Job advertisements, for instance, suggest that literacy became an increasingly desired characteristic for employment as of the 1850s (Mitch 1993, p. 292). In light of the industrial competition from other countries, capitalists started to recognize the importance of technical education for the provision of skilled workers. As noted by Sanderson 1995, pp. 10-13), "reading ...enabled the efficient functioning of an urban industrial society laced with letter writing, drawing up wills, apprenticeship indentures, passing bills of exchange, and notice and

\footnotetext{
${ }^{34}$ See Mokyr (1993, 2001).

${ }^{35}$ Some have argued that the low skill requirements even declined over this period. For instance, Sanderson (1995, p. 89) suggests that "One thus finds the interesting situation of an emerging economy creating a whole range of new occupations which require even less literacy and education than the old ones."

${ }^{36}$ For instance, in his parliamentary speech in defense of his 1837 education bill, the Whig politician, Henry Brougham, reflected upon this gap: "It cannot be doubted that some legislative effort must at length be made to remove from this country the opprobrium of having done less for education of the people than any of the more civilized nations on earth" (Green (1990, pp.10-11)).

${ }^{37}$ The proximity of the education acts in the UK to major wars suggests that the provision of public education was partly a compensation for the services of soldiers.

${ }^{38}$ Even in 1869 the government funded only one-third of school expenditure (Green, 1990, pp. 6-7).
} 
advertisement reading." Moreover, manufacturers argued that: "universal education is required in order to select, from the mass of the workers, those who respond well to schooling and would make a good foreman on the shop floor" (Simon 1987, p. 104).

As it became apparent that skills were necessary for the creation of an industrial society, replacing previous ideas that the acquisition of literacy would make the working classes receptive to radical and subversive ideas, capitalists lobbied for the provision of public education for the masses. ${ }^{39}$ The pure laissez-faire policy failed in developing a proper educational system and capitalists demanded government intervention in the provision of education. As James Kitson, a Leeds iron-master and an advocate of technical education explained to the Select Committee on Scientific Instruction (1867-1868): “... the question is so extensive that individual manufacturers are not able to grapple with it, and if they went to immense trouble to establish schools they would be doing it in order that others may reap the benefit" (Green, 1990, p. 295). ${ }^{40}$

An additional turning point in the attitude of capitalists towards public education was the Paris Exhibition of 1867, where the limitations of English scientific and technical education became clearly evident. Unlike the 1851 exhibition in which England won most of the prizes, the English performance in Paris was rather poor; of the 90 classes of manufacturers, Britain dominated only in 10. Lyon Playfair, who was one of the jurors, reported that: "a singular accordance of opinion prevailed that our country has shown little inventiveness and made little progress in the peaceful arts of industry since 1862." This lack of progress "upon which there was most unanimity conviction is that France, Prussia, Austria, Belgium and Switzerland possess good systems of industrial education and that England possesses none" (Green 1990, p. 296). ${ }^{41}$

In 1868, the government established the Parliamentary Select Committee on Scientific Education. This was the origin of nearly 20 years of various parliamentary investigations into the relationship between science, industry, and education, that were designed to address the capitalists' outcry about the necessity of universal public education. A sequence of reports by the committee in 1868, the Royal Commission on Scientific Instruction and the Advancement of Science during the period 1872-75, and by the Royal Commission on Technical Education in 1882, underlined the inadequate training for supervisors, managers and proprietors, as well as workers. They argued that most managers and proprietors did not understand the manufacturing process and thus, failed to promote efficiency, investigate innovative techniques or value the skills of their workers (Green 1990, pp. 297-298). In particular, W. E. Forster, the Vice President of the committee of the Council of Education told The House of Commons: "Upon the speedy provision of elementary education depends our industrial prosperity...if we leave our work-folk any longer unskilled...they will become overmatched in the competition of the world" (Hurt 1971, pp. 223-224). The reports made various recommendations which highlighted the need to redefine elementary schools, to revise the curriculum throughout the entire school system, particularly with respect to industry and manufacture, and to improve teacher training.

In addition, in 1868, secondary schools were investigated by the Schools Inquiry Commission, which found a very unsatisfactory level for the vast majority of schools that employed untrained teachers and used antiquated methods. Their main proposal was to organize a state inspection of secondary

\footnotetext{
${ }^{39}$ There was a growing consensus among workers and capitalists about the virtues of reform. The labor union movement was increasingly calling for a national system of non-sectarian education. The National Education League (founded in 1869 by radical Liberals and Dissenters) demanded a free, compulsory, non-sectarian national system of education (Green, 1990, p. 302).

${ }^{40}$ Indeed, the Factory Act of 1802 required owners of textile mills to provide elementary instruction for their apprentices, but the law was poorly enforced (Cameron (1989, p. 216-217)).

${ }^{41}$ Moreover, the Nussey brothers, who had written a report on woolen textiles at the Exhibition, returned to Leeds to start a movement for a Yorkshire College of Science.
} 
schools and to provide efficient education geared towards the specific needs of its consumers. In particular, the Royal Commission on Technical Education of 1882 confirmed that England was being overtaken by the industrial superiority of Prussia, France and the United States and recommended the introduction of technical and scientific education into secondary schools.

It appears that the government gradually yielded to the pressure by capitalists as well as labor unions, as reflected by its increased contributions to elementary as well as higher education. In the 1870 Education Act, the government assumed responsibility for ensuring universal elementary education, although it did not provide either free or compulsory education at the elementary level. The Act created a national provision without an integrated system, where voluntary schools existed beside state schools. In 1880, prior to the significant extension of the franchise of 1884 that made the working class the majority in most industrial countries, education was made compulsory throughout England. The 1889 Technical Instruction Act allowed the new local councils to set up technical instruction committees, and the 1890 Local Taxation Act provided public funds that could be spent on technical education (Green, 1990, p. 299).

School enrollment of 10-year olds increased from $40 \%$ in 1870 to $100 \%$ in 1900, the literacy rate among men, which was stable at around $65 \%$ in the first phase of the Industrial Revolution, increased significantly during the second phase reaching nearly $100 \%$ at the end of the 19th century (Clark 2002), and the proportion of children aged 5 to 14 in primary schools increased significantly in the second half of the 19th century, from $11 \%$ in 1855 to $74 \%$ in 1900 (Flora et al. 1983). Finally, the 1902 Balfour Act marked the consolidation of a national education system and created state secondary schools (Ringer 1979 and Green 1990, p. 6) and science and engineering and their application to technology gained prominence (Mokyr 1990, 2002).

Continental Europe The early development of public education occurred in the western countries of continental Europe (e.g., Prussia, France, Sweden, and the Netherlands) well before the Industrial Revolution. The provision of public education at this early stage was motivated by several goals such as social and national cohesion, military efficiency, enlightenment, moral conformity, sociopolitical stability as well as religious reasons. However, as was the case in England, massive educational reforms occurred in the second half of the 19th century due to the rising demand for skills in the process of industrialization. As noted by Green (1990, pp. 293-294) "In continental Europe industrialization occurred under the tutelage of the state and began its accelerated development later when techniques were already becoming more scientific; technical and scientific education had been vigorously promoted from the center as an essential adjunct of economic growth and one that was recognized to be indispensable for countries which wished to close Britain's industrial lead."

In France, indeed, the initial development of the education system occurred well before the Industrial Revolution, but the process was intensified and transformed to satisfy industrial needs in the second phase of the Industrial Revolution. The early development of elementary and secondary education in the 17th and 18th centuries was dominated by the Church and religious orders. Some state intervention in technical and vocational training was designed to reinforce development in commerce, manufacturing and military efficiency. After the French Revolution, the state established universal primary schools. Nevertheless, enrolment rates remained rather low. The state concentrated on the development of secondary and higher education with the objective of producing an effective elite to operate the military and governmental apparatus. Secondary education remained highly selective, offering general and technical instruction largely to the middle class (Green 1990, pp. 135-137 and 141-142)). Legislative proposals during the National Convention quoted by Cubberley (1920, pp. 514-517) are revealing about the 
underlying motives for education in this period: “... Children of all classes were to receive education, physical, moral and intellectual, best adapted to develop in them republican manners, patriotism, and the love of labor... They are to be taken into the fields and workshops where they may see agricultural and mechanical operations going on..."

The process of industrialization in France and the associated increase in the demand for skilled labor, as well as the breakdown of the traditional apprenticeship system, significantly affected the attitude towards education. State grants for primary schools were gradually increased in the 1830s and legislation made an attempt to provide primary education in all regions, extend the higher education, and provide teacher training and school inspections. The number of communities without schools fell by $50 \%$ from 1837 to 1850 and as the influence of industrialists on the structure of education intensified, education became more stratified according to occupational patterns (Anderson 1975 p. 15, 31). According to Green 1990, p.157): "[This] legislation... reflected the economic development of the period and thus the increasing need for skilled labor." The eagerness of capitalists for rapid education reforms was reflected by the organization of industrial societies that financed schools specializing in chemistry, design, mechanical weaving, spinning, and commerce (Anderson 1975, p 86, 204).

As was the case in England, industrial competition led industrialists to lobby for the provision of public education. The Great Exhibition of 1851 and the London Exhibition of 1862 created the impression that the technological gap between France and other European nations was narrowing and that French manufacturers ought to invest in the education of their labor force to maintain their technological superiority. Subsequently, the reports on industrial education by commissions established in the years 1862 to 1865 reflected the plea of industrialists for the provision of industrial education on a large scale and for the implementation of scientific knowledge in the industry. "The goal of modern education... can no longer be to form men of letters, idle admirers of the past, but men of science, builders of the present, initiators of the future." 42 (Anderson 1975, p. 194).

Education reforms in France were extensive in the second phase of the Industrial Revolution, and by 1881 a universal, free, compulsory and secular primary school system had been established and technical and scientific education further emphasized. Illiteracy rates among conscripts tested at the age of 20 declined gradually from $38 \%$ in $1851-55$ to $17 \%$ in 1876-80 (Anderson 1975, p. 158)), and the proportion of children aged 5 to 14 in primary schools increased from $51.5 \%$ in 1850 to $86 \%$ in 1901 (Flora et al. 1983)). Hence, the process of industrialization, and the increase in the demand for skilled labor in the production process, led industrialists to support the provision of universal education, contributing to the extensiveness of education as well as to its focus on industrial needs.

In Prussia, as well, the initial steps towards compulsory education took place at the beginning of the 18th century well before the Industrial Revolution. Education was viewed at this stage primarily as a method to unify the state. In the second part of the 18th century, education was made compulsory for all children aged 5 to 13. Nevertheless, these regulations were not strictly enforced due to the lack of funding associated with the difficulty of taxing landlords for this purpose, and due to the loss of income from child labor. At the beginning of the 19th century, motivated by the need for national cohesion, military efficiency, and trained bureaucrats, the education system was further reformed, establishing provincial and district school boards, making education a secular activity and compulsory for a three-year period, and reconstituting the Gymnasium as a state institution that provided nine years of education for the elite (Cubberly 1920 and Green 1990).

The process of industrialization in Prussia and the associated increase in the demand for skilled labor led to significant pressure for educational reforms and thereby to the implementation of universal

\footnotetext{
${ }^{42}$ L'Enseignement professionnel, ii (1864), p. 332, quoted in Anderson (1975).
} 
elementary schooling. Taxes were imposed to finance the school system and teacher training and certification were established. Secondary schools started to serve industrial needs as well, and the Realschulen, which emphasized the teaching of mathematics and science, was gradually adopted, and vocational and trade schools were founded. Total enrolment in secondary school increased sixfold from 1870 to 1911 (Flora et al. 1983). "School courses...had the function of converting the occupational requirements of public administration, commerce and industry into educational qualifications..." (Muller 1987, pp. 23-24). Furthermore, the Industrial Revolution significantly affected the nature of education in German universities. German industrialists who perceived advanced technology as the competitive edge that could boost German industry, lobbied for reforms in the operation of universities, and offered to pay to reshape their activities so as to favor their interest in technological training and industrial applications of basic research (McClelland 1980, p. 300-301).

The structure of education in the Netherlands also reflected the interest of capitalists in the skill formation of the masses. In particular, as early as the 1830s, industrial schools were established and funded by private organizations, representing industrialists and entrepreneurs. Ultimately, in the latter part of the 19th century, the state, urged by industrialists and entrepreneurs, started to support these schools (Wolthuis, 1999, pp. 92-93, 119, 139-140, 168, 171-172).

United States The process of industrialization in the US also increased the importance of human capital in the production process. Evidence provided by Abramowitz and David (2000) and Goldin and Katz (2001) suggests that over the period 1890-1999, the contribution of human capital accumulation to the growth process of the United States nearly doubled. ${ }^{43}$ As argued by Goldin (2001), the rise of the industrial, business and commerce sectors in the late 19th and early 20th centuries increased the demand for managers, clerical workers, and educated sales personnel who were trained in accounting, typing, shorthand, algebra, and commerce. Furthermore, in the late 1910s, technologically advanced industries demanded blue-collar craft workers who were trained in geometry, algebra, chemistry, mechanical drawing, etc. The structure of education was transformed in response to industrial development and the increasing importance of human capital in the production process, and American high schools adapted to the needs of the modern workplace of the early 20th century. Total enrolment in public secondary schools increased 70-fold from 1870 to 1950 . (Kurian, 1994). ${ }^{44}$

\section{B. Human Capital, Factor Prices and Inequality}

In the first phase of the Industrial Revolution, prior to the implementation of significant education reforms, physical capital accumulation was the prime engine of economic growth. In the absence of significant human capital formation, the concentration of capital among the capitalist class widened

\footnotetext{
${ }^{43}$ It should be noted that literacy rates in the US were rather high prior to this increase in the demand for skilled labor. Literacy rates among the white population were already $89 \%$ in 1870, 92\% in 1890, and $95 \%$ in 1910 (Engerman and Sokoloff (2000)). Education in earlier periods was motivated by social control, moral conformity, and social and national cohesion, as well as required skills for trade and commerce. In particular, Field (1976) and Bowles and Gintis (1975) argue that educational reforms are designed to sustain the existing social order, by displacing social problems into the school system.

${ }^{44}$ As noted by Galor and Moav (2004), due to differences in the structure of education finance in the US in comparison to European countries, capitalists in the US had only limited incentives to lobby for the provision of education and support it financially. Unlike the central role that government funding played in the provision of public education in European countries, the evolution of the education system in the US was based on local initiatives and funding. The local nature of the education initiatives in the US induced community members, in urban as well as rural areas, to play a significant role in advancing their schooling system. American capitalists, however, faced limited incentives to support the provision of education within a county in an environment where labor was mobile across counties and the benefits from educational expenditure in one county may be reaped by employers in other counties. "The impetus to expand education to the secondary level was primarily a grassroots movement led by parents, employers, and even young people themselves" (Goldin (1999)).
} 
wealth inequality. Once education reforms were implemented, however, the significant increase in the return to labor relative to capital, as well as the significant increase in the real return to labor and the associated accumulation of assets by the workers, brought about a decline in inequality.

Evidence suggests that in the first phase of the Industrial Revolution, prior to the implementation of education reforms, capital accumulation brought about a gradual increase in wages along with an increase in the wage-rental ratio. Education reforms in the second phase of the Industrial Revolution were associated with a sharp increase in real wages along with a sharp increase in the wage-rental ratio. ${ }^{45}$ Finally, wealth inequality widened in the first phase of the Industrial Revolution and reversed its course in the second phase, once significant education reforms were implemented.

As documented in Figure 2.29, over the time period 1823-1915, wealth inequality in the UK reached a peak around 1870 and declined thereafter, in close association with the patterns of enrolment rates and factor prices, depicted in Figures 2.28 and 2.29. ${ }^{46}$ It appears that the decline in inequality is associated with the significant changes that occurred around 1870 in the relative returns to the main factors of production possessed by capitalists and workers. These changes in factor prices reflect the increase in enrolment rates - in particular the process of education reforms from 1830 to 1870 and its consolidation in the Education Act of 1870 - and its delayed effect on the skill level per worker.
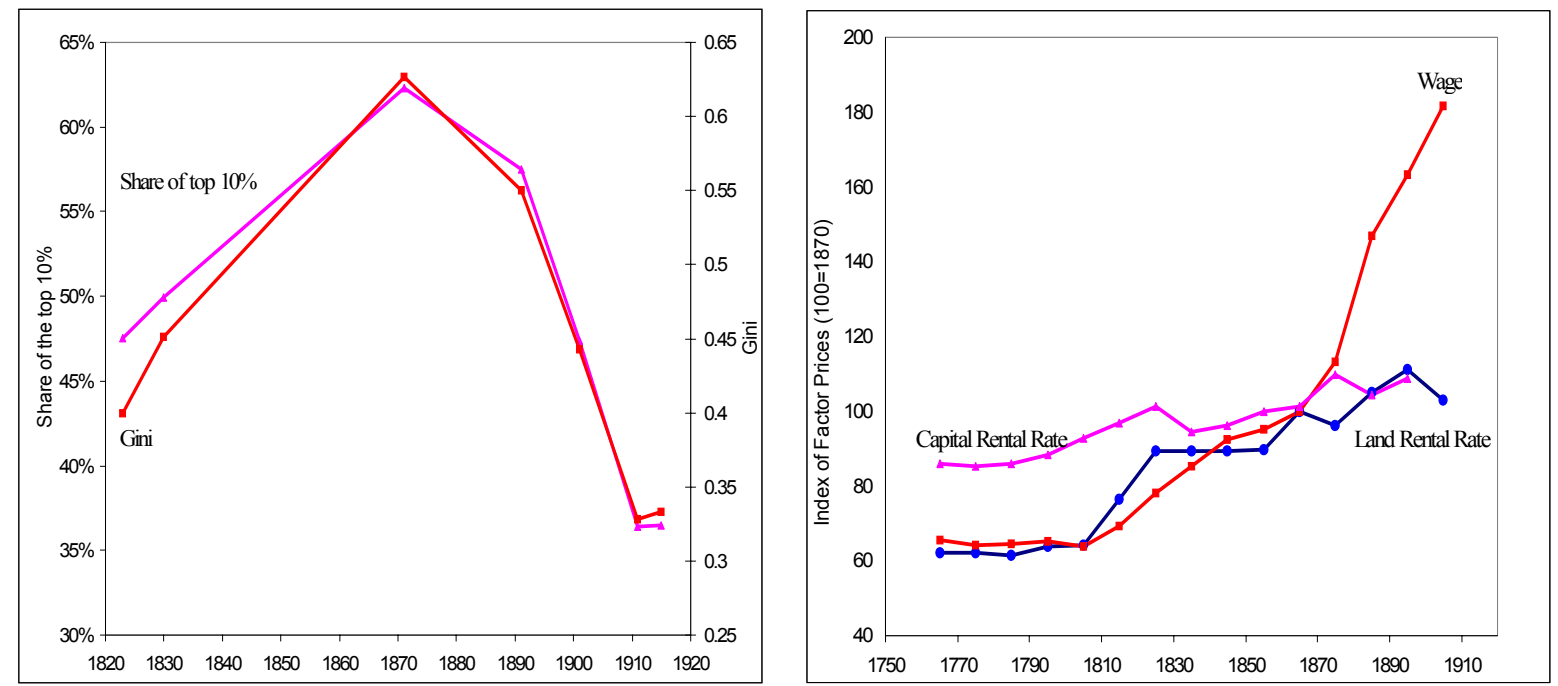

Figure 2.29. Wealth Inequality and Factor Prices: England 1820-1920

Source: Williamson (1985) for inequality and Clark $(2002,2003)$ for factor prices

Similar patterns of the effect of education on factor prices and therefore on inequality are observed in France as well. As argued by Morrisson and Snyder (2000), wealth inequality in France increased during the first half of the 19th century, and started to decline in the last decades of the 19th century in close association with the rise in education rates depicted in Figure 2.28, the rise in real wages depicted in Figure 2.10, and a declining trend of the return to capital over the 19th century. The decline in inequality in France appears to be associated with the significant changes in the relative returns to the main factors of production possessed by capitalists and workers in the second part of the 19th century As depicted in Figures 2.10, based on the data presented in Levy-Leboyer and Bourguignon (1990), real wages as well as the wage-rental ratio increased significantly as of 1860 , reflecting the rise in the demand

\footnotetext{
${ }^{45}$ It should be noted that the main source of the increase in real wages was not a decline in prices. Over this period nominal wages increased significantly as well.

${ }^{46}$ It should be noted that the return to capital increased moderately over this period, despite the increase in the supply of capital, reflecting technological progress, population growth, and accumulation of human capital.
} 
for skilled labor and the effect of the increase in enrolment rates on the skill level per worker.

The German experience is consistent with this pattern as well. Inequality in Germany peaked towards the end of the 19th century (Morrisson and Snyder 2000) in association with a significant increase in the real wages and in the wage-rental ratio from the 1880s (Spree 1977 and Berghahn 1994), which is in turn related to the provision of industrial education in the second half of the 19th century.

The link between the expansion of education and the reduction in inequality is present in the US as well. Wealth inequality in the US, which increased gradually from colonial times until the second half of the 19th century, reversed its course at the turn of the century and maintained its declining pattern during the first half of the 20th century (Lindert and Williamson 1976). As argued by Goldin (2001), the emergence of the "new economy" in the early 20th century increased the demand for educated workers. The creation of publicly funded mass modern secondary schools from 1910 to 1940 provided general and practical education, contributed to workers productivity and opened the gates for college education. This expansion facilitated social and geographic mobility and generated a large decrease in inequality in economic outcomes.

\section{Independence of Political Reforms in the 19th Century}

The 19th century was marked by significant political reforms along with the described education reforms. One could therefore challenge the significance of the industrial motive for education reform, suggesting that political reforms during the 19th century shifted the balance of power towards the working class and enabled workers to implement education reforms against the interest of the industrial elite, has no empirical support. However, political reforms that took place in the 19th century had no apparent effect on education reforms over this period, strengthening the hypothesis that indeed industrial development, and the increasing demand for human capital, were the trigger for human capital formation and the demographic transition. ${ }^{47}$ Education reforms took place in autocratic states that did not relinquish political power throughout the 19th century, and major reforms occurred in societies in the midst of the process of democratization well before the stage at which the working class constituted the majority among the voters.

In particular, the most significant education reforms in the UK were completed before the voting majority shifted to the working class. The patterns of education and political reforms in the UK during the 19th century are depicted in Figure 2.30. The Reform Act of 1832 nearly doubled the total electorate, but nevertheless only $13 \%$ of the voting-age population were enfranchised. Artisans, the working classes, and some sections of the lower middle classes remained outside of the political system. The franchise was extended further in the Reform Acts of 1867 and 1884 and the total electorate nearly doubled in each of these episodes. However, working-class voters did not become the majority in all urban counties until 1884 (Craig 1989).

The onset of England's education reforms, and in particular, the fundamental Education Act of 1870 and its major extension in 1880 occurred prior to the political reforms of 1884 that made the working class the majority in most counties. As depicted in Figure 2.30, a trend of significant increase in primary education was established well before the extension of the franchise in the context of the 1867 and 1884 Reform Acts. In particular, the proportion of children aged 5 to 14 in primary schools increased five-fold (and surpassed 50\%) over the three decades prior to the qualitative extension of the franchise in 1884 in which the working class was granted a majority in all urban counties. Furthermore, the political reforms do not appear to have any effect on the pattern of education reform. In fact, the average growth rate of education attendance from decade to decade over the period 1855 to 1920

\footnotetext{
${ }^{47}$ See for instance, Acemoglu and Robinson (2000), where the extension of the franchise during the 19th century is viewed as a commitment devise ensuring future income redistribution from the elite to the masses.
} 
reaches a peak at around the Reform Act of 1884 and starts declining thereafter. It is interesting to note, however, that the abolishment of education fees in nearly all elementary schools occurs only in 1891, after the Reform Act of 1884, suggesting that the political power of the working class may have affected the distribution of education cost across the population, but consistent with the proposed thesis, the decision to educate the masses was taken independently of the political power of the working class.
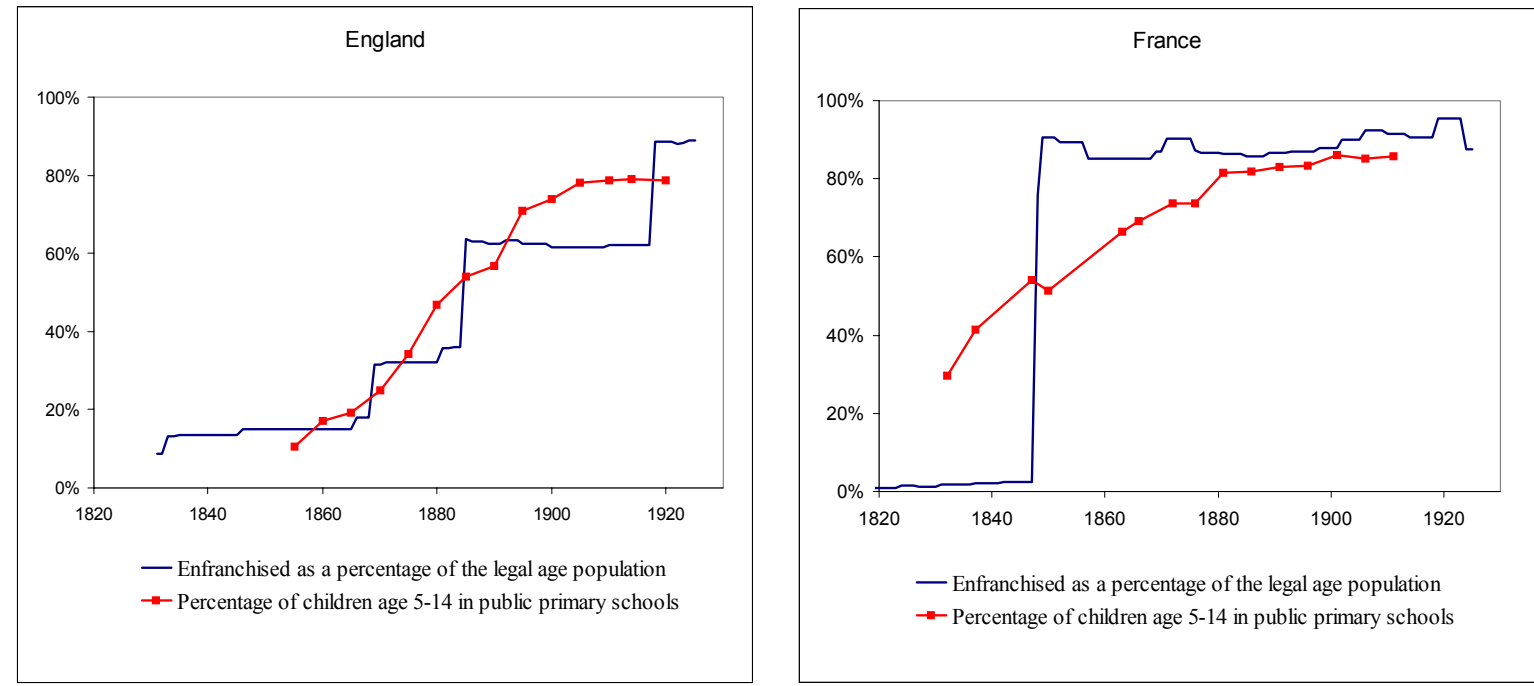

Figure 2.30. The Evolution of Voting Rights and School Enrolment

Source: Flora et al. (1983)

In France, as well, the expanding pattern of education preceded the major political reform that gave the voting majority to the working class. The patterns of education and political reforms in France during the 19th century are depicted in Figure 2.30. Prior to 1848, restrictions limited the electorate to less than $2.5 \%$ of the voting-age population. The 1848 revolution led to the introduction of nearly universal voting rights for males. Nevertheless, the proportion of children aged 5 to 14 in primary schools doubled (and exceeded 50\%) over the two decades prior to the qualitative extension of the franchise in 1848 in which the working class was granted a majority among voters. Furthermore, the political reforms of 1848 do not appear to have any effect on the pattern of education expansion.

A similar pattern occurs in other European countries. Political reforms in the Netherlands did not affect the trend of education expansion and the proportion of children aged 5 to 14 in primary schools exceeded $60 \%$ well before the major political reforms of 1887 and 1897. Similarly, the trends of political and education reforms in Sweden, Italy, Norway, Prussia and Russia do not lend credence to the alternative hypothesis.

\section{Less Developed Economies}

The process of industrialization was characterized by a gradual increase in the relative importance of human capital in less developed economies as well. As depicted in Figure 2.31, educational attainment increased significantly across all less developed regions. Moreover, in line with the pattern that emerged among developed economies in the 19th century, the increase in educational attainment preceded the decline in total fertility rates. In particular, the average years of schooling in Africa increased by $44 \%$ (from 1.56 to 2.44) prior to the onset of decline in total fertility rates in 1980, as depicted in Figure 2.23, whereas the available data for Asia and Latin America demonstrates a simultaneous increase in educational attainment and a decline in fertility. 


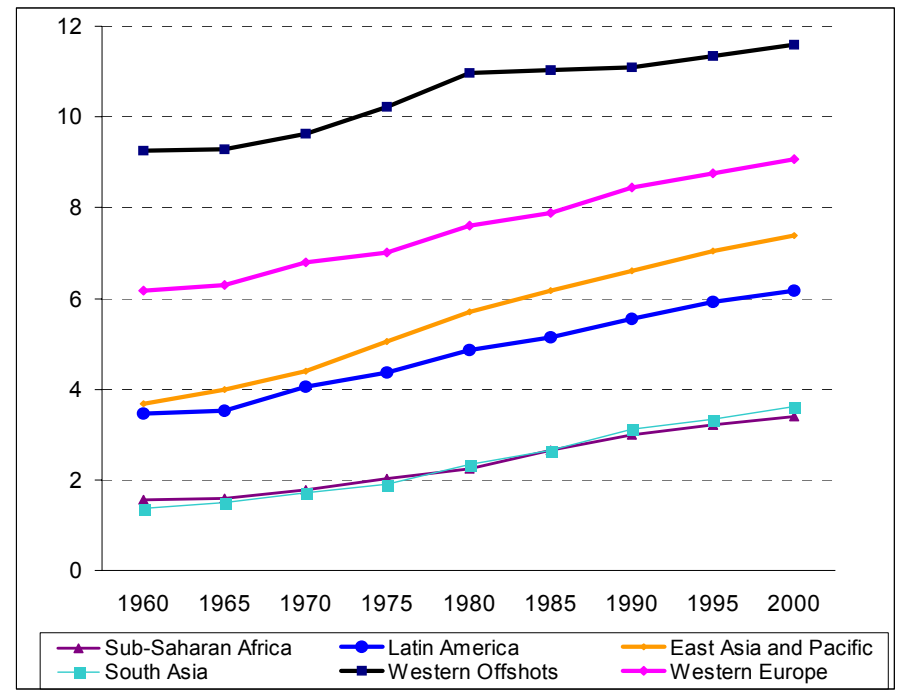

Figure 2.31. The Evolution of Average Years of Education: 1960-2000

Source: Barro and Lee (2000)

\subsubsection{International Trade and Industrialization}

The process of industrialization in developed economies was enhanced by the expansion of international trade. During the 19th century, North-South trade, as well as North-North trade, expanded significantly due to a rapid industrialization in Northwest Europe as well as the reduction of trade barriers and transportation costs and the benefits of the gold standard. The ratio of world trade to output was about $2 \%$ in 1800, but then it rose to $10 \%$ in 1870 , to $17 \%$ in 1900 and $21 \%$ in 1913 (Estavadeordal, Frantz, and Taylor 2002). While much of this trade occurred between industrial economies a significant proportion was between industrial and non-industrial economies. As shown in Table 2.1, before 1900 nearly $50 \%$ of manufactured exports were to non-European and non-North American economies. By the end of 19th century a clear pattern of specialization emerged. The UK and Northwest Europe were net importers of primary products and net exporters of manufactured goods, whereas the exports of Asia, Oceania, Latin America and Africa were overwhelmingly composed of primary products. (Findlay and O'Rourke 2001).

Table 2.1. Regional Shares of World Trade in Manufactures

Source: Yates (1959)

\begin{tabular}{||l|r|r|r|r|r|r||}
\hline & \multicolumn{2}{|c|}{$1876-1880$} & \multicolumn{2}{c||}{$1896-1900$} & \multicolumn{2}{c||}{1913} \\
\hline & Exports & Imports & Exports & Imports & Exports & Imports \\
\hline & & & & & & \\
U.K. and Ireland & $37.8 \%$ & $9.1 \%$ & $31.5 \%$ & $10.4 \%$ & $25.3 \%$ & $8.2 \%$ \\
Northwest Europe & $47.1 \%$ & $18.1 \%$ & $45.8 \%$ & $20.3 \%$ & $47.9 \%$ & $24.4 \%$ \\
Other Europe & $9.2 \%$ & $13.3 \%$ & $10.3 \%$ & $12.2 \%$ & $8.3 \%$ & $15.4 \%$ \\
U.S. and Canada & $4.4 \%$ & $7.7 \%$ & $7.4 \%$ & $9.6 \%$ & $10.6 \%$ & $12.1 \%$ \\
Rest of the World & $1.5 \%$ & $51.8 \%$ & $5.0 \%$ & $47.5 \%$ & $7.9 \%$ & $39.9 \%$ \\
\hline \hline
\end{tabular}


Atlantic trade as well as trade with Asia, in an era of colonialism, had a major effects on European growth starting in the late 16th century (Acemoglu et al. 2003). Furthermore, later expansion of international trade contributed further to the process of industrialization in the UK and Europe (O'Rourke and Williamson 1999). For the UK, the proportion of foreign trade to national income grew from about $10 \%$ in the 1780 s to about $26 \%$ over the years $1837-45$, and $51.5 \%$ in the time period $1909-13$ (Kuznets 1967). Other European economies experienced a similar pattern as well. The proportion of foreign trade to national income on the eve of World War I was 53.7\% in France, 38.3\% in Germany , 33.8\% in Italy, and $40.4 \%$ in Sweden (Kuznets 1967, Table 4). Furthermore, export was critical for the viability of some industries, especially the cotton industry, where $70 \%$ of the UK output was exported in the 1870's. The quantitative study of Stokey (2001) suggests that trade was instrumental for the increased share of manufacturing in total output in the UK, as well as for the significant rise in real wages. Thus while it appears that technological advances could have spawned the Industrial Revolution without an expansion of international trade, the growth in exports increased the pace of industrialization and the growth rate of output per capita. ${ }^{48}$

\subsection{The Great Divergence}

The differential timing of the take-off from stagnation to growth across countries and the corresponding variations in the timing of the demographic transition led to a great divergence in income per capita as well as population growth.

The last two centuries have witnessed dramatic changes in the distribution of income and population across the globe. Some regions have excelled in the growth of income per capita, while other regions have been dominant in population growth. Inequality in the world economy was negligible till the 19th century. The ratio of GDP per capita between the richest region and the poorest region in the world was only 1.1:1 in the year 1000, a 2:1 in the year 1500 and 3:1 in the year 1820. As depicted in Figure 2.32, there has been a 'Great Divergence' in income per capita among countries and regions in the past two centuries. In particular, the ratio of GDP per capita between the richest region (Western offshoots) and the poorest region (Africa) has widened considerably from a modest 3:1 ratio in 1820, to a 5:1 ratio in 1870 , a 9:1 ratio in 1913 , a $15: 1$ in 1950, and a huge 18:1 ratio in 2001 .

\footnotetext{
${ }^{48}$ Pomeranz (2000), provides historical evidence for the vital role of trade in the 'take off' of the European economies. He argues that technological and development differences between Europe and Asia were minor around 1750, but the discovery of the New World enabled Europe, via Atlantic trade, to overcome 'land constraints' and to take-off technologically.
} 


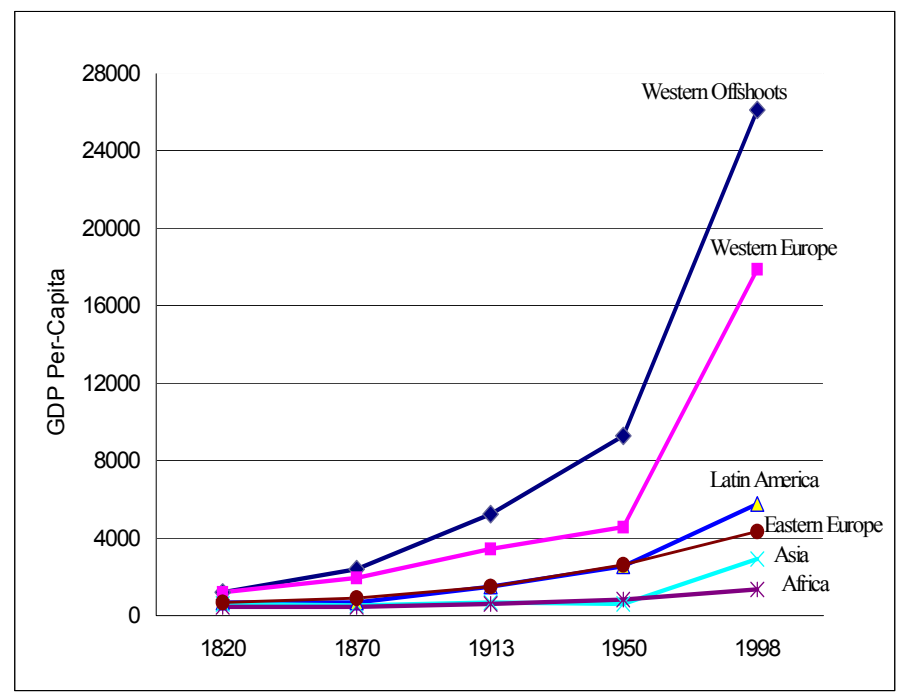

Figure 2.32. The Great Divergence

Source: Maddison (2001)

An equally momentous transformation occurred in the distribution of world population across regions, as depicted in Figure 2.33. The earlier take-off of Western European countries increased the amount of resources that could be devoted for the increase in family size, permitting a $16 \%$ increase in the share of their population in the world economy within a 50 year period (from $12.8 \%$ in 1820 to $14.8 \%$ in 1870). However, the early onset in the Western European demographic transition and the long delay in the demographic transition of less developed regions well into the 2nd half of the twentieth century led to a $55 \%$ decline in the share of Western European population in the world, from $14.8 \%$ in 1870 to $6.6 \%$ in 1998. In contrast, the prolongation of Post-Malthusian period among less developed regions in association with the delay in their demographic transition well into the second half of 20th century, channeled their increased resources towards a significant increase in their population. Africa's share of world population increased $84 \%$, from $7 \%$ in 1913 to $12.9 \%$ in 1998, Asia's share of world population increased 11\% from 51.7\% in 1913 to $57.4 \%$ in 1998, and Latin American countries increased their share in world population from $2 \%$ in 1820 to $8.6 \%$ in 1998.
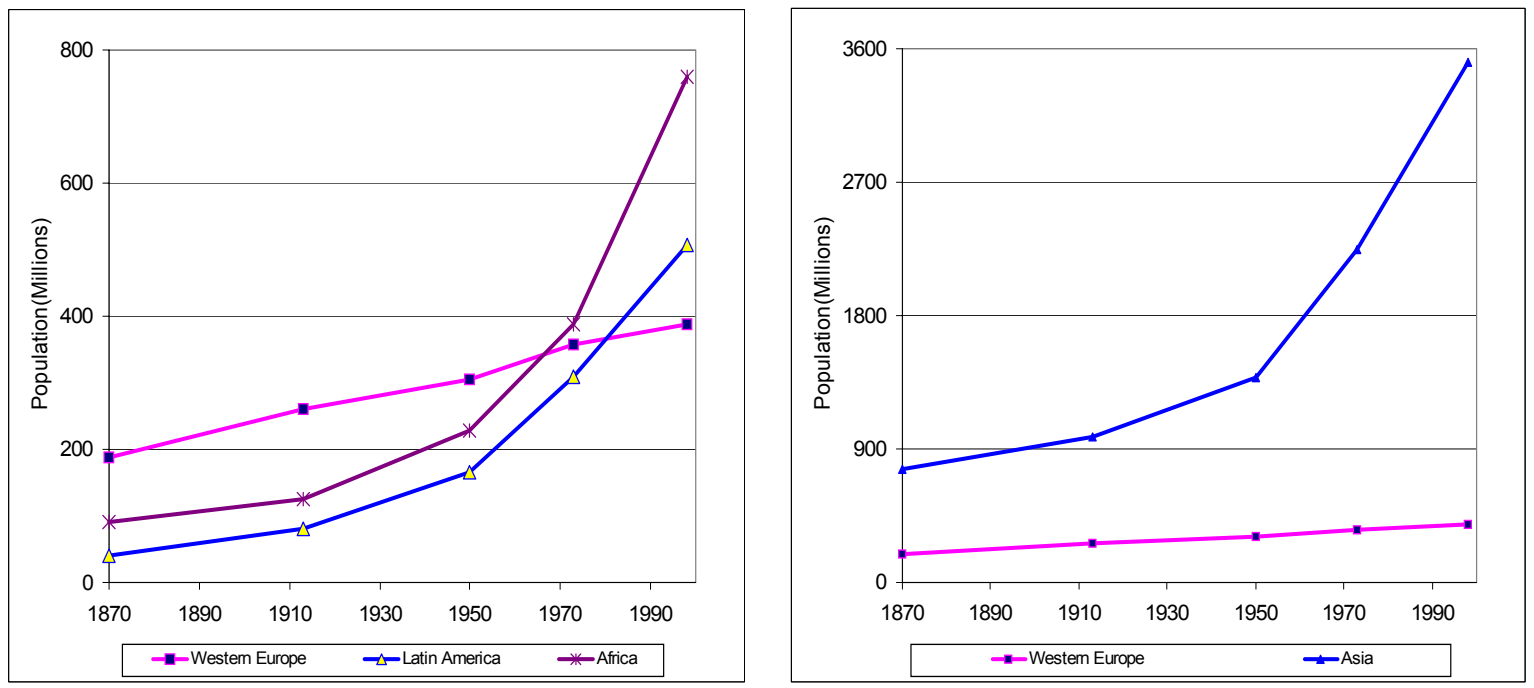

Figure 2.33. Divergence in Regional Populations 
Thus, while the ratio of income per capita in Western Europe to that in Asia has tripled in the last two centuries, the ratio of Asian to European population has doubled. ${ }^{49}$

The divergence that has been witnessed in the last two centuries has been maintained across countries in the last decades as well (e.g., Jones 1997 and Pritchett 1997). Interestingly, however, Sala-i-Martin (2002) has shown that the phenomenon has not been maintained in recent decades across people in the world, (i.e., when national boundaries are removed).

\section{The Fundamental Challenges}

The discovery of a unified theory of economic growth that could account for the intricate process of development in the last thousands of years is one of the most significant research challenges facing researchers in the field of growth and development. A unified theory would unveil the underlying micro-foundations that are consistent with entire the process of economic development, enhancing the confidence in the viability of growth theory, its predictions and policy implications, while improving the understanding of the driving forces that led to the recent transition from stagnation to growth and the Great Divergence. Moreover, a comprehensive understanding of the hurdles faced by less developed economies in reaching a state of sustained economic growth would be futile unless the forces that initiated the transition of the currently developed economies into a state of sustained economic growth would be identified and modified to account for the differences in the structure of less developed economies in an interdependent world.

The evidence presented in section 2 suggests that the preoccupation of growth theory with the empirical regularities that have characterized the growth process of developed economies in the past century and of less developed economies in the last few decades, has become harder to justify from a scientific viewpoint. Could we justify the use of selective observations about the recent course of the growth process and its principal causes in the formulating exogenous and endogenous neoclassical growth models? Could we be confident about the predictions of a theory that is not based on micro-foundations that match the major characteristics of the entire growth process? The evolution of theories in older scientific disciplines suggests that theories that are founded on the basis of a subset of the existing observations are fragile and non-durable.

\subsection{Mysteries of the Growth Process}

The underlying determinants of the stunning recent escape from the Malthusian trap have been shaded in mystery and their significance for the understanding of the contemporary growth process has been explored only very recently. What are the major economic forces that led to the epoch of Malthusian stagnation that had characterized most of human history? What is the origin of the sudden spurt in growth rates of output per capita and population that occurred in the course of the take-off from stagnation to growth? Why had episodes of technological progress in the pre-industrialization era failed to generate sustained economic growth? What was the source of the dramatic reversal in the positive relationship between income per capita and population that existed throughout most human history? What are the main forces that prompted the demographic transition? Would the transition to a state of sustained economic growth be feasible without the demographic transition? Are there

\footnotetext{
${ }^{49}$ Over the period 1820-1998, the ratio between income per capita in Western Europe and Asia (excluding Japan) grew 2.9 times, whereas the ratio between the Asian population (excluding Japan) and the Western European population grew 1.7 times [Maddison, 2001].
} 
underlying unified behavioral and technological structures that can account for these distinct phases of development simultaneously and what are their implications for the contemporary growth process?

The mind-boggling phenomenon of the Great Divergence in income per capita across regions of the world in the past two centuries, that accompanied the take-off from an epoch of stagnation to a state of sustained economic growth, presents additional unresolved mysteries about the growth process. What accounts for the sudden take-off from stagnation to growth in some countries in the world and the persistent stagnation in others? Why has the positive link between income per capita and population growth reversed its course in some economies but not in others? Why have the differences in income per capita across countries increased so markedly in the last two centuries? Has the pace of transition to sustained economic growth in advanced economies adversely affected the process of development in less-developed economies?

The transitions from a Malthusian epoch to a state of sustained economic growth and the emergence of the Great Divergence have shaped the current structure of the world economy. Nevertheless, neoclassical growth models abstracted from these the significant aspects of the growth process. In recent years, however, it has been increasingly recognized that the understanding of the contemporary growth process would be fragile and incomplete unless growth theory would be based on proper micro-foundations that reflect the growth process in its entirety.

\subsection{The Incompatibility of Non-Unified Growth Theories}

Existing (non-unified) growth models are unable to capture the growth process throughout human history. Malthusian models capture the growth process during the Malthusian epoch but are incompatible with the transition to the Modern Growth Regime. Neoclassical growth models (with endogenous or exogenous technological change), in contrast, are compatiable with the growth process of the developed economies during the Modern Growth Regime, but fail to capture the evolution of economies during the Malthusian epoch, the origin of the take-off from the Malthusian epoch into the Post-Malthusian Regime, and the sources of the demographic transition and the emergence of the modern growth regime. Moreover, the failure of non-unified growth models in identifying the underlying factors that led to the transition from stagnation to growth limits their applicability for the contemporary growth process of the less developed economies and thereby for the current evolution of the world income distribution.

\subsubsection{Malthusian and Post-Malthusian Theories}

\section{The Malthusian Theory}

The Malthusian theory, as was outlined initially by Malthus (1798), captures the main attributes of the epoch of Malthusian stagnation that had characterized most of human existence, but is utterly inconsistent with the prime characteristics of the modern growth regime. ${ }^{50}$

The theory suggests that the stagnation in the evolution of income per capita over this epoch reflected the counterbalancing effect of population growth on the expansion of resources, in an environment characterized by diminishing returns to labor. The expansion of resources, according to Malthus, would lead to an increase in population growth, reflecting the natural result of "passion between the sexes" ${ }^{51}$ In contrast, when population size would grow beyond the capacity of the available resources,

\footnotetext{
${ }^{50}$ The Malthusian theory was formalized recently. Kremer (1993) models a reduced-form interaction between population and technology along a Malthusian equilibrium, and Lucas (2002) presents a Malthusian model in which households optimize over fertility and consumption, labor is subjected to diminishing returns due to the presence of a fixed quantity of land, and the Malthusian level of income per capita is determined endogenously.

${ }^{51} \mathrm{As}$ argued by Malthus (1798), "The passion between the sexes has appeared in every age to be so nearly the same, that it may always be considered, in algebraic language as a given quantity."
} 
it would be reduced by the "preventive check" (i.e., intentional reduction of fertility) as well as by the "positive check" (i.e., the tool of nature due to malnutrition, disease, and famine).

According to the theory, periods marked by the absence of changes in the level of technology or in the availability of land, were characterized by a stable population size as well as a constant income per capita. In contrast, episodes of technological progress, land expansion, and favorable climatic conditions, brought about temporary gains in income per capita, triggering an increase in the size of the population which led ultimately to a decline in income per capita to its long-run level. The theory proposes therefore that variations in population density across countries during the Malthusian epoch reflected primarily cross-country differences in technologies and land productivity. Due to the positive adjustment of population to an increase in income per capita, differences in technologies or in land productivity across countries resulted in variations in population density rather than in the standard of living.

The Malthusian theory generates predictions that are largely consistent with the characteristics of economies during the Malthusian epoch, as described in Section 2.1: (a) Technological progress or resource expansion would lead to a larger population, without altering the level of income in the long run. (b) Income per capita would fluctuate during the Malthusian epoch around a constant level. (c) Technologically superior countries would have eventually denser populations but their standard of living in the long run would not reflect the degree of their technological advancement. These predictions, however, are irremediably inconsistent with the relationship between income per capita and population that has existed in the post-demographic transition era as well as with the state of sustained economic growth that had characterized the Modern Growth Regime.

Unified theories of economic growth, in contrast, incorporate the main ingredients of the Malthusian economy into a broader context focusing on the interaction in this epoch between technology and the size of the population and the distribution of its characteristics, that generate the main ingredients of the Malthusian epoch but lead to an inevitable take-off to the Post Malthusian Regime.

\section{The Post-Malthusian Theory}

The Post-Malthusian theories capture the acceleration of the growth rate of income per capita and population growth that occurred in the Post-Malthusian Regime in association with the process of industrialization. They do not capture, however, the stagnation during the Malthusian epoch and the economic forces that gradually emerged in this era and brought about the take-off from the Malthusian trap. Moreover, these theories do not account for the factors that ultimately originated the demographic transition and the transition to a state of sustained economic growth. ${ }^{52}$

These theories suggest that the acceleration in technological progress and the associated rise in income per capita was only channeled partly towards an increase in the size of the population. Although, the Malthusian mechanism linking higher income to higher population growth continued to function, the effect of higher population on diluting resources per capita, and thus lowering income per capita, was counteracted by the acceleration in technological progress and capital accumulation, allowing income

\footnotetext{
${ }^{52}$ Models that are not based on Malthusian elements are unable to capture the long epoch of Malthusian stagnation in which output per capita fluctuates around a subsistence level. For instance, an interesting research by Goodfriend and McDermott (1995) demonstrates that exogenous population growth increases population density and hence generates a greater scope for the division of labor inducing the development of markets and economic growth. Their model, therefore generates a take-off from non-Malthusian stagnation to Post-Malthusian Regime in which population and output are positively related. The model lacks Malthusian elements and counter-factually it implies therefore that since the emergence of a market economy over 5000 years ago growth has been strictly positive. Moreover, it does not generate the forces that would bring about the demographic transition and ultimately sustained economic growth. In the long-run the economy remains in the Post-Malthuisan regime in which the growth of population and output are positively related. Other nonMalthusian models that abstracts from population growth and generate an acceleration of output growth along the process of industrialization include Acemoglu and Zilibotti (1997).
} 
per capita to rise despite the offsetting effects of population growth.

Kremer (1993), in an attempt to defend the role of the scale effect in endogenous growth models, examines a reduced-form of the coevolution of population and technology in a Malthusian and Post Malthusian environment, providing evidence for the presence of a scale effect in the pre-demographic transition era. ${ }^{53}$ Kremer's Post-Malthusian theory does not identify the factors that brought about the take-off from the Malthusian trap, as well as the driving forces behind the demographic transition and the transition to a state of sustained economic growth.

Unified theories capture the main characteristics of the Post-Malthusian Regime, and generate, in contrast, the endogenous driving forces that brought about the take-off from the Malthusian epoch into this regime and ultimately enabled the economy to experience a demographic transition and to reside in a state of sustained economic growth.

\subsubsection{Theories of Modern Economic Growth}

Exogenous growth models (e.g. Solow 1956) that have focused primarily on the role of factor accumulation in the growth process, as well as endogenous growth models (e.g., Romer 1990, Grossman and Helpman 1991, and Aghion and Howitt 1992) that have devoted their attention to the role of endogenous technological progress in the process of development, were designed to capture the main characteristics of the Modern Growth Regime. These models, however, are inconsistent with the pattern of development that had characterized economies over most of human existence. They do not account for Malthusian epoch the economic factors that brought about the take-off from the Malthusian regime into the Post-Malthusian Regime, and the forces that brought about the demographic transition and ultimately the state of sustained economic growth. ${ }^{54}$

Modern non-unified growth theory has not developed the research methodology that would enable researchers to shed light on the principal factors that would enable less developed economies that are in a state of Malthusian stagnation, or in a post-Malthusian regime to take-off to a state of sustained economic growth. Moreover, most endogenous and exogenous growth models are inconsistent with the changes in the demographic regime along the process of development. ${ }^{55}$ With few exceptions non-unified growth models do not generate the hump-shaped relationship between income per capita and population growth in the process of development. Most growth models with endogenous population have been oriented toward the modern regime, capturing the recent negative relationship between population growth and income per capita, but failing to capture the positive effect of income per capita on population growth that had characterized most human existence and the economic factors that triggered the demographic transition..$^{56}$

\footnotetext{
${ }^{53}$ Komlos and Artzrouni (1990) simulates an escape from a Malthusian trap based on the Malthusian and Boserupian interaction between population and technology.

${ }^{54}$ Non-unified growth models are inconsistent with the process of development in the Malthusian epoch. Moreover, as long as the neoclassical production structure of non-decreasing returns to scale is maintained, they could not be modified to account for the Malthusian epoch by the incorporation of endogenous population growth. Suppose that the optimal growth model would be augmented to account for endogenous population. Suppose further that the parameters of the model would be chosen so as to assure that the level of income per capita would reflect the level that existed during the Malthusian epoch and population growth will be near replacement level as was the case during this era. This equilibrium would not possess the prime characteristic of a Malthusian equilibrium. Namely, technological progress would raise income per capita permanently since adjustments in population growth would not offset this rise of income (as long as the return to labor is characterized by non-diminishing returns to scale).

${ }^{55}$ In fact, most endogenous growth models that focus exclusively on the modern growth regime are inconsistent with the demographic structure within this regime, predicting a positive effect of population growth on (the growth rate of) income per capita. A notable exception is Dalgaard and Kreiner (2001).

${ }^{56}$ Earlier papers that captures aspects of the cross-section relationship between income per capita and fertility includes Ben Zion and Razin (1975), Barro and Becker, (1989) and Becker, Murphy and Tamura (1990), and recent ones include Deopke and De la Croix (2003) and Moav (2005).
} 


\subsection{Theories of the Demographic Transition and Their Empirical Validity}

The theories of the demographic transition attempt to capture the determinants of the significant reduction in fertility rates and population growth that characterized the world in the past century, following the unprecedented increase in population growth during the Post-Malthusian regime, enabling economies to convert a increasing share of the benefits of factor accumulation and technological progress into growth of output per capita.

There are several factors that could have theoretically triggered a demographic transition. The simultaneity of the demographic transition across Western European countries suggests that a common cause may have originated the various transitions. Was it an outcome of a simultaneous decline in mortality rates across Western European countries? Was it associated with a nearly simultaneous rise in income across Western European countries? An outcome of the rise in the relative wages of women in the second phase of the Industrial Revolution? Or was it a consequence of the universal rise in the demand for education and the associated decline in child labor in the second phase of the Industrial Revolution? Historical evidence suggests that demographers' explanation of the demographic transition - the decline in mortality - is highly implausible. Moreover, Becker's emphasis on the role of rising income in the demographic transition is inconsistent with the evidence. Empirical evidence suggests that the rise in the demand for human capital is the most significant force behind the demographic transition and it is therefore a critical building block in existing unified theories.

\subsubsection{The Decline in Infant and Child Mortality}

The decline in infant and child mortality rates that preceded the decline in fertility rates in most countries in the world, with the notable exceptions of France and the US, has been demographers' favorite explanation for the onset of the decline in fertility in the course of the demographic transition. ${ }^{57}$ Nevertheless, it appears that this simplistic viewpoint is based on weak theoretical reasonings and is inconsistent with historical evidence.

Existing theories suggest that parents generate utility from the number (and possibly the quality) of their surviving offspring. A decline in mortality rates, therefore, would be expected to lead to a corresponding reduction in total fertility rates, but not necessarily to a reduction in the number of children reaching adulthood. While it is highly plausible that mortality rates were among the factors that affected the level of total fertility rates along human history, historical evidence does not lend credence to the argument that the decline in mortality rates accounts for the reversal of the positive historical trend between income and fertility. A careful examination of the various factors that affect fertility rates (i.e., mortality rate, income level, the return to investment in child quality, and the gender wage gap) reveals that this argument is inconsistent with the evidence.

The decline in mortality rates does not appear to be the trigger for the decline in fertility in Western Europe. As demonstrated in Figures 2.23 and 2.24, the mortality decline in Western Europe started nearly a century prior to the decline in fertility and it was associated initially with increasing fertility rates in some countries and non-decreasing fertility rates in other countries

In particular, as demonstrated in Figure 3.1, the decline in mortality started in England in the 1730s and was accompanied by a steady increase in fertility rates until 1820. The significant rise in income per capita in the Post-Malthusian Regime increased the desirable number of surviving offspring and thus, despite the decline in mortality rates, fertility increased significantly so as to reach this higher

\footnotetext{
${ }^{57}$ The effect of the decline in mortality rates on the prolongation of productive life and thus on the return to human capital is discussed in section 3.3.3.
} 
desirable level of surviving offspring. ${ }^{58}$ As depicted in Figure 3.1, the decline in fertility during the demographic transition occurred in a period in which this pattern of increased income per capita (and its potential positive effect on fertility) was intensified, while the pattern of declining mortality (and its adverse effect on fertility) maintained the trend that existed in the 140 years that preceded the demographic transition, suggesting that in the absence of the intervention of a third factor fertility would have risen further. ${ }^{59}$ Thus, the reversal in the fertility patterns in England as well as other Western European countries in the 1870s suggests that it is very likely that the demographic transition was prompted by a different universal force. ${ }^{60}$

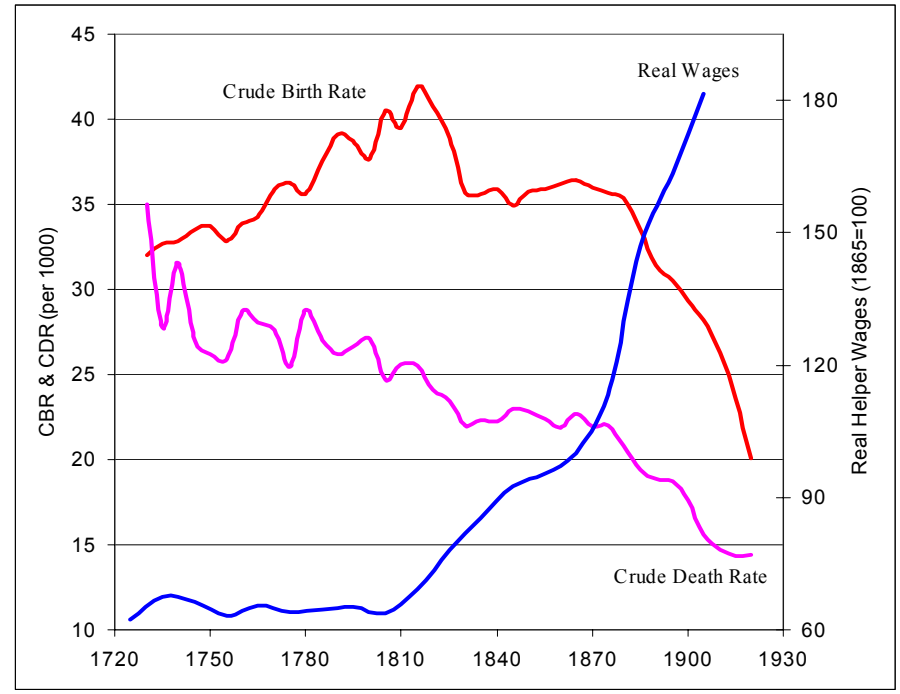

Figure 3.1. Fertility, Mortality and Real Wages, England 1730-1920

Source: Wrigley and Schofield (1981), Clark (2002), and Andorka (1978)

Furthermore, most relevant from an economic point of view is the cause of the reduction in net fertility (i.e. the number of children reaching adulthood). The decline in the number of surviving offspring that was observed during the demographic transition (e.g., Figure 2.22) is unlikely to follow from mortality decline. Mortality decline would lead to a reduction in the number of surviving offspring if the following set implausible of conditions would be met: ${ }^{61}$ (i) there exists a significant precautionary demand for children, i.e., individuals are significantly risk averse with respect to their expected number of surviving offspring and they hold a buffer stock of children in a high mortality environment (highly improbable from an evolutionary perspective), (ii) risk aversion with respect to consumption is smaller than risk aversion with respect to fertility (evolutionary theory would suggest the opposite), (iii) sequential fertility (i.e., replacement of non-surviving children) is modest, ${ }^{62}$ and (iv) parental resources

\footnotetext{
${ }^{58}$ The argument is valid even if fertility rates would have remained unchanged over this period.

${ }^{59}$ One could argue that the decline in mortality was not internalized into the decision of household who had difficulties separating temporary decline from a permanent one. This argument is highly implausible given the fact that mortality declined monotonically for nearly 140 years prior to the demographic transition. It is inconceivable that six generations of household did not update information about mortality rates in their immediate surrounding, while keeping the collective memories about mortality rates two centuries earlier.

${ }^{60}$ The mortality channel is inconsistent with additional evidence: the decline in fertility started in France and the US prior to the decline in mortality rates

${ }^{61}$ In particular, the theoretical analysis of Kalemli-Ozcan (2002) generates a reduction in net fertility in reaction to a decline in mortality assuming (implicitly) that all these implausible conditions are satisfied. Eckstein et al. (1999) argue in their structural quantitative analysis of the demographic transition in Sweden, that mortality decline played a role in the demographic transition. Their underlying theoretical structure, however, requires conditions (iii) and (iv) as well as specific interactions between mortality, wages, and the return to human capital.

${ }^{62}$ Doepke (2005) shows that regardless of the degree of risk aversion, the feasibility of sequential fertility is sufficient to preclude the decline in net fertility in reaction to a decline in mortality.
} 
saved from the reduction in the number of children that do not survive to adulthood do not lead to a rise in fertility. ${ }^{63}$

A quantitative analysis by Doepke (2005) supports the viewpoint that a decline in infant mortality rates was not the trigger for the decline in net fertility during the demographic transition. Utilizing the mortality and fertility data from England in the time period 1861-1951, he shows that the decline in child mortality in this time period should have resulted in an rise in net fertility rates, in contrast to the evidence, suggesting that other factors generated the demographic transition. Similar conclusions about the insignificance of the mortality decline in the decline in fertility during the demographic transition is reached in the quantitative analysis of Fernandez-Vilaverde (2003).

\subsubsection{The Rise in the Level of Income Per Capita}

The rise in income per capita prior to the demographic transition has led some researchers to argue that the demographic transition was triggered by the rise in income per capita and its asymmetric effects on the income of households on the one hand and the opportunity cost of raising children on the other hand.

Becker (1981) advanced the argument that the decline in fertility in the course of the demographic transition is a by-product of the rise in income per capita that preceded the demographic transition. He argues that the rise in income induced a fertility decline because the positive income effect on fertility that was generated by the rise in wages was dominated by the negative substitution effect that was brought about by the rising opportunity cost of children. Similarly, Becker and Lewis (1973) argue that the income elasticity with respect to child quality is greater than that with respect to child quantity, and hence a rise in income led to a decline in fertility along with a rise in the investment in each child.

This theory, however, is counter-factual. It suggests that the timing of the demographic transition across countries in similar stages of development would reflect differences in income per capita. However, remarkably, as depicted in Figure 2.22, the decline in fertility occurred in the same decade across Western European countries that differed significantly in their income per capita. In 1870, on the eve of the demographic transition, England was the richest country in the world, with a GDP per capita of $\$ 3191 .{ }^{64}$ In contrast, Germany that experienced the decline in fertility in the same years as England, had in 1870 a GDP per capita of only $\$ 1821$ (i.e., $57 \%$ of that of England). Sweden's GDP per capita of $\$ 1664$ in 1870 was $48 \%$ of that of England, and Finland's GDP per capita of $\$ 1140$ in 1870 was only $36 \%$ of that of England, but their demographic transitions occurred in the same decade as well.

The simultaneity of the demographic transition across Western European countries that differed significantly in their income per capita suggests that the high level of income that was reached by Western Europeans countries in the Post-Malthusian regime had a very limited role in the demographic transition. ${ }^{65}$ Furthermore, a quantitative analysis of the demographic transition in England, conducted by Fernandez-Vilaverde (2003), demonstrates that Becker's theory is counter-factual. In contrast to Becker's theory, the calibration suggests that a rise in income would have resulted in an increase in fertility rates, rather than in the observed decline in fertility.

Interestingly, and consistent with subsequent theories that underlined the critical role of technological progress in the demographic transition, despite the large differences in the levels of income

\footnotetext{
${ }^{63} \mathrm{An}$ additional force that operates against the decline in the number of surviving offspring is the physiological constraint on the feasible number of birth per woman. If this constraint is binding for some households in a high mortality regime, a reduction in mortality would operate towards an increase the number of surviving offspring.

${ }^{64}$ Source: Maddison (2001). GDP per capita is measured in 1990 international dollars.

${ }^{65}$ Furthermore, cross-section evidence within countries suggest that the elasticity of the number of surviving offspring with respect to wage income was positive prior to the demographic transition (e.g., Clark (2003)), in contrast to Becker's argument that would require a hump-shaped relationship.
} 
per capita across European countries that experiences the demographic transition in the same time period, the growth rates of income per capita of these European countries were rather similar during their demographic transition, ranging from 1.9\% per year over the period 1870-1913 in the UK, $2.12 \%$ in Norway, $2.17 \%$ in Sweden, and $2.87 \%$ in Germany.

\subsubsection{The Rise in the Demand for Human Capital}

The gradual rise in the demand for human capital in the second phase of the Industrial Revolution as well as in the process of industrialization of less developed economies, as documented in section 2.3.3, and its close association with the timing of the demographic transitions, has led researchers to argue that the increasing role of human capital in the production process (rather than the rise in income) induced households to increase their investment in the human capital of their offspring, ultimately leading to the onset of the demographic transition.

Galor and Weil $(1999,2000)$, argue that the acceleration in the rate of technological progress increased gradually the demand for human capital in the second phase of the Industrial Revolution, inducing parents to invest in the human capital of their offspring. The increase in the rate of technological progress and the associated increase in the demand for human capital brought about two effects on population growth. On the one hand, improved technology eased households' budget constraints and provided more resources for quality as well as quantity of children. On the other hand, it induced a reallocation of these increased resources toward child quality. In the early stages of the transition from the Malthusian regime, the effect of technological progress on parental income dominated, and the population growth rate as well as the average quality increased. Ultimately, further increases in the rate of technological progress that were stimulated by human capital accumulation induced a reduction in fertility rates, generating a demographic transition in which the rate of population growth declined along with an increase in the average level of education. Thus, consistent with historical evidence, the theory suggests that prior to the demographic transition, population growth increased along with investment in human capital, whereas the demographic transition brought about a decline in population growth along with a further increase in human capital formation. ${ }^{66}$

Moreover, Galor and Weil's theory suggests that a universal rise in the demand for human capital in Western Europe (as documented in section 2.3.3) followed by a rapid growth rates of output per-capita generated the observed simultaneous onset of the demographic transition across Western European countries that differed significantly in their levels of income per capita. The simultaneous increase in educational attainment across Western European countries in the second phase of the Industrial Revolution appears as a plausible common cause that brought about the demographic transition. The rise in the demand for human capital in the second phase of the Industrial Revolution in some Western European countries (as documented in section 2.3.3) and the expectations for an imminent increase in the demand for human capital in the other Western European countries led to a significant increase in the investment in children's education and therefore to a decline in fertility.

In particular, as depicted in Figure 3.2, the demographic transition in England was associated with a significant increase in the investment in child quality as reflected by years of schooling. Quantitative evidence provided by Doepke (2004) suggests that indeed, educational policy played an important role in the demographic transition in England.

\footnotetext{
${ }^{66}$ Quantitative evidence provided by Greenwood and Seshadri (2002) is supportive of the role of the rise in the demand for skilled labor in the demographic transition in the US. They demonstrate that technological progress in an industrial, skilled-intensive, sector that is larger than that in an unskilled-intensive, agricultural sector matches the data on the US demographic transition.
} 


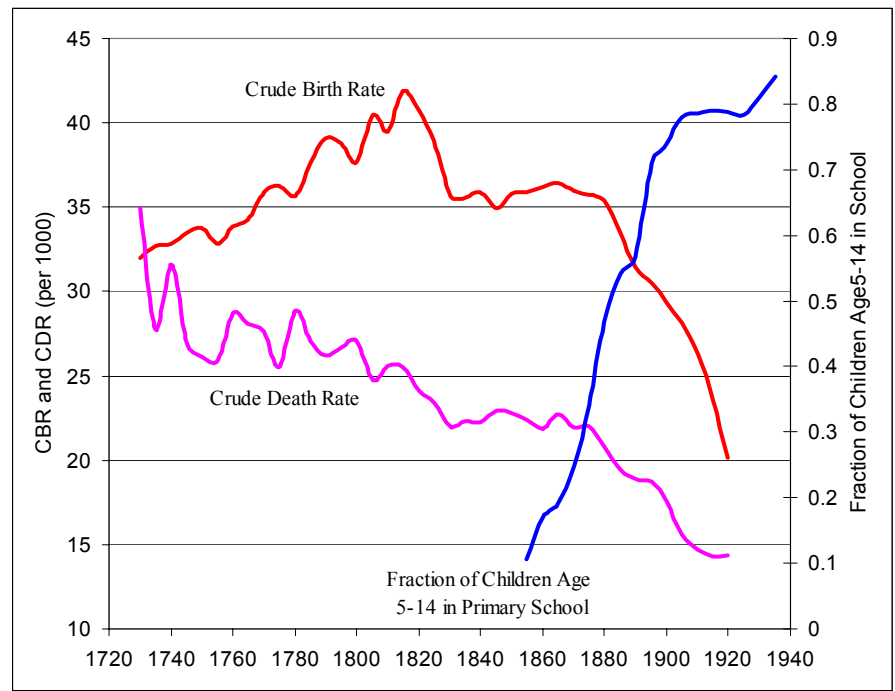

Figure 3.2. Investment in Human Capital and the Demographic Transition, England, 1730-1935 Sources: Flora et al. (1983) and Wrigley and Schofield (1983)

\section{Reinforcing Mechanisms}

\section{The Decline in Child Labor}

The effect of the rise in the demand for human capital on the reduction in the desirable number of surviving offspring was magnified via its adverse effect on child labor. It gradually increased the wage differential between parental labor and child labor inducing parents to reduce the number of their children and to further invest in their quality (Hazan and Berdugo 2002). ${ }^{67}$ Moreover, the rise in the importance of human capital in the production process induced industrialists to support education reforms (Galor and Moav 2004) and thus laws that abolish child labor (Doepke and Zilibotti 2003), inducing a reduction in child labor and thus in fertility. Doepke (2004) provides quantitative evidence that suggests that indeed, child labor law, and to a lesser extent educational policy, played an important role in the demographic transition.

\section{The Rise in Life Expectancy}

The impact of the increase in the demand for human capital on the decline in the desirable number of surviving offspring may have been reinforced by the rise in life expectancy.

The decline in mortality rates in developed countries since the 18th century, as depicted in Figure 2.24 , and the recent decline in mortality rates in less developed countries, as depicted in Figure 2.25, corresponded to a gradual increase in life expectancy. As depicted in Figure 2.26, life expectancy in England increased at a stable pace from 32 years in the 1720 s to about 41 years in the 1870 . This pace of the rise in life expectancy increased and life expectancy reached 50 years in 1900, 69 years in 1950 and 77 years in 1999. Similarly, life expectancy increased in Western Europe during the 19th century from 36 in 1820 to 46 in 1900, 67 in 1950 and 78 in 1999. In less developed economies life expectancy increased markedly in the 20th century, as depicted in Figure 2.27.

\footnotetext{
${ }^{67}$ Hazan and Berdugo (2002)'s hypothesis is consistent with existing historical evidence. For instance, Horrell and Humphries (1995) suggest, based on data from the United Kingdom, that the earnings of children age 10-14 as a percentage of father's earning declined from the period 1817-1839 to the period 1840-1872 by nearly $50 \%$ if the father was employed in a factory. Interestingly, the effect is significantly more pronounced if the father was employed in skilled occupations (i.e., high wage agriculture) rather than low skilled occupations (i.e., mining), reflecting the rise in the relative demand for skilled workers and its effect on the decline in the relative wages of children.
} 
Despite the gradual rise in life expectancy prior to the demographic transition investment in human capital was rather insignificant as long as a technological demand for human capital had not emerged. In particular, the increase in life expectancy in England occurred 150 years prior to the demographic transition and may have resulted in a gradual increase in literacy rates, but not at a sufficient level to induce a reduction in fertility. Similarly, the rise in life expectancy in less developed regions in the first half of the 20th century has not generated a significant increase in education and a demographic transition.

In light of the technologically based rise in the demand for human capital in the second phase of the Industrial Revolution, as documented in section 2.3.3, the rise in the expected length of productive life has increased the potential rate of return to investments in children's human capital, and thus reenforced and complemented the inducement for investment in education and the associated reduction in fertility rates. ${ }^{68}$

\section{Changes in Marriage Institutions.}

The effect of the rise in the demand for human capital on the desirable quality of children, and thus on the decline in fertility was reinforced by changes in marriage institutions. Gould, Moav and Simhon (2003) suggest that the rise in the demand for human capital increased the demand for quality women who have a comparative advantage in raising quality children, increasing the cost of marriage. Polygamy therefore became less affordable, inducing the transition from polygamy to monogamy, and reinforcing the decline in fertility. Edlund and Lagerlof (2002) suggest that love marriage, as opposed to arranged marriage, redirected the payment for the bride from the parent to the couple, promoting investment and human capital accumulation and thus reinforcing the decline in fertility.

\section{Natural Selection and the Evolution of Preference for Offspring's Quality}

The impact of the increase in the demand for human capital on the decline in the desirable number of surviving offspring may have been magnified by cultural or genetic evolution in the attitude of individuals toward child quality. An evolutionary change in the attitude of individuals towards human capital could have generated a swift response to the increase in demand for human capital, generating a decline in fertility along with an increase in human capital formation.

Human beings, like other species, confront the basic trade-off between offspring's quality and quantity in their implicit Darwinian survival strategies. Preference for child quantity as well as for child quality reflects the well-known variety in the quantity-quality survival strategies (or in the $K$ and $r$ strategies) that exists in nature (e.g., MacArthur and Wilson 1967) and the allocation of resources between offspring quantity and quality is subjected to evolutionary changes (Lack 1954).

Galor and Moav (2002) propose that during the epoch of Malthusian stagnation that characterized most of human existence, individuals with a higher valuation for offspring quality gained an evolutionary advantage and their representation in the population gradually increased. The agricultural revolution facilitated the division of labor and fostered trade relationships across individuals and communities,

\footnotetext{
${ }^{68}$ This mechanism was outlined by Galor and Weil (1999) and was examined in different settings by Erlich and Lui (1991), and Hazan and Zoabi (2004). It should be noted, however, that as argued by Moav (2005), the rise in the potential return to investment in child quality due to the prolongation of the productive life is not as straightforward as it may appear. It requires that the prolongation of life would affect the return to quality more than the return to quantity. For example, if parents derive utility from the aggregate wage income of their children, prolongation of life would increase the return to quantity and quality symmetrically. Hence, additional mechanism that would increase the relative complementarity between life expectancy and human capital would be needed to assure the rise in the return to human capital. For instance, Hazan and Zoabi (2004) assume that an increase in life expectancy, and thus the health of students, enhances the production process of human capital and thus increases the relative return to child quality. Alternatively, Moav (2005) argues that an increase in life expectancy, while having no effect on parental choice between quality and quantity, induce the offspring to increase their own human capital bringing about lower fertility rates in the next generation due to the comparative advantage of educated parents in educating their children.
} 
enhancing the complexity of human interaction and raising the return to human capital. Moreover, the evolution of the human brain in the transition to Homo sapiens and the complementarity between brain capacity and the reward for human capital has increased the evolutionary optimal investment in the quality of offspring. The distribution of valuation for quality lagged behind the evolutionary optimal level and individuals with traits of higher valuation for their offspring's quality generated higher income and, in the Malthusian epoch when income was positively associated with aggregate resources allocated to child rearing, a larger number of offspring. Thus, the trait of higher valuation for quality gained the evolutionary advantage, and the Malthusian pressure gradually increased the representation in the population of individuals whose preferences were biased towards child quality.

This evolutionary process was reinforced by its interaction with economic forces. As the fraction of individuals with high valuation for quality increased, technological progress intensified, raising the rate of return to human capital. The increase in the rate of return to human capital along with the increase in the bias towards quality in the population reinforced the substitution towards child quality, setting the stage for a more rapid decline in fertility along with a significant increase in investment in human capital.

This mechanism is consistent with the gradual rise in literacy rates prior to the Industrial Revolution, as depicted in Figure 5.1. It suggests that the increase in the investment in human capital prior to the Industrial Revolution was a reflection of changes in the composition of preference for quality in the population that stimulated investment in human capital, prior to the increase in the demand for human capital in the second phase of the Industrial Revolution.

\subsubsection{The Decline in the Gender Gap}

The rise in women's relative wages in the last two centuries and its potential impact on the rise in female labor force participation and the associated decline in fertility rates have been the center of another theory of the demographic transition that generates the observed hump-shaped relationship between income per capita and population growth, as depicted in Figure 2.15.

The rise in women's relative wages along with declining fertility rates has been observed in a

large number of developed and less developed economies. In particular, as depicted in Figure 3.3, this pattern is observed in the US during the period 1800-1940. 


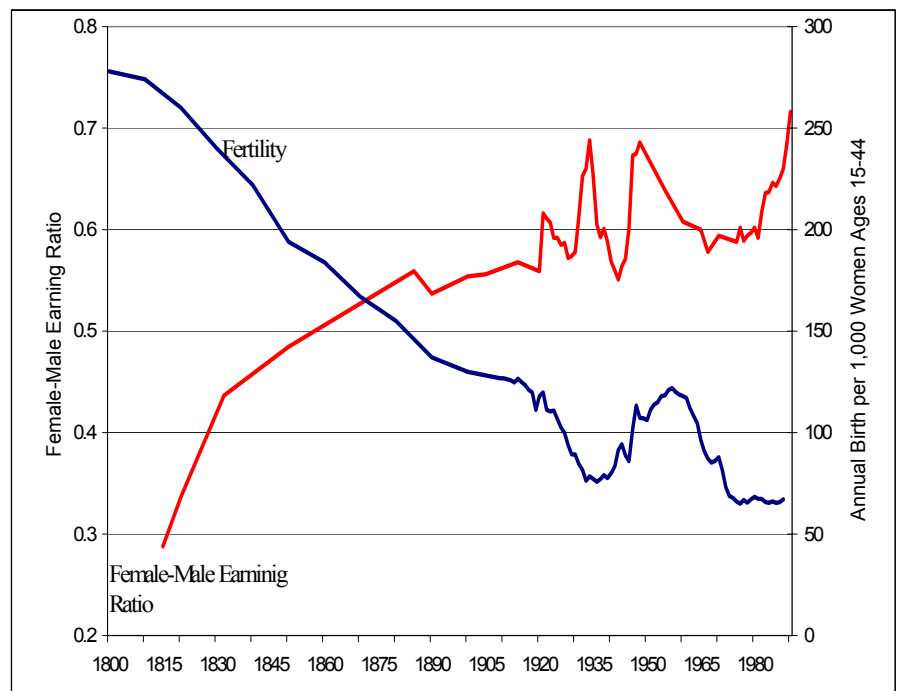

Figure 3.3. Female Relative Wages and Fertility Rates

United States 1800-1990

Source: U.S. Bureau of the Census, (1975), Goldin (1990), and Hernandez (2000)

Galor and Weil (1996) argue that technological progress and capital accumulation increased the relative wages of women in the process of industrialization. They maintain that technological progress along with physical capital accumulation complemented mental-intensive tasks rather than physicalintensive tasks and thus, in light of the comparative advantage of women in mental-intensive tasks, the demand for women's labor input gradually increased in the industrial sector, increasing the absolute wages of men and women but decreasing the gender wage gap. As long as the rise in women wages was insufficient to induce a significant increase in women's labor force participation, fertility increased due to the rise in men's wages. ${ }^{69}$ Ultimately, however, the rise in women's relative wages was sufficient to induce a significant increase in labor force participation, generating a demographic transition. ${ }^{70}$ Unlike the single-parent model in which an increase in income generates conflicting income and substitution effect that cancel one another if preferences are homothetic, in the two-parent household model, if most of the burden of child rearing is placed on women, a rise in women's relative wages increases the opportunity cost of raising children more than the household income, generating a pressure towards a reduction in fertility.

Moreover, the process of development in the Post-Malthusian Regime was associated with a gradual decline in the human capital gap between male and female. As depicted in Figure 3.4, literacy rates among women which were in 1840 only $76 \%$ of those among men, grew faster in the 19th century

\footnotetext{
${ }^{69}$ The U-shaped pattern of female labor force participation in the process of industrialization follows from the coexistence of an industrial sector and a non-modern production sector that is not fully rival with child rearing. Women's marginal product in non-modern sector was not affected by capital accumulation in the industrial sector, while women's potential wages in the modern sector increased. In the early process of industrialization, therefore, capital accumulation increased labor productivity in the industrial sector, family income increased via men's wages, while female wages, based on the production of market goods in the home sector did not change. Fertility increased due to the income effect and female labor force participation fell. Once capital accumulation and technological progress increases female relative wages sufficiently, capital accumulation raised women's relative wages, inducing a rise in female labor force participation in the industrial sector and reducing fertility.

${ }^{70}$ Cavalcanti and Tavares (2003) demonstrate theoretically and empirically that the decline in the gender wage gap and the increase in labor force participation increase government expenditure on public goods reducing the cost of child rearing, further enhancing the decline in fertility.
} 
reaching men's level in 1900.

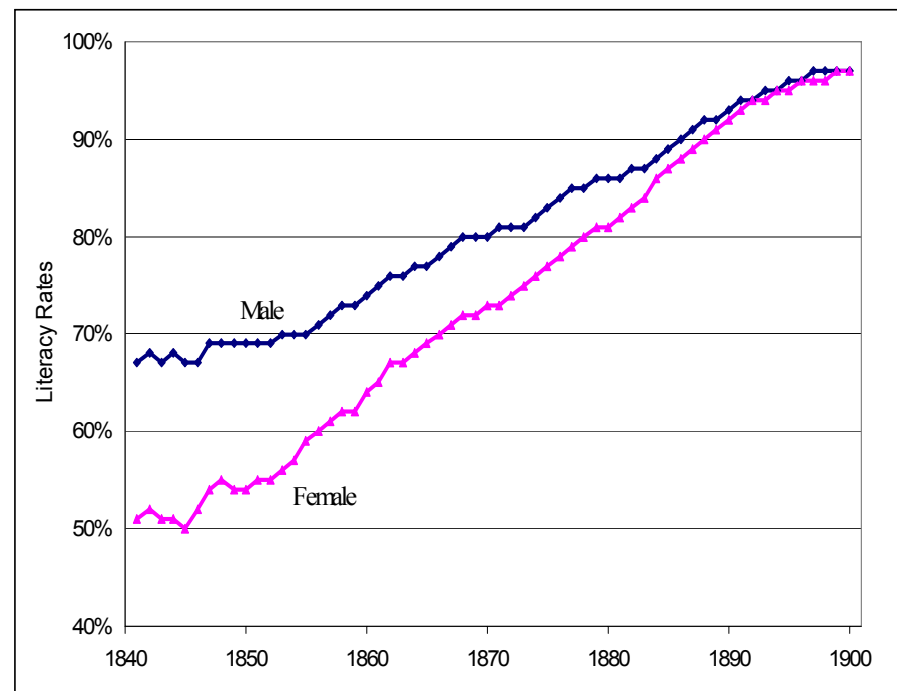

Figure 3.4. The Decline in the Human Capital Gap between Male and Female: England 1840-1900 Source: Cipolla(1969)

Lagerlof (2003b) argues that the process of development permitted a gradual improvement in the level of female education, raising the opportunity cost of children and initiating a fertility decline.

\subsubsection{Other Theories}

\section{The Old-Age Security Hypothesis}

The old-age security hypothesis has been proposed as an additional mechanism for the onset of the demographic transition. suggests that in the absence of capital markets that permit intertemporal lending and borrowing, children are assets that permit parents to smooth consumption over their lifetime. ${ }^{71}$ The process of development and the establishment of capital markets reduce this motivation for rearing children, contributing to the demographic transition.

Although old-age support is a plausible element that may affect the level of fertility, it appears as a minor force. The importance of the decline in the role of children as assets in the onset of the demographic transition is questionable. The rise in fertility rates prior to the demographic transition, in a period of improvements in the credit markets, raises doubts about the significance of the mechanism. Furthermore, cross-section evidence does not indicate that wealthier individuals that presumably had a better access to credit markets had a small number of surviving offspring. On the contrary, fertility rates in the pre-demographic transition era are positively related to skills, income and wealth (e.g., Lee 1997 and Clark 2003). ${ }^{72}$

\section{Exogenous Shocks - Luck}

Becker, Murphy and Tamura (1990) advance a theory that emphasizes the role of a major exogenous shock in triggering the demographic transition, underlying the role of luck in the determination of the relative timing of the demographic transition across nations as well as the wealth of nations. ${ }^{73}$. They

\footnotetext{
${ }^{71}$ See Neher (1971) and Caldwell (1976) for earlier studies and Boldrin and Jones (2002) for a recent quantitative analysis.

${ }^{72}$ Moreover, examples of species in nature in which offspring support their parent in old age are very rare.

${ }^{73}$ As they argue in page S13, "Many attempts to explain why some countries have had the best economic performance in the past several centuries give too little attention to accidents and good fortune".
} 
argue that a major shock shifted economies from the low-output high-fertility steady-state equilibrium towards the high-output low-fertility steady-state equilibrium, triggering a demographic transition.

This theory suffers from critical deficiencies in the micro-structure and it generates predictions that are inconsistent with the evidence. ${ }^{74}$ Moreover, even if economically plausible micro-foundations for the presence of multiple steady-state equilibria would be established, a major shock that would shift the economy from the basin of attraction of a high-fertility to a low-fertility steady-state equilibrium would not account for the main characteristics of the demographic transition and the transition to modern growth. In contrast to existing evidence that shows that for a large number of countries population growth rates increased prior to their decline in the course of the demographic transition and that the rise in income per capita preceded the decline in fertility,.a major shock that would shift the economy from the basin of attraction of a high-fertility to a low-fertility steady-state equilibrium would generate, counterfactually, a monotonic decline in fertility rates along with a simultaneous rise in income per capita.

\section{Unified Growth Theory}

The inconsistency of exogenous and endogenous neoclassical growth models with the process of development along most of human history, induced growth theorists to develop a unified theory of economic growth that would capture in a single framework the epoch of Malthusian stagnation, the era of modern growth, and the principal factors that brought about the transition between these regimes. ${ }^{75}$

The establishment of a unified growth theory has been a great intellectual challenge, requiring major methodological innovations in the construction of dynamical systems that would capture the complexity that has characterized the evolution of economies from a Malthusian epoch to a state of sustained economic growth. Historical evidence suggests that the take-off from the Malthusian epoch to a state of sustained economic growth, rapid as it may appear, was a gradual process and thus could not plausibly (and meaningfully) be viewed as the outcome of a major exogenous shock that shifted the economy from the basin of attraction of the Malthusian epoch into the basin of attraction of the Modern growth regime. ${ }^{76}$ The simplest methodology for the generation of this phase transition - a major shock in an environment characterized by multiple locally stable equilibria - is therefore not applicable for the generation of the transition from stagnation to growth.

An alternative methodology, however, was rather difficult to establish since a unified growth

\footnotetext{
${ }^{74}$ The source of multiplicity of equilibria in their model is the implausible assumption that the return to education increases with the aggregate level of education in society. (Browing, Hansen and Heckman (1998), for instance, show that there is weak empirical evidence in favor of this assumption.) Moreover, they define erroneously the low-output, high population growth, steady-state as a Malthusian steady-state equilibrium. Their "Malthusian" steady-state, however, has none of the features of a Malthusian equilibrium. In contrast to the historical evidence about the Malthusian era, in this equilibrium (in the absence of technological change) population growth rate is not at the reproduction level. Moreover, counter-factually population growth in their "Malthusian" steady-state is higher than the that in the beginning of the demographic transition. Furthermore, a small positive shock to income when the economy is in the "Malthusian" steady-state initially decreases fertility in contrast to the central aspect of the Malthusian equilibrium.

${ }^{75}$ Growth theories that capture the evolution of population, technology, and output from stagnation to sustained economic growth have been established by Galor and Weil (1999, 2000), Galor and Moav (2002), Hansen and Prescott (2002), Jones (2001), Kogel and Prskawetz. (2001), Hazan and Berdugo (2002), Tamura (2002), Lagerlof (2003a, 2003b), Fernandez-Vilaverde (2003), Doepke (2004), as well as others. The Great Divergence and its association with the transition from stagnation to growth was explored in a unified setting by Galor and Mountford (2003).

${ }^{76}$ As established in section 2, and consistently with the revisionist view of the Industrial Revolution, neither the take-off of the currently developed world in the 19th century, nor the recent take-off of less developed economies provide evidence for an unprecedented shock that generated a quantum leap in income per-capita. Moreover, technological progress could not be viewed as a shock to the system. As argued by Mokyr (2002) technological progress during the Industrial Revolution was an outcome of a gradual endogenous process that took place over this time period. Moreover, technological progress in less developed economies was an outcome of a deliberate decision by entrepreneurs to adopt existing advanced technologies.
} 
theory in which economies take-off gradually but swiftly from an epoch of a stable Malthusian stagnation would necessitate a gradual escape from an absorbing (stable) steady-state equilibrium, in contradiction to the essence of a stable steady-state equilibrium. Ultimately, it has become apparent that the observed gradual, rapid, and continuos phase transition would be captured by a single dynamical system, only if the set of steady-state equilibria and their stability would be altered qualitatively in the process of development. As proposed by Galor and Weil (2000), during the Malthusian epoch, the dynamical system would have to be characterized by a stable Malthusian steady-state equilibrium, but ultimately due to the evolution of latent state variables in this epoch, the Malthusian steady-state equilibrium would vanish endogenously leaving the arena to the gravitational forces of the emerging Modern Growth Regime.

Unified growth theories that permit a phase transition and do not rely on the existence of a major exogenous shock, have to be founded on a dynamical system in which economies are for an epoch in the vicinity of a temporary stable Malthusian steady-state equilibrium, but the evolution of latent state variables (i.e., the rise in a latent demand for human capital in Galor and Weil (2000) and the evolution of the distribution of genetic characteristics in Galor and Moav (2002)) ultimately generates a structural change in the dynamical system that causes this Malthusian steady state to vanish endogenously, permitting the economy to take-off and to converge to a modern growth steadystate equilibrium.

The role of the demographic transition in the transition from the Post-Malthusian Regime to the Sustained Growth Regime adds to the complexity of the desirable dynamical system. Capturing this additional transition would require the unified theory to generate endogenously a reversal in the positive Malthusian effect of income on population once the take-off occurs and to provide the reduction in fertility a special role in the transition to a state of sustained economic growth.

This section explores mechanisms that can account for the complexities of these long transitions from stagnation to growth and the emergence of the Great Divergence, focusing on the role of population, technology, income distribution and education in this intricate process. It describes several unified growth theories that encompass the transition between three distinct regimes that have characterized the process of economic development: The Malthusian Epoch, The Post-Malthusian Regime, and the Sustained Growth Regime. ${ }^{77}$ Imposing the constraint that a unified theory would account for the entire intricate process of development in the last thousands of years is a discipline that would enhance the viability of growth theory. A unified theory of economic growth would reveal the underlying microfoundations that are consistent with the process of economic development along the entire spectrum of human history, rather that with the last century only. It would therefore enhance the confidence in the viability of growth theory, its predictions and policy implications, while improving the understanding of the origin of the recent transition from stagnation to growth and the associated phenomenon of the great divergence.

\subsection{From Stagnation to Growth}

The first unified growth theory in which the endogenous evolution of population, technology, and income per capita is consistent with the process of development in the last thousands of years was advanced by Galor and Weil (2000). The theory captures the three regimes that have characterized the process of

\footnotetext{
${ }^{77}$ Although the emphasis is on the experience of Europe and its offshoots, since these were the areas that completed the transition from the Malthusian regime to modern growth, these theories could be modified to account for the incomplete transition of the less developed countries, integrating the drastic influence of the import of pre-existing production and health technologies.
} 
development as well as the fundamental driving forces that generated the transition from an epoch of Malthusian stagnation to a state of sustained economic growth.

The theory proposes that in early stages of development the economy was in a stable Malthusian steady state equilibrium. Technology advanced rather slowly, and generated proportional increases in output and population. The inherent positive interaction between population and technology in this epoch, however, gradually increased the pace of technological progress and the delayed adjustment of population permitted output per capita to creep forward at a miniscule rate. The slow pace of technological progress in the Malthusian epoch provided a limited scope for human capital in the production process and parents therefore had no incentive to reallocate resources towards child quality during this era.

The Malthusian interaction between technology and population accelerated the pace of technological progress permitting a take-off to the Post-Malthusian regime. The expansion of resources was partially counterbalanced by the enlargement of population and the economy was characterized by rapid growth rates of income per capita and population. The acceleration in technological progress increased the demand for human capital, while having two opposing effects on population growth. On the one hand, it eased households' budget constraints, allowing the allocation of more resources for raising children. On the other hand, it induced a reallocation of these additional resources toward child quality. In the Post-Malthusian regime, due to the limited demand for human capital, the first effect dominated and the rise in real income permitted households to increase their family size as well the quality of each child.

As investment in human capital took place the Malthusian steady state equilibrium vanished and the economy started to be attracted by the gravitational forces of the Modern Growth Regime. The interaction between investment in human capital and technological progress generated a virtuous circle: human capital generated faster technological progress, which in turn further raised the demand for human capital, inducing further investment in child quality, and ultimately initiating a demographic transition. ${ }^{78}$ The offsetting effect of population growth on the growth rate of income per capita was eliminated and the interaction between human capital accumulation and technological progress permitted a transition to a state of sustained economic growth.

The theory suggests that the transition from stagnation to growth is an inevitable by-product of the Malthusian interaction between population and technology and its ultimate impact on the demand for human capital and the demographic transition. The timing of the transition differ however across countries and regions due to initial variations in geographical factors and historical accidents and their manifestation in variations in institutional, demographic, and cultural factors, trade patterns, colonial status, as well as in disparity in public policy. ${ }^{79}$

\subsubsection{Central Building Blocks}

The theory is based upon the interaction between the several building blocks: the Malthusian elements, the engines of technological progress, the origin of human capital formation, and the determinants of parental choice regarding the quantity and quality of offspring.

First, the Malthusian elements. Individuals are subjected to a subsistence consumption constraint and as long as the constraint is binding, an increase in income results in an increase in population growth. Technological progress, which brings about temporary gains in income per capita, triggers

\footnotetext{
${ }^{78}$ In less developed countries the stock of human capital determines the pace of adaptation of existing technologies whereas in developed countries it determined the pace of the advancement of the technological frontier.

${ }^{79} \mathrm{~A}$ fertile land in a Malthusian environment, for instance, would generate a larger population density and a scale effect.
} 
therefore in early stages of development an increase in the size of the population that offsets the gain in income per capita due to the existence of decreasing returns to labor. Growth in income per capita is generated ultimately, despite decreasing returns to labor, since technological progress outpaces the rate of population growth.

Second, the forces behind technological progress in the process of development. The size of the population stimulates technological progress in early stages of development (Boserup (1965)), whereas investment in human capital is the prime engine of technological progress in more advanced stages of development. In the Malthusian era, the technological frontier was not distant from the working environment of most individuals, and the scale of the population affected the rate of technological progress due to its effect on: (a) the supply of innovative ideas, (b) the demand for new technologies, (c) technological diffusion, (d) the division of labor, and (e) trade. ${ }^{80}$ As the distance from the technological frontier gets larger, however, the role of human capital becomes more significant in technological advancement (e.g., Nelson and Phelps (1966)) and individuals with high levels of human capital are more likely to advance the technological frontier.

Third, the origin of human capital formation. The introduction of new technologies is mostly skill-biased although in the long run, these technologies may be either "skill biased" or "skill saving." The "disequilibrium" brought about by technological change raises the demand for human capital. ${ }^{81}$ Technological progress reduces the adaptability of existing human capital for the new technological environment and educated individuals have a comparative advantage in adapting to the new technological environment. ${ }^{82}$

Fourth, the determination of paternal decisions regarding the quantity and quality of their offspring. Individuals choose the number of children and their quality in the face of a constraint on the total amount of time that can be devoted to child-raising and labor market activities. The rise in the demand for human capital induces parents to substitute quality for quantity of children. ${ }^{83}$

\subsubsection{The Basic Structure of the Model}

Consider an overlapping-generations economy in which activity extends over infinite discrete time. In every period the economy produces a single homogeneous good using land and efficiency units of labor as inputs. The supply of land is exogenous and fixed over time whereas the number of efficiency units of labor is determined by households' decisions in the preceding period regarding the number and level of human capital of their children.

\footnotetext{
${ }^{80}$ The positive effect of the scale of the population on technological progress in the Malthusian epoch is supported by Boserup (1965) and recent evidence (e.g., Kremer (1993)). The role of the scale of the population in the modern era is, however, controversial. The distance to the technological frontier is significantly larger and population size per-se may have an ambiguous effect on technological progress, if it comes on the account of population quality.

${ }^{81}$ If the return to education rises with the level of technology the qualitative results would not be affected. Adopting this mechanism, however, would be equivalent to assuming that changes in technology were skill-biased throughout human history. Although on average technological change may have been skilled biased, Galor and Weil's mechanism is consistent with periods in which the characteristics of new technologies could be defined as unskilled-biased (most notably, the first phase of the industrial revolution).

${ }^{82}$ Schultz (1975) cites a wide range of evidence in support of this theory. Similarly, Foster and Rosenzweig (1996) find that technological change during the green revolution in India raised the return to schooling, and that school enrollment rates responded positively to this higher return. This element is central in the analysis of Galor and Tsiddon (1997), Galor and Moav (2000), and Hassler and Mora (2000).

${ }^{83}$ The existence of a trade-off between quantity and quality of children is supported empirically (e.g., Hanushek (1992) and Rosenzweig and Wolpin (1980)).
} 
Production of Final Output Production occurs according to a constant-returns-to-scale technology that is subject to endogenous technological progress. The output produced at time $t, Y_{t}$, is

$$
Y_{t}=H_{t}^{\alpha}\left(A_{t} X\right)^{1-\alpha}
$$

where $H_{t}$ is the aggregate quantity of efficiency units of labor employed in period $t, X$ is land employed in production in every period $t, A_{t}$ represents the endogenously determined technological level in period $t, A_{t} X$ are therefore the "effective resources" employed in production in period $t$, and $\alpha \in(0,1)$.

Output per worker produced at time $t, y_{t}$, is

$$
y_{t}=h_{t}^{\alpha} x_{t}^{1-\alpha}
$$

where $h_{t} \equiv H_{t} / L_{t}$ is the level of efficiency units of labor per worker, and $x_{t} \equiv\left(A_{t} X\right) / L_{t}$ is the level of effective resources per worker at time $t$.

Suppose that there are no property rights over land. ${ }^{84}$ The return to land is therefore zero, and the wage per efficiency unit of labor is therefore equal to the output per efficiency unit of labor.

$$
w_{t}=\left(x_{t} / h_{t}\right)^{1-\alpha} \text {. }
$$

Preferences and Budget Constraints In each period $t$, a generation that consists of $L_{t}$ identical individuals joins the labor force. Each individual has a single parent. Members of generation $t$ (those who join the labor force in period $t$ ) live for two periods. In the first period of life (childhood), $t-1$, individuals consume a fraction of their parental unit time endowment. The required time increases with children's quality. In the second period of life (parenthood), $t$, individuals are endowed with one unit of time, which they allocate between child rearing and labor force participation. They choose the optimal mixture of quantity and quality of (surviving) children and supply their remaining time in the labor market, consuming their wages.

Individuals' preferences are represented by a utility function defined over consumption above a subsistence level $\tilde{c}>0$, as well as over the quantity and quality (measured by human capital) of their (surviving) children. ${ }^{85}$

$$
u^{t}=\left(c_{t}\right)^{1-\gamma}\left(n_{t} h_{t+1}\right)^{\gamma} \quad \gamma \in(0,1),
$$

where $c_{t}$ is the consumption of individual of generation $t, n_{t}$ is the number of children of individual $t$, and $h_{t+1}$ is the level of human capital of each child. ${ }^{86}$ The utility function is strictly monotonically increasing and strictly quasi-concave, satisfying the conventional boundary conditions that assure that, for a sufficiently high income, there exists an interior solution for the utility maximization problem.

\footnotetext{
${ }^{84}$ The modeling of the production side is based upon two simplifying assumptions. First, capital is not an input in the production function, and second the return to land is zero. Alternatively it could have been assumed that the economy is small and open to a world capital market in which the interest rate is constant. In this case, the quantity of capital will be set to equalize its marginal product to the interest rate, while the price of land will follow a path such that the total return on land (rent plus net price appreciation) is also equal to the interest rate. Allowing for capital accumulation and property rights over land would complicate the model to the point of intractability, but would not affect the qualitative results.

${ }^{85}$ For simplicity parents derive utility from the expected number of surviving offspring and the parental cost child rearing is associated only with surviving children. A more realistic cost structure would not affect the qualitative features of the theory.

${ }^{86}$ Alternatively, the utility function could have been defined over consumption above subsistence rather than over a consumption set that is truncated from below by the subsistence consumption constraint. In particular, if $u^{t}=\left(c_{t}-\right.$ $\tilde{c})^{(1-\gamma)}\left(n_{t} h_{t+1}\right)^{\gamma}$. the qualitative analysis would not be affected, but the complexity of the dynamical system would be greatly enhanced. The income expansion path would be smooth, transforming continuously from being nearly vertical for low levels of potential income to asymptotically horizontal for high levels of potential income. The subsistence consumption constraint would therefore generate the Malthusian effect of income on population growth at low income levels.
} 
However, for a sufficiently low level of income the subsistence consumption constraint is binding and there is a corner solution with respect to the consumption level. ${ }^{87}$

Individuals choose the number of children and their quality in the face of a constraint on the total amount of time that can be devoted to child-raising and labor market activities. For simplicity, only time is required in order to produce child quantity and quality. ${ }^{88}$ Let $\tau+e_{t+1}$ be the time cost for a member $i$ of generation $t$ of raising a child with a level of education (quality) $e_{t+1}$. That is, $\tau$ is the fraction of the individual's unit time endowment that is required in order to raise a child, regardless of quality, and $e_{t+1}$ is the fraction of the individual's unit time endowment that is devoted for the education of each child. ${ }^{89}$

Consider members of generation $t$ who are endowed with $h_{t}$ efficiency units of labor at time $t$. Define potential income, $z_{t}$, as the potential earning if the entire time endowment is devoted to labor force participation, earning the competitive market wage, $w_{t}$, per efficiency unit. The potential income, $z_{t} \equiv w_{t} h_{t}$, is divided between consumption, $c_{t}$, and expenditure on child rearing (quantity as well as quality), evaluated according to the value of the time cost, $w_{t} h_{t}\left[\tau+e_{t+1}\right]$, per child. Hence, in the second period of life (parenthood), the individual faces the budget constraint

$$
w_{t} h_{t} n_{t}\left(\tau+e_{t+1}\right)+c_{t} \leq w_{t} h_{t} \equiv z_{t} .
$$

The Production of Human Capital Individuals' level of human capital is determined by their quality (education) as well as by the technological environment. Technological progress is assumed to raise the value of education in the production of human capital. ${ }^{90}$ Technological progress reduces the adaptability of existing human capital for the new technological environment (the 'erosion effect'). Education, however, lessens the adverse effects of technological progress. That is, skilled individuals have a comparative advantage in adapting to the new technological environment. In particular, the time required for learning the new technology diminishes with the level of education and increases with the rate of technological change.

The level of human capital of children of a member $i$ of generation $t, h_{t+1}^{i}$, is an increasing strictly concave function of their parental time investment in education, $e_{t+1}^{i}$, and a decreasing strictly convex function of the rate of technological progress, $g_{t+1}$ :

$$
h_{t+1}=h\left(e_{t+1}, g_{t+1}\right) \text {, }
$$

where $g_{t+1} \equiv\left(A_{t+1}-A_{t}\right) / A_{t}$. Education lessens the adverse effect of technological progress. That is, technology complements skills in the production of human capital (i.e., $h_{e g}\left(e_{t+1}^{i}, g_{t+1}\right)>0$ ). In the absence of investment in quality, each individual has a basic level human capital that is normalized to 1 in a stationary technological environment, i.e., $h(0,0)=1 .{ }^{91}$

\footnotetext{
${ }^{87}$ The subsistence consumption constraint generates the positive income elasticity of population growth at low income levels, since higher income allows individuals to afford more children.

${ }^{88}$ If both time and goods are required in order to produce child quality, the process we describe would be intensified. As the economy develops and wages increase, the relative cost of a quality child will diminish and individuals will substitute quality for quantity of children.

${ }^{89} \tau$ is assumed to be sufficiently small so as to assure that population can have a positive growth rate. That is, $\tau<\gamma$.

${ }^{90}$ Schultz [1975] cites a wide range of evidence in support of this assumption. More recently, Foster and Rosenzweig [1996] find that technological change during the green revolution in India raised the return to schooling, and that school enrollment rate responded positively to this higher return. The effect of technological transition on the return to human capital is at the center of the theoretical approach of Galor and Tsiddon (1997), Caselli (1999), Galor and Moav (2000), and Hassler and Rodriguez Mora (2002).

${ }^{91}$ For simplicity, investment in quality is not beneficial in a stationary technological environment, i.e., $h_{e}(0,0)=0$, and in the absence of investment in education, there exists a sufficiently rapid technological progress, that due to the erosion effect renders the existing human capital obsolete (i.e., $\left.\lim _{g \rightarrow \infty} h\left(0, g_{t+1}\right)=0\right)$. Furthermore, although the potential
} 
Optimization Members of generation $t$ choose the number and quality of their children, and therefore their own consumption, so as to maximize their intertemporal utility function subject to the subsistence consumption constraint. Substituting (5)-(6) into (4), the optimization problem of a member of generation $t$ is:

$$
\left\{n_{t}, e_{t+1}\right\}=\operatorname{argmax}\left\{w_{t} h_{t}\left[1-n_{t}\left(\tau+e_{t+1}\right)\right]\right\}^{1-\gamma}\left\{\left(n_{t} h\left(e_{t+1}, g_{t+1}\right)\right\}^{\gamma}\right.
$$

Subject to:

$$
\begin{aligned}
& w_{t} h_{t}\left[1-n_{t}\left(\tau+e_{t+1}\right)\right] \geq \tilde{c} \\
& \left(n_{t}, e_{t+1}\right) \geq 0 .
\end{aligned}
$$

Hence, as long as potential income at time $t$ is sufficiently high so as to assure that $c_{t}>\tilde{c}$ (i.e., as long as $z_{t} \equiv w_{t} h_{t}$, is above the level of potential income at which the subsistence constraint is just binding, (i.e., $\left.z_{t}>\tilde{z} \equiv \tilde{c} /(1-\gamma)\right)$ ), the fraction of time spent by individual $t$ raising children is $\gamma$, while $1-\gamma$ is devoted for labor force participation. However, if $z_{t} \leq \tilde{z}$, the subsistence constraint is binding, the fraction of time necessary to assure subsistence consumption, $\tilde{c}$, is larger than $1-\gamma$ and the fraction of time devoted for child rearing is therefore below $\gamma$. That is,

$$
n_{t}\left[\tau+e_{t+1}\right]= \begin{cases}\gamma & \text { if } \quad z_{t} \geq \tilde{z} \\ 1-\left[\tilde{c} / w_{t} h_{t}\right] & \text { if } \quad z_{t} \leq \tilde{z} .\end{cases}
$$

Figure 4.1 shows the effect of an increase in potential income $z_{t}$ on the individual's allocation of time between child rearing and consumption. The income expansion path is vertical as long as the subsistence consumption constraint is binding. As the wage per efficiency unit of labor increases in this income range, the individual can generate the subsistence consumption with a smaller labor force participation and the fraction of time devoted to child rearing increases. Once, the level of income is sufficiently high such that the subsistence consumption constraint is not binding, the income expansion path becomes horizontal at a level $\gamma$ in terms of time devoted for child rearing.

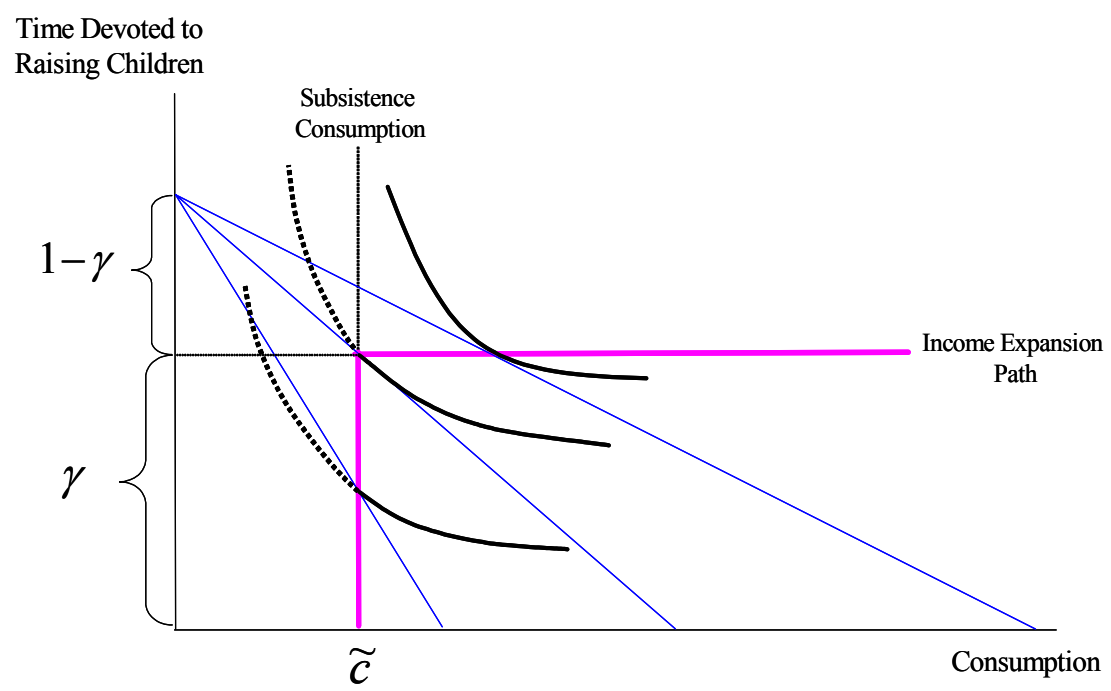

Figure 4.1. Preferences, Constraints, and Income Expansion Path

number of efficiency units of labor is diminished due to the transition from the existing technological state to a superior one (due to the erosion effect), each individual operates with a superior level of technology and the productivity effect is assumed to dominate. That is, $\partial y_{t} / \partial g_{t}>0$. 
Furthermore, the optimization with respect to $e_{t+1}$ implies that the level of education chosen by members of generation $t$ for their children, $e_{t+1}$, is an increasing function of $g_{t+1}$.

$$
e_{t+1}=e\left(g_{t+1}\right)\left\{\begin{array}{lll}
=0 & \text { if } & g_{t+1} \leq \hat{g} \\
>0 & \text { if } & g_{t+1}>\hat{g}
\end{array}\right.
$$

where $e^{\prime}\left(g_{t+1}\right)>0$ and $e^{\prime \prime}\left(g_{t+1}\right)<0 \forall g_{t+1}>\hat{g}>0 .{ }^{92}$ Hence, regardless of whether potential income is above or below $\tilde{z}$, increases in wages will not change the division of child-rearing time between quality and quantity. However, the division between time spent on quality and time spent on quantity is affected by the rate of technological progress, which changes the return to education.

Furthermore, substituting (9) into (8), it follows that $n_{t}$ is:

$$
n_{t}= \begin{cases}\frac{\gamma}{\tau+e\left(g_{t+1}\right)} \equiv n^{b}\left(g_{t+1}\right) & \text { if } \quad z_{t} \geq \tilde{z} \\ \frac{1-\left[\tilde{c} / z_{t}\right]}{\tau+e\left(g_{t+1}\right)} \equiv n^{a}\left(g_{t+1}, z\left(e_{t}, g_{t}, x_{t}\right)\right) & \text { if } \quad z_{t} \leq \tilde{z} .\end{cases}
$$

where $z_{t} \equiv w_{t} h_{t}=z\left(e_{t}, g_{t}, x_{t}\right)$ as follows from (3) and (6)

Hence, as follows from the properties of $e\left(g_{t+1}\right), n^{b}\left(g_{t+1}\right)$, and $n^{a}\left(g_{t+1}, z_{t}\right)$ :

(a) An increase in the rate of technological progress reduces the number of children and increases their quality, i.e.,

$$
\partial n_{t} / \partial g_{t+1} \leq 0 \text { and } \partial e_{t+1} / \partial g_{t+1} \geq 0 .
$$

(b) If the subsistence consumption constraint is binding (i.e., if parental potential income is below $\tilde{z}$ ), an increase in parental potential income raises the number of children, but has no effect on their quality, i.e.,

$$
\partial n_{t} / \partial z_{t}>0 \text { and } \partial e_{t+1} / \partial z_{t}=0 \quad \text { if } z_{t}<\tilde{z} .
$$

(c) If the subsistence consumption constraint is not binding (i.e., if parental potential income is above $\tilde{z})$, an increase in parental potential income does not affect the number of children or their quality, i.e.,

$$
\partial n_{t} / \partial z_{t}=\partial e_{t+1} / \partial z_{t}=0 \quad \text { if } z_{t}>\tilde{z}
$$

Technological Progress Suppose that technological progress, $g_{t+1}$, that takes place between periods $t$ and $t+1$ depends upon the education per capita among the working generation in period $t, e_{t}$, and the population size in period $t, L_{t} \cdot{ }^{93}$

$$
g_{t+1} \equiv \frac{A_{t+1}-A_{t}}{A_{t}}=g\left(e_{t}, L_{t}\right)
$$

where for $e_{t} \geq 0$ and a sufficiently large population size $L_{t}, g\left(0, L_{t}\right)>0, g_{i}\left(e_{t}, L_{t}\right)>0$, and $g_{i i}\left(e_{t}, L_{t}\right)<$ $0, i=e_{t}, L_{t} \cdot{ }^{94}$ Hence, for a sufficiently large population size, the rate of technological progress between

\footnotetext{
${ }^{92} e^{\prime \prime}\left(g_{t+1}\right)$ depends upon the third derivatives of the production function of human capital. $e^{\prime \prime}\left(g_{t+1}\right)$ is assumed to be concave, which appears plausible.

${ }^{93}$ While the role of the scale effect in the Malthusian epoch, is essential, none of the existing results depend on the presence or the absence of the scale effect in the modern era. The functional form of technological progress given in (11) can capture both the presence and the absence of the scale effect in the modern era. In particular, the scale effect can be removed, once investment in education is positive, assuming for instance that $\lim _{L \rightarrow \infty} g_{L}\left(e_{t}, L\right)=0$ for $e_{t}>0$.

${ }^{94}$ For a sufficiently small population the rate of technological progress is strictly positive only every several periods. Furthermore, the number of periods that pass between two episodes of technological improvement declines with the size of population. These assumptions assure that in early stages of development the economy is in a Malthusian steady-state with zero growth rate of output per capita, but ultimately the growth rates is positive and slow. If technological progress would occur in every time period at a pace that increases with the size of population, the growth rate of output per capita would always be positive, despite the adjustment in the size of population.
} 
time $t$ and $t+1$ is a positive, increasing, strictly concave function of the size and level of education of the working generation at time $t$. Furthermore, the rate of technological progress is positive even if labor quality is zero.

The state of technology at time $t+1, A_{t+1}$, is therefore

$$
A_{t+1}=\left(1+g_{t+1}\right) A_{t}
$$

where the state of technology at time 0 is given at a level $A_{0}$.

Population The size of population at time $t+1, L_{t+1}$, is

$$
L_{t+1}=n_{t} L_{t}
$$

where $L_{t}$ is the size of population at time $t$ and $n_{t}$ is the number of children per person; $L_{0}$ is given. Hence, given (10), the evolution of population over time is

$$
L_{t+1}= \begin{cases}n^{b}\left(g_{t+1}\right) L_{t} & \text { if } \quad z_{t} \geq \tilde{z} \\ n^{a}\left(g_{t+1}, z\left(e_{t}, g_{t}, x_{t}\right)\right) L_{t} & \text { if } \quad z_{t} \leq \tilde{z} .\end{cases}
$$

Effective Resources The evolution of effective resources per worker, $x_{t} \equiv\left(A_{t} X\right) / L_{t}$, is determined by the evolution of population and technology. The level of effective resources per worker in period $t+1$ is

$$
x_{t+1}=\frac{1+g_{t+1}}{n_{t}} x_{t}
$$

where $x_{0} \equiv A_{0} X / L_{0}$ is given. Furthermore, as follows from (10) and (11)

$$
x_{t+1}= \begin{cases}\frac{\left[1+g\left(e_{t}, L_{t}\right)\right]\left[\tau+e\left(g\left(e_{t}, L_{t}\right)\right)\right]}{\gamma} x_{t} \equiv \phi^{b}\left(e_{t}, L_{t}\right) x_{t} & \text { if } \quad z_{t} \geq \tilde{z} \\ \frac{\left[1+g\left(e_{t}, L_{t}\right)\right]\left[\tau+e\left(g\left(e_{t}, L_{t}\right)\right)\right]}{1-\left[\tilde{c} / z\left(e_{t}, g_{t}, x_{t}\right)\right]} x_{t} \equiv \phi^{a}\left(e_{t}, g_{t}, x_{t}, L_{t}\right) x_{t} & \text { if } \quad z_{t} \leq \tilde{z},\end{cases}
$$

where $\phi_{e}^{b}\left(e_{t}, L_{t}\right)>0$, and $\phi_{x}^{a}\left(e_{t}, g_{t}, x_{t}, L_{t}\right)<0 \quad \forall e_{t} \geq 0$.

\subsubsection{The Dynamical System}

The development of the economy is fully determined by a sequence $\left\{e_{t}, g_{t}, x_{t}, L_{t}\right\}_{t=0}^{\infty}$ that satisfies (9), $(11), 14)$, and (16), in every period $t$ and describe the joint evolution of education, technological progress, effective resources per capita, and population over time.

The dynamical system is characterized by two regimes. In the first regime the subsistence consumption constraint is binding and the evolution of the economy is governed by a four dimensional non-linear first-order autonomous system:

$$
\left\{\begin{array}{l}
x_{t+1}=\phi^{a}\left(e_{t}, g_{t}, x_{t} ; L_{t}\right) x_{t} \\
e_{t+1}=e\left(g\left(e_{t} ; L_{t}\right)\right) \\
g_{t+1}=g\left(e_{t}, L_{t}\right) \\
L_{t+1}=n^{a}\left(g\left(e_{t}, L_{t}\right), z\left(e_{t}, g_{t}, x_{t}\right)\right) L_{t},
\end{array} \quad \text { for } z_{t} \leq \tilde{z}\right.
$$

where the initial conditions $e_{0}, g_{0}, x_{0}$ are historically given. 
In the second regime the subsistence consumption constraint is not binding and the evolution of the economy is governed by a three dimensional system:

$$
\left\{\begin{array}{l}
x_{t+1}=\phi^{b}\left(e_{t}, x_{t} ; L\right) x_{t} \\
e_{t+1}=e\left(g\left(e_{t} ; L\right)\right) \\
L_{t+1}=n^{b}\left(g\left(e_{t}, L_{t}\right)\right) L_{t} .
\end{array} \quad \text { for } z_{t} \geq \tilde{z}\right.
$$

In both regimes, however, the analysis of the dynamical system is greatly simplified by the fact that the evolution of $e_{t}$ and $g_{t}$ is independent of whether the subsistence constraint is binding, and by the fact that, for a given population size $L$, the joint evolution of $e_{t}$ and $g_{t}$ is determined independently of the $x_{t}$. The education level of workers in period $t+1$ depends only on the level of technological progress expected between period $t$ and period $t+1$, while technological progress between periods $t$ and $t+1$ depends only on the level of education of workers in period $t$. Thus the dynamics of technology and education can be analyzed independently of the evolution resources per capita.

A. The Dynamics of Technology and Education The evolution of technology and education, for a given population size $L$, is characterized by the sequence $\left\{g_{t}, e_{t} ; L\right\}_{t=0}^{\infty}$ that satisfies in every period $t$ the equations $g_{t+1}=g\left(e_{t} ; L\right)$, and $e_{t+1}=e\left(g_{t+1}\right)$. Although this dynamical sub-system consists of two independent one dimensional, non-linear first-order difference equations, it is more revealing to analyze them jointly.

In light of the properties of the functions $e\left(g_{t+1}\right)$ and $g\left(e_{t} ; L\right)$ this dynamical sub-system is characterized by three qualitatively different configurations, which are depicted in Figures 4.2.A, 4.3.A and 4.4.A. The economy shifts endogenously from one configuration to another as population increases and the curve $g\left(e_{t} ; L\right)$ shifts upward to account for the effect of an increase in population.

In Figure 4.2.A, for a range of small population size, the dynamical system is characterized by globally stable steady-state equilibria, $(\bar{e}(L), \bar{g}(L))=\left(0, g^{l}(L)\right)$, where $g^{l}(L)$ increases with the size of the population while the level of education remains unchanged. In Figure 4.3.A, for a range of moderate population size, the dynamical system is characterized by three steady state equilibria, two locally stable steady-state equilibria: $(\bar{e}(L), \bar{g}(L))=\left(0, g^{l}(L)\right)$ and $(\bar{e}(L), \bar{g}(L))=\left(e^{h}(L), g^{h}(L)\right)$, and an interior unstable steady-state $(\bar{e}(L), \bar{g}(L)) \equiv\left(e^{u}(L), g^{u}(L)\right)$, where $\left(e^{h}(L), g^{h}(L)\right)$ and $g^{l}(L)$ increase monotonically with the size of the population. Finally, in Figure 4.4.A, for a range of large population sizes, the dynamical system is characterized by globally stable steady-state equilibria, $(\bar{e}(L), \bar{g}(L))=$ $\left(e^{h}(L), g^{h}(L)\right)$, where $e^{h}(L)$ and $g^{h}(L)$ increases monotonically with the size of the population.

B. Global Dynamics This section analyzes the evolution of the economy from the Malthusian Regime, through the Post-Malthusian Regime, to the demographic transition and Modern Growth. The global analysis is based a sequence of phase diagrams that describe the evolution of the system, within each regime, for a given population size, and the transition between these regimes as population increases in the process of development. Each of the phase diagrams is a two dimensional projection in the plain $\left(e_{t}, x_{t} ; L\right)$,of the three dimensional system in the space $\left\{e_{t}, g_{t}, x_{t} ; L\right\}$.

The phase diagrams, depicted in Figure 4.2.B, 4.4.B, and 4.5.B contain three elements: the Malthusian Frontier, which separates the regions in which the subsistence constraint is binding from those where it is not; the $X X$ locus, which denotes the set of all triplets $\left(e_{t}, g_{t}, x_{t} ; L\right)$ for which effective resources per worker are constant; and the $E E$ locus, which denotes the set of all pairs $\left(e_{t}, g_{t} ; L\right)$ for which the level of education per worker is constant.

\section{The Malthusian Frontier}


As was established in (17) and (18) the economy exits from the subsistence consumption regime when potential income, $z_{t}$, exceeds the critical level $\tilde{z}$. This switch of regime changes the dimensionality of the dynamical system from three to two.

Let the Malthusian Frontier be the set of all triplets of $\left(e_{t}, x_{t}, g_{t} ; L\right)$ for which individuals' income equal $\tilde{z} \cdot{ }^{95}$ Using the definitions of $z_{t}$ and $\tilde{z}$, it follows from (3) and (6) that the The Malthusian Frontier, $M M \equiv\left\{\left(e_{t}, x_{t}, g_{t} ; L\right): x_{t}^{1-\alpha} h\left(e_{t}, g_{t}\right)^{\alpha}=\tilde{c} /(1-\gamma)\right\}$.

Let the Conditional Malthusian Frontier be the set of all pairs $\left(e_{t}, x_{t} ; L\right)$ for which, conditional on a given technological level $g_{t}$, individuals incomes equal $\tilde{z}$. Following the definitions of $z_{t}$ and $\tilde{z}$, equations (3) and (6) imply that the Conditional Malthusian Frontier, $M M_{\mid g_{t}}$, is $M M_{\mid g_{t}} \equiv\left\{\left(e_{t}, x_{t} ; L\right)\right.$ : $\left.x_{t}^{(1-\alpha)} h\left(e_{t}, g_{t}\right)^{\alpha}=\tilde{c} /(1-\gamma) \mid g_{t}\right\}$, where $x_{t}$ is a decreasing strictly convex function of $e_{t}$ along the $M M_{\mid g_{t}}$ locus.

Hence, the Conditional Malthusian Frontier, as depicted in Figures 4.2.B-4.4.B, is a strictly convex, downward sloping, curve in the $\left(e_{t}, x_{t}\right)$ space. Furthermore, it intersects the $x_{t}$ axis and approaches asymptotically the $e_{t}$ axis as $x_{t}$ approaches infinity. The frontier shifts upward as $g_{t}$ increases in the process of development.

\section{The $X X$ Locus}

Let $X X$ be the locus of all triplets $\left(e_{t}, g_{t}, x_{t} ; L\right)$ such that the effective resources per worker, $x_{t}$, is in a steady-state: $X X \equiv\left\{\left(e_{t}, x_{t}, g_{t} ; L\right): x_{t+1}=x_{t}\right\}$.

As follows from (15), along the $X X$ locus the growth rates of population and technology are equal. Above the Malthusian frontier, the fraction of time devoted to child-rearing is independent of the level of effective resources per worker. In this case, the growth rate of population will just be a negative function of the growth rate of technology, since for higher technology growth, parents will spend more of their resources on child quality and thus less on child quantity. Thus there will be a particular level of technological progress which induces an equal rate population growth. Since the growth rate of technology is, in turn, a positive function of the level of education, this rate of technology growth will correspond to a particular level of education, denoted $\hat{e}$. Below the Malthusian Frontier, the growth rate of population depends on the level of effective resources per capita, $x$, as well as on the growth rate of technology. The lower is $x$, the smaller the fraction of the time endowment devoted to child-rearing, and so the lower is population growth. Thus, below the Malthusian frontier, a lower value of effective resources per capita would imply that lower values of technology growth (and thus education) would be consistent with population growth being equal to technology growth. Thus, as drawn in Figures 4.2.B, 4.3.B, and 4.4.B, lower values of $x$ are consistent with lower values of $e$ on the part of the $X X$ locus that is below the Malthusian Frontier.

If the subsistence consumption constraint is not binding, it follows from (16) that for $z_{t} \geq \tilde{z}$, there exists a unique value $0<\hat{e}(L)<e^{h}(L)$, such that $x_{t} \in X X .^{96}$

$$
x_{t+1}-x_{t}\left\{\begin{array}{ccc}
>0 & \text { if } & e_{t}>\hat{e}(L) \\
=0 & \text { if } & e_{t}=\hat{e}(L) \\
<0 & \text { if } & e_{t}<\hat{e}(L)
\end{array}\right.
$$

Hence, the $X X$ Locus, as depicted in Figures 4.2.B, 4.3.B, and 4.4.B is a vertical line above the Condi-

\footnotetext{
${ }^{95}$ Below the Malthusian Frontier, the effect of income on fertility will be positive, while above the frontier there will be no effect of income on fertility. Thus the Malthusian Frontier separates the Malthusian and Post-Malthusian regimes, on the one hand, from the Modern Growth regime, on the other, and crossing this frontier is associated with the demographic transition.

${ }^{96}$ In order to simplify the exposition without affecting the qualitative nature of the dynamical system, the parameters of the model are restricted so as to assure that the XX Locus is non-empty when $z_{t} \geq \tilde{z}$. That is, $\hat{g}<(\gamma / \tau)-1<$ $g\left(e^{h}\left(L_{0}\right), L_{0}\right)$.
} 
tional Malthusian Frontier at a level $\hat{e}(L)$.

If the subsistence constraint is binding, the evolution of $x_{t}$, is based upon the rate of technological change, $g_{t}$, the effective resources per-worker, $x_{t}$ as well as the quality of the labor force, $e_{t}$. Let $X X_{\mid g_{t}}$ be the locus of all pairs $\left(e_{t}, x_{t} ; L\right)$ such that $x_{t+1}=x_{t}$, for a given level of $g_{t}$. That is, $X X_{\mid g_{t}} \equiv\left\{\left(e_{t}, x_{t} ; L\right): x_{t+1}=x_{t} \mid g_{t}\right\}$ It follows from (16 that for $z_{t} \leq \tilde{z}$, and for $0 \leq e_{t} \leq \hat{e}(L)$, there exists a single-valued function $x_{t}=x\left(e_{t}\right)$ such that $\left(x\left(e_{t}\right), e_{t}\right) \in X X_{\mid g_{t}}$.

$$
x_{t+1}-x_{t}\left\{\begin{array}{lllll}
<0 & \text { if } & \left(e_{t}, x_{t}\right)>\left(e_{t}, x\left(e_{t}\right)\right) & \text { for } & 0 \leq e_{t} \leq \hat{e}(L), \\
=0 & \text { if } & x_{t}=x\left(e_{t}\right) & \text { for } & 0 \leq e_{t} \leq \hat{e}(L), \\
>0 & \text { if } & {\left[\left(e_{t}, x_{t}\right)<\left(e_{t}, x\left(e_{t}\right)\right)\right.} & \text { for } & \left.0 \leq e_{t} \leq \hat{e}(L),\right] \quad \text { or } \quad\left[e_{t}>\hat{e}(L)\right]
\end{array}\right.
$$

Hence, without loss of generality, the locus $X X_{\mid g_{t}}$ is depicted in Figure 4.2, as an upward slopping curve in the space $\left(e_{t}, x_{t}\right)$, defined for $e_{t} \leq \hat{e}(L) . X X_{\mid g_{t}}$ is strictly below the Conditional Malthusian Frontier for value of $e_{t}<\hat{e}(L)$, and the two coincides at $\hat{e}(L)$. Moreover, the Conditional Malthusian Frontier, the $X X$ Locus, and the $X X_{\mid g_{t}}$ Locus, coincide at $(\hat{e}(L), \hat{x}(L))$.

\section{The $E E$ Locus}

Let $E E$ be the locus of all triplets $\left(e_{t}, g_{t}, x_{t} ; L\right)$ such that the quality of labor, $e_{t}$, is in a steadystate: $E E \equiv\left\{\left(e_{t}, x_{t}, g_{t} ; L\right): e_{t+1}=e_{t}\right\}$.

As follows from (9) and (11), $e_{t+1}=e\left(g\left(e_{t} ; L\right)\right.$ and thus, for a given population size, the steadystate values of $e_{t}$ are independent of the values of $x_{t}$ and $g_{t}$. The locus $E E$ evolves through three phases in the process of development, corresponding to the three phases that describe the evolution of education and technology, as depicted in Figures 4.2.A, 4.3.A, and 4.4.A.

In early stages of development, when population size is sufficiently small, the joint evolution of education and technology is characterized by a globally stable temporary steady-state equilibrium, $(\bar{e}(L), \bar{g}(L))=\left(0, g^{l}(L)\right)$, as depicted in Figure 4.2.A. The corresponding EE Locus, depicted in the space $\left(e_{t}, x_{t} ; L\right)$ in Figure 4.2.B, is vertical at the level $e=0$, for a range of small population sizes. Furthermore, for this range, the global dynamics of $e_{t}$ are given by:

$$
e_{t+1}-e_{t}\left\{\begin{array}{lll}
=0 & \text { if } & e_{t}=0 \\
<0 & \text { if } & e_{t}>0
\end{array}\right.
$$

In later stages of development as population size increases sufficiently, the joint evolution of education and technology is characterized by multiple locally stable temporary steady-state equilibria, as depicted in Figure 4.3.A. The corresponding EE Locus, depicted in the space $\left(e_{t}, x_{t} ; L\right)$ in Figure 4.3.B, consists of 3 vertical lines corresponding the three steady-state equilibria for the value of $e_{t}$. That is, $e=0, e=e^{u}(L)$, and $e=e^{h}(L)$. The vertical lines $e=e^{u}(L)$, and $e=e^{h}(L)$ shift rightward as population size increases. Furthermore, the global dynamics of $e_{t}$ in this configuration are given by:

$$
e_{t+1}-e_{t}\left\{\begin{array}{lll}
<0 & \text { if } & 0<e_{t}<e^{u}(L) \text { or } e_{t}>e^{h}(L) \\
=0 & \text { if } \quad e_{t}=\left(0, e^{u}(L), e^{h}(L)\right) \\
>0 & \text { if } \quad e^{u}(L)<e_{t}<e^{h}(L)
\end{array}\right.
$$

In mature stages of development when population size is sufficiently large, the joint evolution of education and technology is characterized by a globally stable steady-state equilibrium, $(\bar{e}(L), \bar{g}(L))=$ $\left(e^{h}(L), g^{h}(L)\right)$, as depicted in Figure 4.4.A. The corresponding EE Locus, as depicted in Figure 4.4.B in the space $\left(e_{t}, x_{t} ; L\right)$, is vertical at the level $e=e^{h}(L)$. This vertical line shifts rightward as population size increases. Furthermore, the global dynamics of $e_{t}$ in this configuration are given by: 


$$
e_{t+1}-e_{t}\left\{\begin{array}{lll}
>0 & \text { if } & 0 \leq e_{t}<e^{h}(L) \\
=0 & \text { if } & e_{t}=e^{h}(L) . \\
<0 & \text { if } & e_{t}>e^{h}(L) .
\end{array}\right.
$$

\section{Conditional Steady-State Equilibria}

In early stages of development, when population size is sufficiently small, the dynamical system, as depicted in Figure 4.2.B is characterized by a unique and globally stable conditional steady-state equilibrium. ${ }^{97}$ It is given by a point of intersection between the $E E$ Locus and the $x_{t+1}=x_{t}$ Locus. That is, conditional on a given technological level, $g_{t}$, the Malthusian steady-state $(0, \bar{x}(L))$ is globally stable. ${ }^{98}$ In later stages of development as population size increases sufficiently, the dynamical system as depicted in Figure 4.3.B is characterized by two conditional steady-state equilibria. The Malthusian conditional steady-state equilibrium is locally stable, whereas the steady-state equilibrium $\left(e^{u}(L), x^{u}(L)\right)$ is a saddle point. ${ }^{99}$ For education levels above $e^{u}(L)$ the system converges to a stationary level of education $e^{h}(L)$ and possibly to a steady-state growth rate of $x_{t}$. In mature stages of development when population size is sufficiently large, the system convergence globally to an educational level $e^{h}(L)$ and possibly to a steady-state growth rate of $x_{t}$.

\subsubsection{From Malthusian Stagnation to Sustained Growth}

The economy evolves from an epoch of Malthusian stagnation through the Post-Malthusian regime to the demographic transition and a Modern Growth regime. This pattern and the prime driving forces in this transition emerge from the phase diagrams depicted in Figures 4.2-4.4.

Consider an economy in early stages of development. Population size is relatively small and the implied slow rate of technological progress does not provide an incentive to invest in the education of children. As depicted in Figure 4.2.A,the interaction between education, $e_{t}$, and the rate of technological change, $g_{t}$, for a constant small population, $L^{l}$, is characterized by a globally stable steady-state equilibrium $\left(0, g^{l}(L)\right)$, where education is zero and the rate of technological progress is slow. This steady-state equilibrium corresponds to a globally stable conditional Malthusian steady-state equilibrium, depicted in Figure 4.2.B. For a constant small population, $L^{l}$, and for a given rate of technological progress, effective resources per capita, as well as the level of education are constant, and output per capita is therefore constant as well. Moreover, shocks to population or resources will be resolved in a classic Malthusian fashion.

As population grows slowly in reaction to technological progress, the $g\left(e_{t+1}, L^{l}\right)$ locus, depicted in Figure 4.2.A, gradually shifts upward and the steady-state equilibrium shifts vertically upward reflecting small increments in the rate of technological progress, while the level of education remains constant at a zero level. Similarly, the conditional Malthusian steady-state equilibrium drawn in Figure 4.2.B shifts vertically upward, as the XX locus shifts upward. However, output per capita remains initially constant at the subsistence level and ultimately creeps forward at a miniscule rate.

\footnotetext{
${ }^{97}$ Since the dynamical system is discrete, the trajectories implied by the phase diagrams do not necessarily approximate the actual dynamic path, unless the state variables evolve monotonically over time. As shown, the evolution of $e_{t}$ is monotonic, whereas the evolution and convergence of $x_{t}$ may be oscillatory. Non-monotonicity in the evolution of $x_{t}$ may arise only if $e<\hat{e}$ and it does not affect the qualitative description of the system. Furthermore, if $\phi_{x}^{a}\left(e_{t}, g_{t}, x_{t}\right) x_{t}>-1$ the conditional dynamical system is locally non-oscillatory. The phase diagrams in Figures 4.3.A-4.5.A are drawn under the assumptions that assure that there are no oscillations.

${ }^{98}$ The local stability of the steady-state equilibrium $\left(0, \bar{x}\left(g_{t}\right)\right)$ can be derived formally. The eigenvalues of the Jacobian matrix of the conditional dynamical system evaluated at the conditional steady-state equilibrium are both smaller than one (in absolute value)

${ }^{99}$ Convergence to the saddle point takes place only if the level of education is $e^{u}$. That is, the saddle path is the entire vertical line that corresponds to $e_{t}=e^{u}$.
} 
A

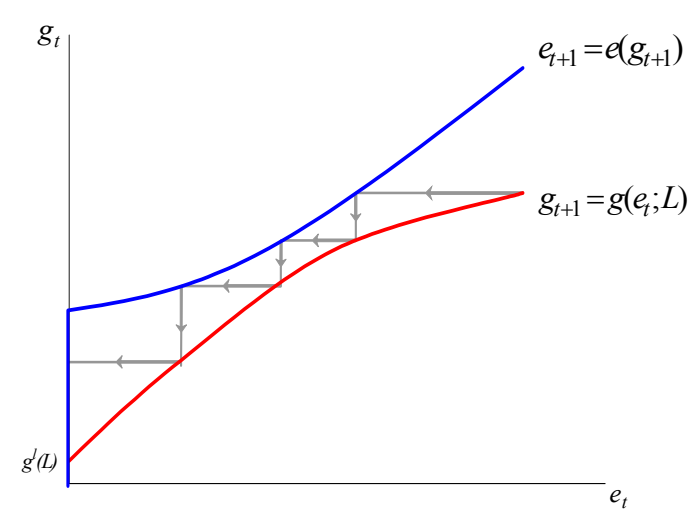

B

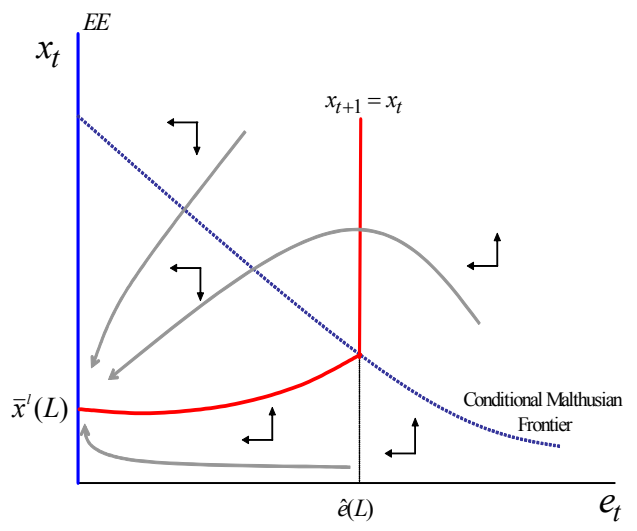

Figure 4.2. The Evolution of Technology, $g_{t}$, Education, $e_{t}$, and Effective Resources, $x_{t}$ Small Population

Over time, the slow growth in population that takes place in the Malthusian regime raises the rate of technological progress and shift the $g\left(e_{t+1}, L^{l}\right)$ locus in Figure 4.2.A sufficiently upward, generating a qualitative change in the dynamical systems depicted in Figure 4.3.A.

A

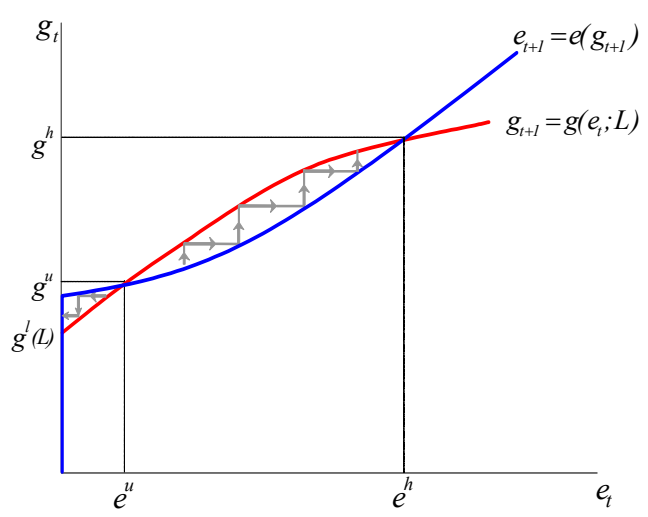

B

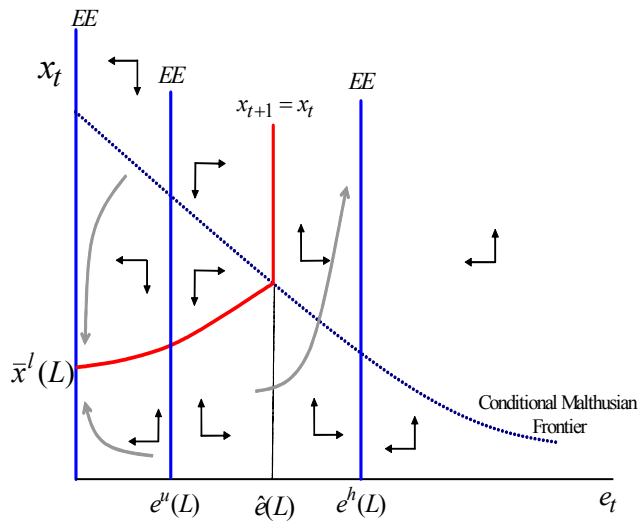

Figure 4.3. The Evolution of Technology, $g_{t}$, Education, $e_{t}$, and Effective Resources, $x_{t}$ : Moderate Population

The dynamical system of education and technology, for a moderate population, is characterized by multiple, history-dependent, stable steady state equilibria: The steady-state equilibria $\left(0, g^{l}(L)\right)$ and $\left(e^{h}(L), g^{h}(L)\right)$ are locally stable, whereas $\left(e^{u}(L), g^{u}(L)\right)$ is unstable. Given the initial conditions, in the absence of large shocks the economy remains in the vicinity of the low steady-state equilibrium $\left(0, g^{l}(L)\right)$, where education is still zero but the rate of technological progress is moderate. This steadystate equilibria correspond to a multiple locally stable conditional Malthusian steady-state equilibrium, depicted in Figure 4.3.B. A Malthusian steady-state, characterized by constant resources per capita, slow 
technological progress, and no education, and a modern growth steady state, characterized by a high level of education, rapid technological progress, growing income per capita, and moderate population growth. However, since the economy starts in the vicinity of Malthusian steady state, it remains there. ${ }^{100}$

As the rate of technological progress continue to rise in reaction to the increasing population size, the $g\left(e_{t+1}, L_{t}\right)$ locus shifts upward further and ultimately, as depicted in Figure 4.4, the dynamical system experiences another qualitative change. The Malthusian steady state equilibrium vanishes, and the economy is the system is characterized by a unique globally stable modern steady-state equilibrium $\left(e^{h}(L), g^{h}(L)\right)$ characterized by high levels of education and technological progress.

A

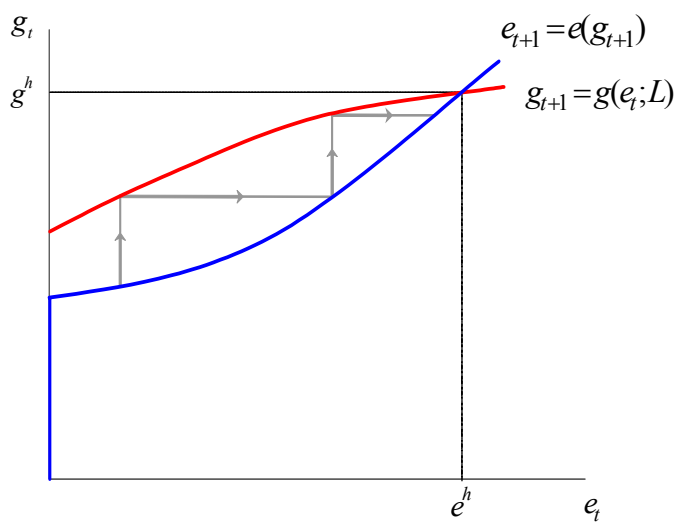

B

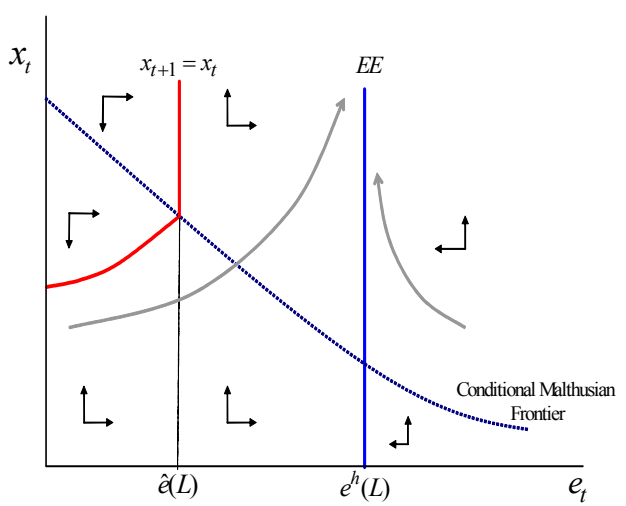

Figure 4.4. The Evolution of Technology, $g_{t}$, Education, $e_{t}$, and Effective Resources, $x_{t}$ Large Population

Increases in the rate of technological progress and the level of education feed back on each other until the economy converges rapidly to the stable modern steady state equilibrium. The increase in the pace of technological progress has two opposing effects on the evolution of population. On the one hand, it eased households' budget constraints, allowing the allocation of more resources for raising children. On the other hand, it induced a reallocation of these additional resources toward child quality. In the Post-Malthusian regime, due to the limited demand for human capital, the first effect dominated and the rise in real income permitted households to increase their family size as well the quality of each child. ${ }^{101}$ The interaction between investment in human capital and technological progress generate a virtuous circle: human capital formation prompted faster technological progress, which in turn further raised the demand for human capital, inducing further investment in child quality, and ultimately, as the economy crosses the Malthusian frontier triggering a demographic transition. The offsetting effect of population growth on the growth rate of income per capita is eliminated and the interaction between human capital accumulation and technological progress permitted a transition to a state of sustained economic growth.

\footnotetext{
${ }^{100}$ Large shock to education or technological progress would permit the economy to jump to the Modern Growth steady state, but this possibility appears inconsistent with the evidence.

${ }^{101}$ Literally, income per capita does not change during the Post-Malthusian regime. It remains fixed at the subsistence level. This is an artifact of the assumption that the only input into child (quality and quantity) is parental time, and that this time input does not produce measured output. If child-rearing, especially the production of quality, requires goods or time supplied through a market (e.g., schooling), the shift toward higher child quality that takes place during the post-Malthusian regime would be reflected in higher market expenditures (as opposed to parental time expenditures) and rising measured income.
} 
In the modern growth regime, resources per capita rise, as technological progress outstrips population growth. Provided that population size is constant (i.e., population growth is zero), the levels of education and technological progress and the growth rates of resources per capita, and thus the output per capita are constant in the modern growth steady state equilibrium. ${ }^{102}$

\subsubsection{Major Hypotheses and their Empirical Validity}

The theory generates several hypotheses about the evolution of population, human capital and income per capita in the process of development, underlying the roles of the inherent interaction between population and technology in the Malthusian epoch, as well as the formation of human capital in the second phase of the Industrial Revolution and the associated demographic transition, in the emergence of a state of sustained economic growth.

\section{Main Hypotheses:}

- During the initial phases of the Malthusian epoch the growth rate of output per capita is nearly zero and the growth rate of population is miniscule, reflecting the sluggish pace of technological progress and the full adjustment of population to the expansion of resources. In the later phases of the Malthusian epoch, the increasing rate of technological progress, along with the inherent delay in the adjustment of population to the rise in income per capita, generated a positive but very small growth rates of output per capita and population.

The hypothesis is consistent with the evidence provided in section 2.1 about the evolution of the world economy in the Malthusian epoch. In particular, the infinitesimal pace of resource expansion in the first millennium was reflected in a miniscule increase in the Western European population from 24.7 million people in the year 1 to 25.4 million in the year 1000, along with a zero average growth rate of output per capita. The more rapid (but still very slow) expansion of resources in the period 1000-1500, permitted the Western European population to grow at a slow average rate of $0.16 \%$ per year, from 25 million in the year 1000 to 57 million in the year 1500, along with a slow average growth rate of income per capita at a rate of about $0.13 \%$ per year. Resource expansion over the period $1500-1820$ had a more significant impact on the Western European population that grew at an average pace of $0.26 \%$ per year, from 57 million in the year 1500 to 133 million in the year 1820, along with a slightly faster average growth rate of income per capita at a rate of about $0.15 \%$ per year.

- The reinforcing interaction between population and technology during the Malthusian epoch, increased the size of the population sufficiently so as to support a faster pace of technological progress, generating the transition to the Post-Malthusian Regime. The growth rates of output per capita increased significantly, but the positive Malthusian effect of income per capita on population growth was still maintained, generating a sizeable increase in population growth, and offsetting some of the potential gains in income per capita. Moreover, human capital accumulation did not play a significant role in the transition to the Post-Malthusian Regime and thus in the early take-off in the first phase of the Industrial Revolution. It emerged in the midst of the Post-Malthusian Regime, inducing further technological progress.

\footnotetext{
${ }^{102}$ If population growth is positive in the Modern Growth regime, then education and technological progress continue to rise, and, similarly, if population growth is negative they fall. In fact, the model makes no firm prediction about what the growth rate of population will be in the Modern Growth regime, other than that population growth will fall once the economy exits from the Malthusian region. If the growth rate of technology is related to the growth rate of population, rather than to its level, then there exists a steady state modern growth regime in which the growth rates of population and technology would be constant. Further, such a steady state would be stable: if population growth fell, the rate of technological progress would also fall, inducing a rise in fertility.
} 
The hypothesis is consistent with the evidence provided in section 2.2 about the evolution of the world economy in the Post-Malthusian regime. In particular, the acceleration in the pace of resource expansion in the period 1820-1870 increased the Western European population from 133 million people in the year 1820 to 188 million in the year 1870 , and the average growth rate of output per capita over this period increased significantly to $0.95 \%$ per year. Furthermore, the evidence suggest that the industrial demand for human capital increased only in the second phase of the of the Industrial Revolution. As shown by Clark (2003) human capital formation prior to the Industrial Revolution as well as in its first phase occurred in an era in which the market rewards for skill acquisition were at historically low levels. ${ }^{103}$

- The acceleration in the rate of technological progress increased the demand for human capital in the Post-Malthusian Regime, inducing significant investment in human capital, and triggering the demographic transition and a rapid pace of economic growth.

The hypotheses is consistent with the evidence, provided in section 2.3 and depicted partly in Figure 4.5, about the significant rise in the industrial demand for human capital in the second phase of the Industrial Revolution and a marked increased in educational attainment, in association with a decline in fertility rates, and a transition to a state of sustained economic growth. In particular, it is consistent with the revisionist view on the British Industrial Revolution (e.g., Crafts and Harley 1992, Clark 2001, and Voth 2003) that argue that the first phase of the Industrial Revolution in England was characterized by a moderate increase in the growth rate of output per capita, and the standard of living and the "take-off", as depicted in Figure 4.5, occurred only in 1860s.

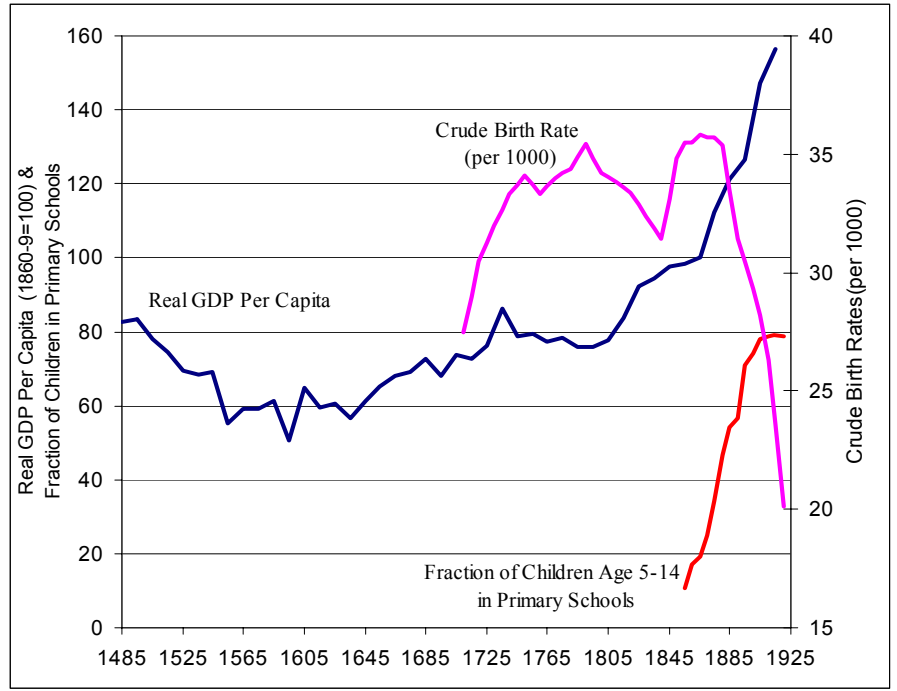

Figure 4.5. The Sharp Rise in Real GDP Per Capita and it association with Investment in Education and Fertility Decline: England 1865-1920

Source: Clark (2001), Feinstein (1972), Flora et al. (1983), Wrigley and Schofield (1981)

Furthermore, quantitative analysis of unified growth theories by Fernandez-Vilaverde (2003), Doepke (2004), and Pereira (2004) suggests that indeed the rise in the demand for human capital was a significant force behind the demographic transition and the emergence of a state of sustained economic growth ${ }^{104}$

\footnotetext{
${ }^{103}$ The rise in human capital formation over this period may reflect religious, cultural and social forces, as well as the rise in valuation for offspring quality due to the forces of natural selection, as discussed in section 5.2.

${ }^{104}$ The rise in the demand for human capital in Fernandez-Vilaverde (2003) is based on capital-skill complementarity, and is indistinguishable from the complementarity between technology and skills (in the short run) that is maintained by Galor and Weil (2000).
} 
Moreover, the theory is consistent with the observed simultaneous onset of the demographic transition across Western European countries that differed significantly in their income per capita. It suggests that a universal rise in the demand for human capital in Western Europe (as documented in section 2.3.3) generated this simultaneous transition. It should be noted that the lack of clear evidence about the increase in the return to human capital in the second phase of the Industrial Revolution does not indicate the absence of a significant increase in the demand for human capital over this period. The significant increase in schooling that took place in the 19th century and in particular the introduction of public education (e.g., The Education Act of 1870) that lowered the cost of education, generated significant increase in the supply of educated workers that may have prevented a significant rise in the return to education. ${ }^{105}$

- a. The growth process is characterized by stages of development and the evolution of the growth rates of output per capita is nonlinear. Technological leaders experienced a monotonic increase in the growth rates of their income per capita. Their growth was rather slow in early stages of development, it increased rapidly during the take-off from the Malthusian epoch, and then continued to rise at a lower pace, possibly stabilizing at higher level. Technological followers that made the transition to sustained economic growth, in contrast, experienced a non-monotonic increase in the growth rates of their income per capita. Their growth rates rather slow in early stages of development, it increased rapidly in the early stages of the take-off from the Malthusian epoch and was boosted by the adoption of technologies from the existing technological frontier, and then once the economy reached the technological frontier, the growth rates dropped to the level of the technological leaders.

b. The differential timing of the take-off between economies generated convergence clubs characterized by a group of poor countries in the vicinity of the Malthusian equilibrium, a group of rich countries in the vicinity of the sustained growth equilibrium, and others that are in the attempting to shift from one camp to another. ${ }^{106}$

These hypotheses are consistent the Maddison (2001)'s evidence about the growth process in the last 2000 years, as well as with contemporary cross section evidence that suggest that the growth process is characterized by multiple growth regimes (e.g., Duraluf and Johnson 1995) and thus with non-linearities in the growth process (e.g., Duraluf and Quah 1998, and Bloom, Canning and Silva 2003), and that divergence along with a twin peak have emerged in the distribution of income across countries in the world (Quah 1996, 1997, Jones 1997, and Prichett 1997). ${ }^{107}$

\subsection{Complementary Theories}

Subsequent theories of economic growth in the very long run demonstrate that the unified theory of economic growth can be augmented and fortified by additional characteristics of the transition from stagnation to growth without altering the fundamental hypothesis regarding the central roles played by the emergence of human capital formation and the demographic transition in this process. Various qualitative and quantitative unified theories explore plausible mechanisms for the emergence of human capital and the onset of the demographic transition such as, the rise in the demand for human capital

\footnotetext{
${ }^{105}$ Some of this supply response was a direct reaction of the potential increase in the return to human capital, and thus may only operate to partially offset the increase in the return to human capital, but the reduction in the cost of education via public schooling, generated an additional force that operated towards a reduction in the return to human capital.

${ }^{106}$ For the definition and the theory of club convergence see Azariadis (1996) and Galor (1996).

${ }^{107}$ Other studies that focused on nonlinearity of the growth process includes Fiaschi and Lavezzi (2003). Other research on the emergence of twin peak is Feyrer (2003).
} 
(due to: technological acceleration, capital-skill complementarity, skilled biased technological change, and reallocation of resources towards skilled intensive sectors), the decline in child and infant mortality, the rise in life expectancy, the emergence of public education, the decline in child labor, as well as cultural and genetic evolution in the valuation of human capital. They suggest that indeed the emergence of human capital formation, and the onset of the demographic transition played a central role in the shift from stagnation to growth.

\subsubsection{Alternative Mechanisms for the Emergence of Human Capital Formation}

The emergence of human capital formation and its impact on the demographic transition and the technological frontier is a central element in the transition from the Post-Malthusian Regime to the state of sustained economic growth in all unified theories of economic growth in which population, technology and income per capita are endogenously determined. ${ }^{108}$ Various complementary mechanisms that generate or reinforce the rise in human capital formation have been proposed and examined quantitatively, demonstrating the robustness and the empirical plausibility of this central hypothesis.

\section{The Rise in the Industrial Demand for Human Capital}

The rise in industrial demand for human capital in advanced stages of industrialization, as documented in section 2.3.3, and its impact on human capital formation led researchers to incorporate it as a central feature in unified theories of economic growth.

The link between industrial development and the demand for human capital have been modeled in various complementary ways. Galor and Weil (2000) modeled the rise in the demand for human capital as an outcome of the acceleration in technological progress, underlying the role of educated individuals in coping with a rapidly changing technological environment. Their mechanism is founded on the premise that the introduction of new technologies increases the demand for skilled labor in the short-run, although in some periods the characteristics of new technologies may be complementarity to unskilled labor, as was the case in the first phase of the Industrial Revolution. ${ }^{109}$

Subsequent unified theories of economic growth have demonstrated that the rise in the demand for human capital in association with advanced stages of industrialization could emerge from alternative mechanisms, without altering the fundamental insights of the theory. Fernandez-Vilaverde (2003) bases his quantitative unified theory on capital-skill complementarity, Doepke (2004) constructs his unified theory on the basis of a rising level of skilled-intensive industrial technology, and Galor and Mountford (2003) generate the rise in the demand for human capital via an increased specialization in the production of skilled-intensive goods due to international trade.

The rise in the demand for human capital stimulated public policy designed to enhance investment in human capital. In particular, as established in the quantitative unified theory of Doepke (2004), educational policy and child labor laws in England played an important role in human capital formation and the demographic transition.

\section{Mortality Decline, the Rise in Life Expectancy, and Human Capital Formation}

Several unified theories of economic growth demonstrated that the basic mechanism for the emergence of human capital proposed by Galor and Weil (2000) can be augmented and reinforced by the incorporation of the effect of the decline in mortality rates and the rise in life expectancy (as

\footnotetext{
${ }^{108}$ Even in the multiple-regime structure of Lucas (2002) a shock to the return to human capital is suggested in order to generate the switch from the Malthusian Regime to the Modern Growth Regime.

${ }^{109}$ Evidence for the complementarity between technological progress (or capital) and skills is provided by Katz and Goldin (1988) and on the basis of cross-section studies by Duffy, Papageorgiou and Perez-Sebastain (2004).
} 
documented in section 2.3.2) on the rise in human capital formation, the decline in the desirable number of surviving offspring, and thus on the transition from stagnation to growth. ${ }^{110}$

The significant decline in mortality rates in developed countries since the 18th century, as depicted in Figure 2.24, and the recent decline in mortality rates in less developed countries, as depicted in Figure 2.25 , corresponded to an acceleration in the rise in life expectancy and a significant rise in human capital formation, towards the end of the 19th century in developed countries (Figures 2.26 and 2.28) and towards the middle of the 20th century in less developed countries (Figures 2.27 and 2.31). The rise in the expected length of the productive life may have increased the potential rate of return to investments in children's human capital, and thus could have induced an increase in human capital formation along with a decline in fertility. However, despite the gradual rise in life expectancy in developed and less developed countries, investment in human capital has been insignificant as long as the industrial demand for human capital has not emerged. Thus, it appears that the industrial demand for human capital, as documented in section 2.3.3, provided the inducement for investment in education and the associated reduction in fertility rates, whereas the prolongation of life may have re-enforced and complemented this process.

Galor and Weil (1999) argue that the Malthusian interaction between technology and population accelerated the pace of technological progress, improving industrial technology as well as medical and health technologies. Consistent with the historical evidence provided in section 2.3.3, the improvements in the industrial technology increased the demand for human capital, whereas the development of medical technology and health infrastructure generated a significant rise in life expectancy. The expected rate of return to human capital investment increased therefore due to the prolongation of life, as well as the rise in industrial demand for human capital, enhancing the positive interaction between schooling and technological progress, bringing about a demographic transition and the emergence of the state of sustained economic growth.

Various theories formally examined mechanisms that capture the interaction between human capital formation, the decline in mortality rate, and the rise in life expectancy, in the process of development. ${ }^{111}$ Cervellati and Sunde (2003) and Boucekkine, de la Croix and Licandro (2003) focus on the plausible role of the reinforcing interaction between life expectancy and human capital formation in the transition from stagnation to growth, abstracting from its effect on fertility decisions. Others suggest that a decline in mortality rates increased the return to investment in human capital via: (a) increased population density and thus efficiency of the transmission of human capital (Lagerlof 2003a), (b) increased population growth and the advancement of skill-biased technologies (Weisdorf 2004), and (c) improved healthiness and thus the capacity to absorb human capital (Hazan and Zoabi 2004), generating a substitution of quality for quantity, a demographic transition and a transition to a state of sustained economic growth. ${ }^{112}$

\section{Capital-Skill Complementarity and the Emerging Incentives for Capitalists to Support Education Reforms}

The accumulation of physical capital in the early stages of industrialization enhanced the importance of human capital in the production process and generated an incentive for the capitalists to support the provision of public education for the masses. ${ }^{113}$ Consistent with the evidence provided in

\footnotetext{
${ }^{110}$ The effect of an increase in life expectancy on the incentive of individuals to invest in their own human capital is well established since Ben-Porath (1967). See Kalemli-Ozcan, Ryder and Weil (2000), as well.

${ }^{111} \mathrm{As}$ argued in section 3.2.3, qualitative and quantitative evidence do not lend credence to the theory that a decline in infant and child mortality rates triggered the decline in the number of surviving offspring and the increase in the investment in offspring's human capital.

${ }^{112}$ See Iyigun (2003) as well.

${ }^{113}$ Attentively, other argued that increased polarization induced the elite to enact costly educational reforms. Grossman
} 
section 2.3.3, Galor and Moav (2004) argue that due to capital-skill complementarity, the accumulation of physical capital by the capitalists in the first phase of the Industrial Revolution increased the importance of human capital in sustaining the rate of return to physical capital inducing capitalists to support the provision of public education for the masses. ${ }^{114}$

\section{The Decline in Child Labor}

Other theories that focused on the transition from stagnation to growth suggested that the central role of human capital formation and the demographic transition can be augmented and reinforced by the incorporation of the adverse effect of the rise in the demand for human capital on child labor. Hazan and Berdugo (2002) suggest that technological change increased the wage differential between parental labor and child labor inducing parents to reduce the number of their children and to further invest in their quality, stimulating human capital formation, a demographic transition, and a shift to a state of sustained economic growth. ${ }^{115}$ Alternatively, the rise in the importance of human capital in the production process, as documented in section 2.3.3, induced industrialists to support laws that abolish child labor (Doepke and Zilibotti (2003)), inducing a reduction in child labor, and stimulating human capital formation and a demographic transition.

\section{Cultural and Genetic Evolution in the Valuation of Human Capital}

Human capital formation and its impact on the decline in the desirable number of surviving offspring may have been reinforced by cultural or genetic evolution in the attitude of individuals towards human capital formation. Consistent with the gradual rise in literacy rates prior to the Industrial Revolution, Galor and Moav (2002), argue that during the epoch of Malthusian stagnation that had characterized most of human existence, individuals with a higher valuation for offspring quality generated an evolutionary advantage and their representation in the population gradually increased. The increase in the rate of return to human capital along with the increase in the bias towards quality in the population reinforced the substitution towards child quality, setting the stage for a significant increase in human capital formation along with a rapid decline in fertility.

\subsubsection{Alternative Triggers for the Demographic Transition}

The demographic transition that separated the Post-Malthusian Regime and the Sustained Growth Regime is a central element in quantitative and qualitative unified theories of economic growth in which population, technology and income per capita are endogenously determined. As discussed in section 2.3.2, the demographic transition brought about a reversal in the unprecedented increase in population growth that occurred during the Post-Malthusian Regime, leading to a significant reduction in fertility rates and population growth in various regions of the world, and enabling economies to convert a larger share of the fruits of factor accumulation and technological progress into growth of output per capita. ${ }^{116}$ The demographic transition enhanced the growth process reducing the dilution of the stock of capital and land, enhancing the investment in the human capital of the population, and alternating the age

and Kim (1999) argue that education decreases predation, and Bowles and Gintis (1975) suggest that educational reforms are designed to sustain the existing social order, by displacing social problems into the school system. In contrast, Bourguignon and Verdier (2000) suggest that if political participation is determined by the education (socioeconomic status) of citizens, the elite may not find it beneficial to subsidize universal public education despite the existence of positive externalities from human capital.

${ }^{114}$ Since firms have limited incentive to invest in the general human capital of their workers, in the presence of credit market imperfections, the level of education would be suboptimal unless it would be financed publicly (Galor and Zeira (1993), Duraluf (1996), Fernandez and Rogerson (1996) Benabou (2000), Mookherjee and Ray (2003), and Galor and Moav (2004)). Moreover, a mixture of vocational and general education would be enacted (Bertocchi and Spagat 2004).

${ }^{115}$ The decline in the relative wages of children is documented empirically (e.g., Horrell and Humphries (1995)).

${ }^{116}$ Demographic shocks generate a significant effect on economic growth in Connolly and Peretto (2003) as well. 
distribution of the population, increasing temporarily the size of the labor force relative to the population as a whole. ${ }^{117}$

Various complementary mechanisms for the demographic transition have been proposed in the context of unified growth theories, establishing, theoretically and quantitatively the importance of this central hypothesis in the understanding of the transition from stagnation to growth. ${ }^{118}$

\section{The Emergence of Human Capital Formation}

The gradual rise in the demand for human capital in the process of industrialization, as documented in section 2.3.3, and its close association with the timing of the demographic transition has led researchers to argue that the increasing role of human capital in the production process induced households to increase their investment in the human capital of their offspring, ultimately leading to the onset of the demographic transition.

The link between the rise in the demand for human capital and the demographic transition have been modeled in various complementaries ways. Galor and Weil (2000) argue that the gradual rise in the demand for human capital induced parents to invest in the human capital of their offspring. In the early stages of the transition from the Malthusian regime, the effect of technological progress on parental income permitted the rise in population growth as well as the average quality. Further increases in the rate of technological progress ultimately induced a reduction in fertility rates, generating a demographic transition in which the rate of population growth declined along with an increase in the average level of education. Thus, consistent with historical evidence, the theory suggests that prior to the demographic transition, population growth increased along with investment in human capital, whereas the demographic transition brought about a decline in population growth along with a further increase in human capital formation.

Other unified theories examine several reinforcing mechanisms that could have triggered the demographic transition and the transition to sustained economic growth, such as the decline in child labor (Hazan and Berdugo 2002, Doepke 2004 and Doepke and Zilibotti 2003), the decline in mortality rates and the rise in life expectancy (Lagerlof 2003a, and Weisdorf 2004), and the evolution of preferences for offspring quality (Galor and Moav 2002)), as discussed in section 4.1. The quantitative unified theories of Fernandez-Villaverde (2003) and Doepke (2004) confirm the significance of these various channels in originating the demographic transition and the shift from stagnation to growth.

\section{The Decline in the Gender Gap}

The observed decline in the gender gap in the last two centuries, as discussed in section 3.3.4, is an alternative mechanism that could have triggered a demographic transition and human capital formation in other unified theories.

A unified theory based upon the decline in the gender wage gap and the associated increase in female labor force participation and fertility decline was explored by Galor and Weil (1996, 1999), as elaborated in section 3.3.4. They argue that technological progress and capital accumulation complemented mental intensive tasks and substituted for physical-intensive tasks in the industrial production process. In light of the comparative physiological advantage of men in physical-intensive tasks and women in mental-intensive tasks, the demand for women's labor input gradually increased in the industrial sector, decreasing monotonically the wage deferential between men and women. In early stages of

\footnotetext{
${ }^{117}$ Bloom and Williamson (1998) suggest that the cohort effect played a significant role in the growth "miracle" of East Asian countries in the time period 1960-1990.

${ }^{118}$ As established in section 3.3, some mechanisms that were proposed for the demographic transition, such as the decline in infant and child mortality, as well as the rise in income, are inconsistent with the evidence. These mechanisms were excluded in the formulation of unified growth theory.
} 
industrialization, wages of men and women increased, but the rise in female's relative wages was insufficient to induce a significant increase in women's labor force participation. Fertility, therefore increased due to the income effect that was generated by the rise in men's absolute wages. Ultimately, however, the rise in women's relative wages was sufficient to induce a significant increase in labor force participation, increasing the cost of child rearing proportionally more that households income and triggering a demographic transition and a shift from stagnation to growth.

Similarly, a transition from stagnation to growth based upon a declining gender gap in human capital formation was proposed by Lagerlof (2003b). He argues that the process of development permitted a gradual improvement in the relative level of female education, raising the opportunity cost of children and initiating a fertility decline. ${ }^{119}$

\subsubsection{Alternative Modeling of the Transition from Agricultural to Industrial Economy}

The shift from agriculture to industry that accompanied the transition from stagnation to growth, as described in section 2.2.3, influenced the specifications of the production structure of most unified theories of economic growth. In some unified theories (e.g., Galor and Weil (2000)) the structure of the aggregate production function and its interaction with technological progress, reflects implicitly a transition from an agricultural to an industry economy in the process of development. In other theories (e.g., Hansen and Prescott 2002, Kogel and Prskawetz 2001, Hazan and Berdugo 2002, Tamura 2002, Doepke 2004, Galor and Mountford 2003, Bertocchi 2003, and Galor, Moav and Vollrath 2003) the process of development generates explicitly a transition from an agricultural sector to an industrial sector.

In Galor and Weil (2000) production occurs according to a constant-returns-to-scale technology that is subject to endogenous technological progress. The output produced at time $t$, is $Y_{t}=$ $H_{t}^{\alpha}\left(A_{t} X\right)^{1-\alpha}$, where $H_{t}$ is the aggregate quantity of efficiency units of labor employed in period $t, X$ is land employed in production in every period $t$, and $A_{t}$ represents the endogenously determined technological level in period $t$. Hence $A_{t} X$ are the "effective resources" employed in production in period $t$. In early stages of development, the economy is agricultural (i.e., the fixed amount of land is a binding constraint on the expansion of the economy). Population growth reduces labor productivity since the rate of technological progress is not sufficiently high to compensate for the land constraint. However as the rate of technological progress intensifies in the process of development the economy becomes industrial. Technological progress counterbalanced the land constraint, the role of land gradually diminishes, and "effective resources" are expanding at a rate that permit sustained economic growth.

Hansen and Prescott (2002) develop a model that captures explicitly the shift from an agricultural sector to an industrial sector in the transition from stagnation to growth. In early stages of development, the industrial technology is not sufficiently productive and production takes place solely in an agricultural sector, where population growth (that is assumed to increase with income) offset increases in productivity. An exogenous technological progress in the latent industrial technology ultimately makes the industrial sector economically viable and the economy gradually shifts resources from the agricultural sector to the industrial one. Assuming that the positive effect of income on population is reversed, the rise in productivity in the industrial sector is not counterbalanced by population growth permitting the transition to a state of sustained economic growth.

\footnotetext{
${ }^{119}$ Alternatively, one could have adopted the mechanism proposed by Fernandez, Fogli and Olivetti (2004) for the gradual decline in the education gap and labor force participation between men and women. They suggest that it reflects a dynamic process in which the home experience of sons of working, educated mothers makes them more likely to prefer educated and working wives, inducing a gradual increase in investment in education as well as labor force participation among women.
} 
Unlike most unified theories in which the time paths of technological progress, population growth, and human capital formation are endogenously determined and are determined on the basis on explicit micro-foundations, in Hansen and Prescott (2002) technological progress is exogenous, population growth is assumed to follow the hump-shaped pattern that is observed along human history and human capital formation that appears central in the transition is absent. Based upon this reduced form approach, they demonstrate that there exists a rate of technological progress in the latent industrial sector and a well specified reduced form relationship between population and output under which the economy will shift from Malthusian stagnation to sustained economic growth. Unfortunately, however, this methodology does not advance us in identifying the underlying micro-foundations that led to the transition from stagnation to growth - the ultimate goal of unified growth theory.

Formally, the transition from stagnation to growth in Hansen and Prescott (2002) does not rely on the forces of human capital in the transition. However, the lack of a role for human capital in their structure is an artifact of the reduced form analysis that does not identify the economic factors behind the process of technological change in the latent industrial technology, as well as the forces behind the assumed hump shaped pattern of population dynamics. If the micro-foundations of these critical factors behind the transition would have been properly established, human capital would have played a central role sustaining the rate of technological progress in the industrial sector and in generating the demographic transition that is assumed in their setting.

Thus, no major insight has been generated from this explicit modeling of the transition from agriculture to industry in a closed economy setting. In contrast, the two-sector framework is instrumental in the exploring of the effect of international trade on the differential timing of the transition from stagnation to growth and the associate phenomenon of the great divergence (Galor and Mountford 2003), as discussed in section 6.1. Moreover, this two-sector setting would be necessary in order to examine the incentives of land owners to block education reforms and the process of industrialization (Galor, Moav, and Vollrath 2003), and the evolution of property rights and their impact on political reforms (Bertocchi 2003).

\section{$5 \quad$ Unified Evolutionary Growth Theory}

"It is not the strongest of the species that survive, nor the most intelligent, but the one most responsive to change." Charles Darwin

\subsection{Human Evolution and Economic Development}

This section explores the dynamic interaction between human evolution and the process of economic development. It focuses on a recent development of a unified evolutionary growth theory that, based on historical evidence, generates innovative hypotheses about the interplay between the process of development and human evolution, shedding new light about the origin of modern economic growth and the observed intricate evolution of health, life expectancy, human capital, and population growth since the Neolithic revolution.

The unified evolutionary growth theory advances a novel analytical methodology that is designed to capture the complexity of the dynamic interaction between the economic, social, and behavioral aspects of the process of development and evolutionary processes in the human population. The proposed hybrid between Darwinian methodology and the methodology of unified theories of economic growth permits the exploration of the dynamic reciprocal interaction between the evolution of the distribution of genetic traits and the process of economic development. It captures potential non-monotonic 
evolutionary processes that were triggered by major socioeconomic transitions, and may have played a significant role in the observed time path of health, life expectancy, human capital, and population growth. ${ }^{120}$

Humans were subjected to persistent struggle for existence for most of their history. The Malthusian pressure affected the size of the population (as established in section 2.1.2), and conceivably via natural selection, the composition of the population as well. Lineages of individuals whose traits were complementary to the economic environment generated higher income, a larger number of surviving offspring and the representation of their traits in the population gradually increased, contributing significantly to the process of development.

Consistent with the historical evidence presented in section 2, the proposed unified evolutionary growth theory demonstrates that the Malthusian epoch that characterized most of human existence stimulated a process of natural selection that generated an evolutionary advantage to human traits that were complementary to the growth process, and ultimately generating a take-off from an epoch of Malthusian stagnation to a state of sustained economic growth.

Evidence suggests that evolutionary processes in the composition of existing genetic traits may be rather rapid and the time period between the Neolithic Revolution and the Industrial Revolution that lasted about 10,000 years is sufficient for significant evolutionary changes. There are numerous examples of rapid evolutionary changes among various species. ${ }^{121}$ In particular, evidence establishes that evolutionary changes occurred in the Homo sapiens within the time period that is the focus of our analysis. For instance, lactose tolerance was developed among European and Near Easterners since the domestication of dairy animals in the course of the Neolithic revolution, whereas in regions that were exposed to dairy animals in later stages a larger proportion of the adult population suffers from lactose intolerance. Furthermore, genetic immunity to malaria provided by the sickle cell trait is prevalent among descendents of Africans whose engagement in agriculture improved the breeding ground for mosquitoes and thereby raised the incidence of malaria, whereas this trait is absent among descendents of nearby populations that have not made the transition to agriculture. ${ }^{122}$

Despite the existence of compelling evidence about the interaction between human evolution and the process of economic development, only few attempts have been made to explore the reciprocal interaction between the process of development and human evolution. ${ }^{123}$ This exploration is likely to revolutionize our understanding of the process of economic development as well as the process of human

\footnotetext{
${ }^{120}$ The conventional methodology of evolutionary stable strategies that has been employed in various fields of economics, ignores the dynamics of the evolutionary process, and is thus inappropriate for the understanding of the "short-run" interaction between human evolution and the process of development since the Neolithic revolution. As will become apparent the dynamics of the evolutionary process are essential for the understanding of the interaction between human evolution and economic growth since the Neolithic revolution that was marked by fundamental non-monotonic evolutionary processes.

${ }^{121}$ The color change that peppered moths underwent during the 19th century is a classic example of evolution in nature [See Kettlewell 1973]. Before the Industrial Revolution light-colored English peppered moths blended with the lichencovered bark of trees. By the end of the 19th century a black variant of the moth, first recorded in 1848, became far more prevalent than the lighter varieties in areas in which industrial carbon removed the lichen and changed the background color. Hence, a significant evolutionary change occurred within a time period that correspond to only hundreds of generations. Moreover, evidence from Daphne Major in the Galapagos suggests that significant evolutionary changes in the distribution of traits among Darwin's Finches occurred within few generations due to a major drought [Grant and Grant 1989]. Other evidence, including the dramatic changes in the color patterns of guppies within 15 generations due to changes in the population of predators, are surveyed by Endler [1986].

${ }^{122}$ See Levingston [1958], Weisenfeld [1967] and Durham [1982].

${ }^{123}$ Notable exceptions are Galor and Moav (2002)'s exploration of the interaction between human evolution and the transition from stagnation to growth, Saint Paul (2003)'s examination of the effect of the emergence of markets on the evolution of heterogeneity in the human population, Clark and Hamilton (2003) analysis of the relationship between the evolution of time preference and the sharp decline in interest rate in England in the 14th and 15th centuries, and Galor and Moav (2004)'s exploration of the effect of an increased population density in the process of development on the evolution of life expectancy.
} 
evolution.

\subsection{Natural Selection and the Origin of Economic Growth}

The first evolutionary growth theory that captures the interplay between human evolution and the process of economic development in various phases of development, was developed by Galor and Moav (2002). The theory suggests that during the epoch of Malthusian stagnation that had characterized most of human existence, traits of higher valuation for offspring quality generated an evolutionary advantage and their representation in the population gradually increased. This selection process and its effect on investment in human capital stimulated technological progress and ultimately initiated a reinforcing interaction between investment in human capital and technological progress that brought about the demographic transition and the state of sustained economic growth. ${ }^{124}$

The theory maintains that during the Malthusian epoch, the distribution of valuation for quality lagged behind the evolutionary optimal level. The evolution of the human brain in the transition to Homo sapiens and the complementarity between brain capacity and the reward for human capital has increased the evolutionary optimal investment in the quality of offspring (i.e., the level that maximizes reproduction success). ${ }^{125}$ Moreover, the increase in the return to human capital in the aftermath of the Neolithic revolution increased the evolutionary optimal levels of investment in child quality. The agricultural revolution facilitated the division of labor and fostered trade relationships across individuals and communities, enhancing the complexity of human interaction and raising the return to human capital. Thus, individuals with traits of higher valuation for offspring's quality generated higher income and, in the Malthusian epoch when child rearing was positively affected by aggregate resources, a larger number of offspring. Traits of higher valuation for quality gained the evolutionary advantage and their representation in the population increased over time.

The Malthusian pressure increased the representation of individuals whose preferences are biased towards child quality, positively affecting investment in human capital and ultimately the rate of technological progress. In early stages of development, the proportion of individuals with higher valuation for quality was relatively low, investment in human capital was minimal, resources above subsistence were devoted primarily to child rearing, and the rate of technological progress was rather slow. Technological progress therefore generated proportional increases in output and population and the economy was in the vicinity of a Malthusian equilibrium, where income per capita is constant, but the proportion of individuals with high valuation for quality was growing over time. ${ }^{126}$

As the fraction of individuals with high valuation for quality continued to increase, technological progress intensified, raising the rate of return to human capital. The increase in the rate of technological progress generated two effects on the size and the quality of the population. On the one hand, improved

\footnotetext{
${ }^{124}$ The theory is applicable for either social or genetic intergenerational transmission of traits. A cultural transmission is likely to be more rapid and may govern some of the observed differences in fertility rates across regions. The interaction between cultural and genetic evolution is explored by Boyd and Richardson (1985) and Cavalli-Sforza and Feldman (1981), and a cultural transmission of preferences is examined by Bisin and Verdier (2000).

${ }^{125}$ The evolutionary process in valuation for quality that was triggered by the evolution of the human brain has not reached a new evolutionary stable state prior to the Neolithic period because of the equality that characterized resource allocation among hunter-gatherers tribes. Given this tribal structure, a latent attribute of preferences for quality, unlike observable attributes such as strength and intelligence, could not generate a disproportionate access to sexual mates and resources that could affect fertility rates and investment in offspring's quality, delaying the manifestation of the potential evolutionary advantage of these traits. It was the emergence of the nuclear family in the aftermath of the agricultural revolution that fostered intergenerational links, and thereby enhanced the manifestation of the potential evolutionary advantage of this trait.

${ }^{126}$ Unlike Galor and Weil (2000) in which the adverse effect of limited resources on population growth delays the process of development, in the proposed theory the Malthusian constraint generates the necessary evolutionary pressure for the ultimate take-off.
} 
technology eased households' budget constraints and provided more resources for quality as well as quantity of children. On the other hand, it induced a reallocation of these increased resources toward child quality. In the early stages of the transition from the Malthusian regime, the effect of technological progress on parental income dominated, and the rate of population growth as well as the average quality increased, further accelerating technological progress. Ultimately, the rate of technological progress induced universal investment in human capital along with a reduction in fertility rates, generating a demographic transition in which the rate of population growth declined along with an increase in the average level of education. The positive feedback between technological progress and the level of education reinforced the growth process, setting the stage for the transition to a state of sustained economic growth. ${ }^{127}$

During the transition from the Malthusian epoch to the sustained growth regime, once the economic environment improved sufficiently, the significance of quality for survival (fertility) declined, and traits of higher valuation for quantity gained the evolutionary advantage. Namely, as technological progress brought about an increase in income, the Malthusian pressure relaxed and the domination of wealth in fertility decisions diminished. The inherent advantage of higher valuation for quantity in reproduction has started to dominate, and individuals whose preferences are biased towards child quantity gained the evolutionary advantage. Nevertheless, the growth rate of output per worker has remained positive since the high rate of technological progress sustained an attractive return to investment in human capital even from the viewpoint of individuals whose valuation for quality is relatively low.

The transition from stagnation to growth is an inevitable by product of the interaction between the composition of the population and the rate of technological progress in the Malthusian epoch. However, for a given composition of population, the timing of the transition may differ significantly across countries and regions due to historical accidents, as well as variation in geographical, cultural, social and institutional factors, trade patterns, colonial status, and public policy, that have affected the relationship between human capital formation and technological progress.

\subsubsection{Primary Ingredients}

The theory is based upon the interaction between several building blocks: the Darwinian elements, the Malthusians elements, the nature of technological progress, the determinants of human capital formation, and the factors that affect parental choice regarding the quantity and quality of offspring.

The Darwinian elements. The theory incorporates the main ingredients of Darwinian evolution (i.e., variety, intergenerational transmission of traits, and natural selection) into the economic environment. Inspired by fundamental components of the Darwinian theory (Darwin 1859, 1871), individuals do not operate consciously so as to assure their evolutionary advantage. Nevertheless, their preferences (or strategies) assure that those individuals whose operations are most complementary to the environment would ultimately dominate the population.

Individuals' preferences are defined over consumption above a subsistence level as well as over the quality and the quantity of their children. ${ }^{128}$ These preferences capture the Darwinian survival

\footnotetext{
${ }^{127}$ The theory suggests that waves of rapid technological progress in the Pre-Industrial Revolution era did not generate sustained economic growth due to the shortage of preferences for quality in the population. Although technological progress increased the return to quality temporarily, in these previous episodes, the level of human capital that was generated by the response of the existing population was insufficient to sustain technological progress and economic growth.

${ }^{128}$ The subsistence consumption constraint is designed to capture the fact that the physiological survival of the parent is a pre-condition for the survival of the lineage (dynasty). Resources allocated to parental consumption beyond the subsistence level may be viewed as a force that raises parental productivity and resistance to adverse shocks (e.g., famine and disease), generating a positive effect on the fitness of the parent and the survival of the lineage. This positive effect, however, is counterbalanced by the implied reduction in resources allocated to the offspring, generating a negative effect on the survival of the lineage.
} 
strategy as well as the most fundamental trade-offs that exist in nature: namely, the trade-off between the resources allocated to the parent and the offspring, and the trade-off between the number of offspring and resources allocated to each offspring. ${ }^{129}$ The economy consists of a variety of types of individuals distinguished by the weight given to child quality in their preferences. ${ }^{130}$ This trait is assumed to be transmitted intergenerationally, the economic environment determines the type with the evolutionary advantage (i.e., the type characterized by higher fertility rates), and the distribution of preferences in the population evolves over time due to differences in fertility rates across types. ${ }^{131}$

The significance that individuals attribute to child quantity as well as to child quality reflects the well-known variety in the quality-quantity survival strategies (or in the $K$ and $r$ strategies) that exists in nature (e.g., MacArthur and Wilson 1967). Human beings, like other species, confront the basic trade-off between offspring's quality and quantity in their implicit Darwinian survival strategies. Although a quantity-biased preference has a positive effect on fertility rates and may therefore generate a direct evolutionary advantage, it adversely affects the quality of offspring, their income, and their fitness and may therefore generate an evolutionary disadvantage. "Increased bearing is bound to be paid for by less efficient caring." (Dawkins 1989, p. 116). As was established in the evolutionary biology literature since the seminal work of Lack (1954), the allocation of resources between offspring "caring" and "bearing" is subjected to evolutionary changes. ${ }^{132}$

The Malthusian elements. Individuals are subjected to a subsistence consumption constraint and as long as the constraint is binding, an increase in income results in an increase in population growth along with an increase in the average quality of a minor segment of the population. Technological progress, which brings about temporary gains in income per capita, triggered therefore in early stages of development an increase in the size of the population that offset the gain in income per capita due to the existence of diminishing returns to labor. Growth in income per capita is generated ultimately, despite decreasing returns to labor, since technological progress induces investment in human capital among a growing minority.

The determinants of technological progress. The composition of the population as reflected by the average level of human capital is the prime engine of technological progress. ${ }^{133}$

\footnotetext{
${ }^{129}$ Resources allocated to quality of offspring in different stages of development take different forms. In early stages of development it is manifested in investment in the durability of the offspring via better nourishment and parental guidance, whereas in mature stages, investment in quality may capture formal education.

${ }^{130}$ The analysis abstracts from heterogeneity in the degree of the trade-off between resources allocated to parent and offspring. The introduction of this element would not alter the qualitative results. On the evolution of preferences see the survey by Bowles (1998).

${ }^{131}$ Recent research across historical and modern data from the United States and Europe suggests that fertility behavior has a significant hereditary component [Rogdgers et al. 2001a]. For instance, as established recently by Kohler et al. (1999) and Rodgers et al. (2001b), based on the comparison of fertility rates among identical and fraternal twins born in Denmark during the periods 1870-1910 and 1953-1964, slightly more than one-quarter of the variance in completed fertility is attributable to genetic influence. These findings are consistent with those of Rodgers and Doughty [2000] based on kinship data from the United States.

${ }^{132}$ Lack (1954) suggests that clutch sizes (i.e., number of eggs per nest), among owls and other predatory vole-eating birds, for instance, are positively related to food abundance. He argues that the clutch size is selected such that under any feeding conditions fertility rates ensure the maximal reproductive success. Furthermore, Cody (1966) documents the existence of significant differences between clutch sizes of the same bird species on islands and nearby mainland localities of the same latitude. In temperate regions where food is more abundant in the mainland than on islands, the average clutch size is smaller on the islands. For instance, for Cyanoramphus novaezelandeae, the average mainland clutch is 6.5 whereas the average in the island is 4 .

${ }^{133}$ This link between education and technological change was proposed by Nelson and Phelps (1966) and was supported empirically by Easterlin (1981), Doms et al. (1997), as well as others. Consistently with Mokyr (2002) who argues that the effect of human capital accumulation on technological progress became significant only in the course of the Scientific Revolution that preceded the Industrial Revolution, the effect of human capital accumulation on the rate of technological progress, need not be significant prior to the scientific revolution as long as it becomes significant prior to the Industrial Revolution. In order to focus on the role of the evolutionary process, the model abstracts from the potential positive effect of the size of the population on the rate of technological progress. Adding this scale effect would simply accelerate the
} 
The origin of human capital formation. Technological change raises the demand for human capital. Technological progress reduces the adaptability of existing human capital for the new technological environment and educated individuals (and thus offspring of parent with high valuation for quality) have a comparative advantage in adapting to the new technological environment. ${ }^{134}$

The determination of paternal decision regarding offspring quantity and quality. Individuals choose the number of children and their quality based upon their preferences for quality as well as their time constraint. ${ }^{135}$ The rise in the (genetic or cultural) bias towards quality in the population, as well as the rise in the demand for human capital, induce parents to substitute quality for quantity of children. ${ }^{136}$

\subsubsection{Main Hypotheses and their Empirical Assessment}

The theory generates several hypotheses about human evolution and the process of development, underlying the role of natural selection in: (i) the gradual process of human capital formation and thus technological progress prior to the Industrial Revolution, and (ii) the acceleration of the interaction between human capital and technological progress in the second phase of the Industrial Revolution, the associated demographic transition, and the emergence of a state of sustained economic growth.

\section{The Main Hypotheses:}

- During the initial phases of the Malthusian epoch, the growth rate of output per capita is nearly zero and the growth rate of population and literacy rates is minuscule, reflecting the sluggish pace of technological progress, the low representation of individuals with high valuation for child quality, and the slow pace of the evolutionary process.

This hypothesis is consistent with the characteristics of the Malthusian epoch, as described in section 2.1 .

- In the pre-demographic transition era, traits for higher valuation for offspring quality generated an evolutionary advantage. Namely, individuals with higher valuation for the quality of children had a larger number of surviving offspring and their representation in the population increased over time. In contrast, in the post-demographic transition era, when income per capita has no longer been the binding constraint on fertility decisions, individuals with higher valuation for offspring quantity have had an evolutionary advantage, bearing a lager number of surviving offspring. Thus, in the pre-demographic transition era, the number of surviving offspring was affected positively by parental education and parental income whereas in the post-demographic transition era, in contrast, this pattern is reversed and more educated, higher income individuals have a smaller number of surviving offspring.

transition process (e.g., Galor and Weil 2000)

${ }^{134}$ See Schultz (1964) and Nelson and Phelps (1966). If the return to education rises with the level of technology rather than with the rate of technological progress, the qualitative analysis would not be affected. However, this alternative would imply that changes in technology were skill-biased throughout human history in contrast to those periods in which technological change was skilled-saving, notably, in the first phase of the Industrial Revolution.

${ }^{135}$ Anthropological evidence suggests that fertility control was indeed exercised even prior to the Neolithic Revolution. Reproductive control in hunter-gatherer societies is exemplified by "pacing birth" (e.g., birth every four years) conducted by tribes who live in small, semi nomadic bands in Africa, Southeast Asia, and New Guinea in order to prevent the burden of carrying several children while wandering. They abstained from sexual intercourse for a three-year period after each birth. Similarly, Nomadic women of the Kung (a group of the San people of Southern Africa), use no contraceptives but nurse their babies frequently, suppressing ovulation and menstruation for two to three years after birth, and reaching a mean interval between births of 44 months.

${ }^{136}$ The existence of a trade-off between quantity and quality of children is supported empirically (e.g., Rosenzweig and Wolpin (1980) and Hanushek (1992)). 
Clark and Hamilton (2003) examine empirically this hypothesis on the basis of data that they have constructed from wills written in England in the time period 1620-1636. The wills that were written in a closed proximity to the death of a person in urban and rural areas, across a large variety of occupations and wealth, contain information about the number of surviving offspring, literacy of testator (measured by whether the will was signed), occupation of testator (if male), the amount of money bequeathed and to whom (spouse, children, the poor, unrelated persons), and houses and land that were bequeathed. Based on this data, Clark and Hamilton find a positive and statistically significant effect of literacy (and wealth) on the number of surviving offspring. ${ }^{137}$ They confirm the hypothesis that literate people (born, according to the theory, to parents with quality-bias) had an evolutionary advantage in this (predemographic transition) period. ${ }^{138}$ The negative relationship between education and fertility within a country in the post-demographic transition era was documented extensively. ${ }^{139}$

- The process of natural selection prior to the Industrial Revolution increased the representation of individuals with higher valuation for quality, gradually increasing the average level of investment in human capital, ${ }^{140}$ permitting a slow growth of output per capita.

The prediction about the rise in literacy rates prior to the Industrial Revolution is consistent with historical evidence. Various measures of literacy rates demonstrate a significant rise in literacy rates in the 2 centuries that preceded the Industrial Revolution in England. ${ }^{141}$ As depicted in Figure 5.1, male literacy rates increased gradually in the time period 1600-1760. Literacy rates for men doubled over this period, rising from about $30 \%$ in 1600 to over $60 \%$ in 1760 . Similarly, as reported by Cipolla (1968), literacy rates of women more than tripled from less than $10 \%$ in 1640 to over $30 \%$ in $1760 .{ }^{142}$

\footnotetext{
${ }^{137}$ In addition, Boyer (1989) argues that in early nineteenth century England, agricultural laborers' income had a positive effect on fertility: birth rates increased by 4.4 percent in response to a 10 percent increase in annual income. Further evidence are surveyed by Lee (1997).

${ }^{138}$ Interestingly, in New France, where land was abundant, and thus fertility decisions were not constraint by the availability of resources, the number of surviving offspring was higher among less educated individuals. These findings are consistent with the theory as well. If resource constraint is not binding for fertility decisions (e.g., in the post-demographic transition era, or due to a positive shock to income in the Malthusian era), individuals with higher valuation for quantity gain an evolutionary advantage.

${ }^{139}$ See, for instance, Kremer and Chen (2002).

${ }^{140}$ In contrast to Galor and Weil (2000) in which the inherent positive interaction between population and technology during the Malthusian regime is the force behind the increase in the rate of technological progress that induced investments in human capital and led to further technological progress, a demographic transition, and sustained economic growth, Galor and Moav (2002) is structured such that the gradual change in the composition of the population (rather than by the size of the population) brings about the take-off from Stagnation to growth. Thus, a scale effect is not needed for the take-off. However, this is just a simplifying modelling devise and both forces could operated simultaneously in triggering the take-off.

${ }^{141}$ Moreover, this hypothesis appears consistent with the increase in the number and size of universities in Europe since the establishment of the first university in Bologna in the 11th century, significantly outpacing the growth rate of population.

${ }_{142}$ This pattern is robust and is observed in various diocese over this period. For instance Cressy (1981, table 6.3 p. 113) reports a gradual rise in average literacy rate of average of yeomen, husbandmen and tradesmen in Norwich from $30 \%$ in 1580 to nearly $61 \%$ in 1690 , and Cressy $(1980$, table 7.1 p. 143) reports a gradual rise in Gentle literacy in the diocese of Durham over the period 1565 to 1624 .
} 


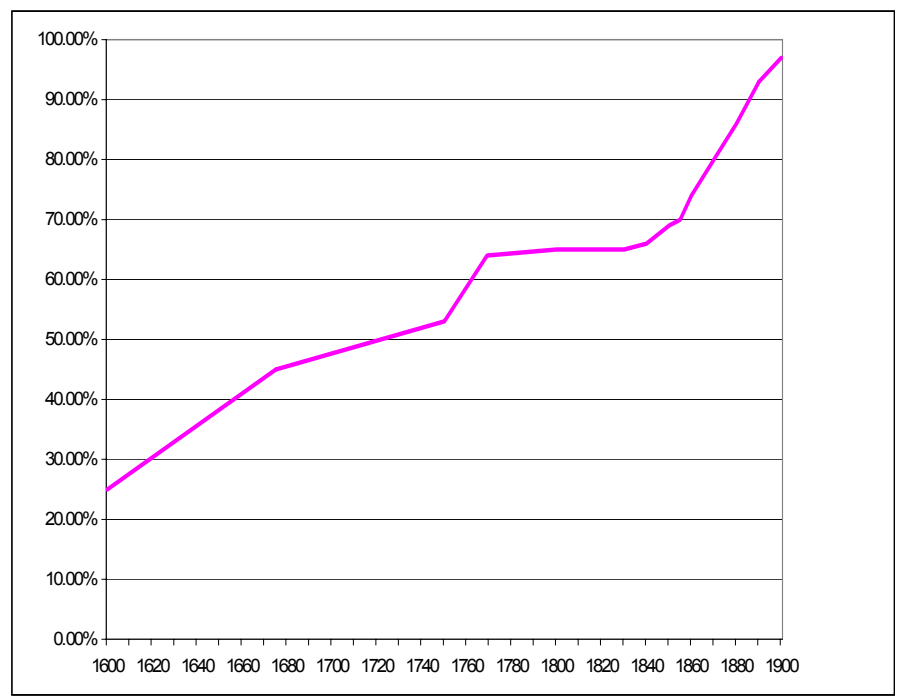

Figure 5.1 The Rise in Male Literacy Rates Prior and During the Industrial Revolution:

England: 1600-1900

Sources: Cipolla (1969), Stone (1969) and Schofield (1973)

Moreover, as argued by Clark (2003), human capital accumulation in England began in an era when the market rewards to skill acquisition were at historically low levels, consistent with the argument that the rise in human capital reflected a rise in the preference for quality offspring.

- The acceleration in the rate of technological progress that was reinforced by the investment in human capital of individuals with high valuation for offspring quality, increased the demand for human capital in the Post-Malthusian Regime, generating a universal investment in human capital, a demographic transition and a rapid pace of economic growth.

The hypothesis is consistent with the evidence, provided in section 2.3 and depicted partly in Figure 4.1 , about the significant rise in the demand for human capital in the second phase of the Industrial Revolution, the marked increased in educational attainment, and the emergence of universal education towards the end of the 19th century in association with a decline in fertility rates, and a transition to a state of sustained economic growth.

\subsection{Complementary Mechanisms}

The theory argues that during the Malthusian epoch hereditary human traits, physical or mental, that generate higher earning capacity, and thereby potentially larger number of offspring, would generate an evolutionary advantage and would dominate the population in the long run. Hereditary traits that stimulate technological progress or raise the incentive to invest in offspring's human capital (e.g., ability, longevity, and a preference for quality), may trigger a positive feedback loop between investment in human capital and technological progress that would bring about a take-off from an epoch of Malthusian stagnation, a demographic transition and a shift to a state of sustained economic growth. Hence, the struggle for existence that had characterized most of human history stimulated natural selection and generated an evolutionary advantage to individuals whose characteristics are complementary to the growth process, ultimately triggering a take-off from an epoch of stagnation to sustained economic growth. Galor and Moav (2002) focus on the evolution of the trade-off between resources allocated to 
the quantity and the quality of offspring. Their framework of analysis can be modified to account for the interaction between economic growth and the evolution of other hereditary traits.

\subsubsection{The Evolution of Ability and Economic Growth}

Consider the model described earlier. Suppose that individual's preferences, are defined over consumption above a subsistent level and over child quality and quantity. Individuals are identical in their preferences, but differ in their hereditary innate ability. Suppose further that offspring's level of human capital is an increasing function of two complementary factors: innate ability and investment in quality. Thus, since the marginal return to investment in child quality increases with ability, higher ability individuals and hence dynasties would allocate a higher fraction of their resources to child quality.

In the Malthusian era individuals with a higher ability generate more income and hence are able to allocate more resources for child quality and quantity. High ability individuals, therefore, generate higher income due to fact that their innate ability as well as their quality are higher. In the Malthusian era fertility rates are positively affected by the level of income and (under plausible configurations) the high ability individuals have therefore an evolutionary advantage over individuals of lower ability. As the fraction of individuals of the high ability type increases, investment in quality rises, and technological progress intensified. Ultimately the dynamical system changes qualitatively, the Malthusian temporary steady-state vanishes endogenously and the economy takes-off from the Malthusian trap. Once the evolutionary process generates the positive feedback between the rate of technological progress and the level of education, technological progress is reinforced, the return to human capital increases further, setting the stage for the demographic transition and sustained economic growth.

\subsubsection{The Evolution of Life Expectancy and Economic Growth}

Suppose that individuals differ in their level of health due to hereditary factors. Suppose further that there exist a positive interaction between the level of health and economic well-being. Higher income generates a higher level of health, whereas higher level of health increases labor productivity and life expectancy. Parents that are characterized by high life expectancy and thereby expect their offspring to have a longer productive life, would allocate more resources toward child quality. In the Malthusian era fertility rates are positively affected by the level of income and individuals with higher life expectancy, and therefore higher quality and higher income, would have (under plausible configurations) an evolutionary advantage. Natural selection therefore, increases the level of health as well as the quality of the population. Eventually, this process generates a positive feedback loop between investment in child quality, technological progress and health, bringing about a transition to sustained economic growth with low fertility rates and high longevity.

Alternatively, Galor and Moav (2004b) hypothesize that major socioeconomic and environmental changes in the process of development that were associated with significant increases in population density (e.g., the Neolithic Revolution and the process of urbanization) triggered evolutionary processes that contributed significantly to the long lasting improvements in longevity. Consistent with historical evidence, the theory suggests that the rise in the extrinsic mortality rate, brought about by a denser population, led initially to a decline in life expectancy, as document for instance in Figure 2.8. ${ }^{143}$ However, the evolutionary process that was originated by the rise in mortality, gradually increased the representation of traits associated with resistance to diseases and thus higher life expectancy, contributing

\footnotetext{
${ }^{143}$ Moreover, the evolutionary forces that major epidemics (e.g., the Black Death) and climatic changes have triggered, might have influenced the time path of human longevity and economic development in the subsequent centuries.
} 
significantly to the observed rise in longevity. Moreover, this evolutionary process in life expectancy reinforced the interaction between investment in human capital, life expectancy, and technological progress thereby expediting the demographic transition and enhancing the economic transition from stagnation to growth. ${ }^{144}$

\subsection{Assessment of the Various Mechanisms}

The significance of the evolution of various genetic traits in the transition from an epoch of Malthusian stagnation to a state of sustained economic growth, ought to consider the possibility that some of these traits may have completed most of their evolutionary change tens of thousands of years before the take-off and may be therefore a pre-condition for the take-off rather than the trigger itself.

In particular, the conventional wisdom among evolutionary biologists is that intelligence has not evolved markedly since the emergence of Homo Sapience (i.e., intelligence may have reached a temporary evolutionary optimum, reflecting the trade-off between the benefits and the energy cost associated with a lager brain). In contrast, it is unlikely that preferences reflecting quality-bias would have reached a an evolutionary stable state very early in the evolution of mankind. Prior to the Neolithic period, the majority of people lived in tribes where resources as well as child rearing were shared by the community. Given this tribal structure, the latent attribute of preferences for quality, unlike observable attributes such as strength and intelligence, could not generate a disproportionate access to sexual mates and resources that could affect fertility rates and investment in offspring's quality, delaying the manifestation of the potential evolutionary advantage of individuals with a quality-bias. It was the emergence of the nuclear family in the aftermath of the agricultural revolution that fostered intergenerational links, and thereby enhanced the manifestation of the potential evolutionary advantage of individuals with a quality-bias. ${ }^{145}$

\section{Differential Takeoffs and the Great Divergence}

The last two centuries have witnessed dramatic changes in the distribution of income and population across the globe. The differential timing of the take-off from stagnation to growth across countries and the corresponding variations in the timing of the demographic transition have led to a great divergence in income as depicted in Figure 2.32 and to significant changes in the distribution of population around the globe, as depicted in Figure 2.33. Some regions have excelled in the growth of income per capita, while other regions have been dominant in population growth. ${ }^{146}$

Inequality in the world economy had been insignificant until the 19th century. The ratio of GDP per capita between the richest region and the poorest region in the world was only 1.1:1 in the year 1000, 2:1 in the year 1500 and 3:1 in the year 1820. In contrast, the past two centuries have been characterized

\footnotetext{
${ }^{144}$ The evolution of the human brain along with the evolution of life expectancy in the prior to the Neolithic revolution is examined by Robson and Kaplan (2003).

${ }^{145} \mathrm{An}$ alternative explanation for the delay in the evolutionary process of the quality bias relative to the evolution of ability is based on the notion of punctuated equilibria (Gould 1977). A sequence of mutations, which result in a gradual increase in the variance in the distribution of the (latent) quality bias trait, had not affected investment in offspring's quality for a long period due to the low rate of return to human capital. Ultimately, however, mutations increased the variance sufficiently so as to induce investment in offspring's quality, despite the low return, and brought about an evolutionary advantage for the quality type. In contrast, a gradual increase in the variance of non-latent variables, such as ability, would have an immediate effect on the evolutionary process.

${ }^{146}$ Some researchers (e.g., Jones (1997) and Pritchett (1997)) have demonstrated that the great divergence that has been witnessed in the last two centuries has been maintained in the last decades as well, across countries. Interestingly, however, as established by Sala-i-Martin (2002), the phenomena has not been maintained across people in the world, (i.e., when national boundaries are removed).
} 
by a 'Great Divergence' in income per capita among countries and regions. In particular, the ratio of GDP per capita between the richest and the poorest regions has widened considerably from a modest $3: 1$ ratio in 1820 , to a large 18:1 ratio in 2001. An equally impressive transformation occurred in the distribution of world population across regions, as depicted in Figure 2.33. The earlier take-off of Western European countries generated a $16 \%$ increase in the share of their population in the world economy within the time period 1820-1870. However, the early onset in the Western European demographic transition, and the long delay in the demographic transition of less developed regions well into the second half of the twentieth century, led to a $55 \%$ decline in the share of Western European population in the world in the time period 1870-1998. In contrast, the prolongation of the Post-Malthusian period of less developed regions and the delay in their demographic transition, generated a $84 \%$ increase in Africa's share of world population, from $7 \%$ in 1913 to $12.9 \%$ in 1998, an $11 \%$ increase in Asia's share of world population from 51.7\% in 1913 to $57.4 \%$ in 1998, and a four-fold increase in Latin American's share in world population from $2 \%$ in 1820 to $8.6 \%$ in 1998 .

The phenomenon of the Great Divergence in income per capita across regions of the world in the past two centuries, that was associated with the take-off from the epoch of near stagnation to a state of sustained economic growth, presents intriguing questions about the growth process. How does one account for the sudden take-off from stagnation to growth in some countries in the world and the persistent stagnation in others? Why has the positive link between income per capita and population growth reversed its course in some economies but not in others? Why have the differences in per capita incomes across countries increased so markedly in the last two centuries? Has the transition to a state of sustained economic growth in advanced economies adversely affected the process of development in less-developed economies?

\subsection{Non-Unified Theories}

The origin of the Great Divergence has been a source of controversy. The relative role of geographical and institutions factors, ethnic, linguistic, and religious fractionalization, colonialism and globalization has been in the center of a debate about the origins of this remarkable change in the world income distribution in the past two centuries.

The role of institutional and cultural factors has been the focus of influential hypotheses regarding the origin of the great divergence. North (1981), Landes (1998), Mokyr (1990, 2002), Hall and Jones (1999), Parente and Prescott (2000), and Acemoglu, Johnson and Robinson (2002) have argued that institutions that facilitated the protection of property rights and enhanced technological research and the diffusion of knowledge, have been the prime factors that enabled the earlier European take-off and the great technological divergence across the globe. ${ }^{147}$

The effect of geographical factors on economic growth and the great divergence have been emphasized by Jones (1981), Diamond (1997) and Gallup, Sachs, and Mellinger (1998). ${ }^{148}$ The geographical hypothesis suggests that advantageous geographical conditions made Europe less vulnerable to the risk associated with climate and diseases, leading to the early European take-off, whereas adverse geographical conditions (e.g. harsh climate, prevalence of diseases, scarcity of natural resources, high transportation costs, limited regional diffusion of knowledge and technology) in disadvantageous regions, generated permanent hurdles for the process of development, contributing to the great divergence. ${ }^{149}$

\footnotetext{
${ }^{147}$ Barriers to technological adoption that may lead to divergence are explored by Caselli and Coleman (2002), Howitt and Mayer-Foulkes (2002) and Acemoglu, Aghion and Zilibotti (2003) as well.

${ }^{148}$ See Hall and Jones (1999), Masters and McMillan (2001) and Hibbs and Olson (2004) as well.

${ }^{149}$ Bloom, Canning and Sevilla (2003) cross section analysis rejects the geographical determinism, but maintain nevertheless that favorable geographical conditions have mattered for economic growth since they increase the likelihood of an
} 
Recent research by Engerman and Sokoloff (2000) and Acemoglu, Johnson and Robinson (2002) propose that initial geographical conditions had a persistent effect on the quality of institutions, leading to divergence and overtaking in economic performance. Engerman and Sokolof (2000) provide descriptive evidence that geographical conditions that led to income inequality, brought about oppressive institutions designed to preserve the existing inequality, whereas geographical characteristics that generated an equal distribution of income led to the emergence of growth promoting institutions. Acemoglu, Johnson and Robinson (2002) provide evidence that reversals in economic performance across countries have a colonial origin, reflecting institutional reversals that were introduced by European colonialism across the globe. ${ }^{150}$ "Reversals of fortune" reflect the imposition of extractive institutions by the European colonialists in regions in which favorable geographical conditions led to prosperity, and the implementation of growth enhancing institutions in poorer regions. ${ }^{151}$

Furthermore, the role of ethnic, linguistic, and religious fractionalization in the emergence of divergence and "growth tragedies" has been linked to their effect on the quality of institutions. Easterly and Levine (1997) and Alesina et al. (2003) demonstrate that geopolitical factors brought about a high degree of fractionalization in some regions of the world, leading to the implementation of institutions that are not conducive for economic growth and thereby to diverging growth paths across regions.

Empirical research suggests that indeed initial geographical conditions affected the current economic performance primarily via their effect on institutions. Acemoglu, Johnson and Robinson (2002), Easterly and Levine (2003), and Rodrik, Subramanian and Trebbi (2004) provide evidence that variations in the contemporary growth processes across countries can be attributed to institutional factors whereas geographical factors are secondary, operating primarily via variations in institutions.

A theory that unifies the geographical and the institutional paradigms, capturing the transition from the domination of the geographical factors in the determination of productivity in early stages of development to the domination of the institutional factors in mature stages of development has been proposed by Galor, Moav and Vollrath (2003). The theory identifies and establishes the empirical validity of a novel channel through which favorable geographical conditions that were inherently associated with inequality affected the emergence of human capital promoting institutions (e.g., public schooling, child labor regulations, abolishment of slavery, etc.), and thus the pace of the transition from an agricultural to an industrial society. ${ }^{152}$ They suggest that the distribution of land within and across countries affected the nature of the transition from an agrarian to an industrial economy, generating diverging growth patterns across countries. The accumulation of physical capital in the process of industrialization has raised the importance of human capital in the growth process, reflecting the complementarity between capital and skills. Investment in human capital, however, has been sub-optimal due to credit markets imperfections, and public investment in education has been growth enhancing. Nevertheless, human capital accumulation has not benefited all sectors of the economy. Due to a low degree of complementarity between human capital and land, universal public education has increased the cost of labor beyond the increase in average labor productivity in the agricultural sector, reducing the return to land. Landowners, therefore, had no economic incentives to support these growth enhancing educational policies as long as their stake in the productivity of the industrial sector was insufficient. Land abundance, which was beneficial in early stages of development, brought about a hurdle for human capital accu-

economy to escape a poverty trap.

${ }^{150}$ Additional aspects of the role of colonialism in comparative development are analyzed by Bertocchi and Canova (2002).

${ }^{151}$ Brezis, Krugman and Tsiddon (1993) attribute technological leapfrogging to the acquired comparative advantage (via learning by doing) of the current technological leaders in the use of the existing technologies.

${ }^{152}$ As established by Chanda and Dalgaard (2003), variations in the structural composition of economies and in particular the allocation of scarce inputs between the agriculture and the non-agriculture sectors are important determinants of international differences in TFP, accounting for between 30 and 50 percents of these variations. 
mulation and economic growth among countries that were marked by an unequal distribution of land ownership. ${ }^{153}$

\subsection{A Unified Theory - Globalization and the Great Divergence}

Unified theories of economic growth generate direct hypotheses about the factors that determine the timing of the transition from stagnation to growth and thus the factors that contributed to the Great Divergence. The timing of the transition may differ significantly across countries and regions due to historical accidents, as well as variation in geographical, cultural, social and institutional factors, trade patterns, colonial status, and public policy, that have affected the relationship between human capital formation and technological progress. ${ }^{154}$

This section explores a unified growth theory that generates a transition from stagnation to growth along with a great divergence, focusing on the asymmetric effect of globalization on the timing of the take-off from the Malthusian epoch of developed and less developed countries. Galor and Mountford (2003) suggest that sustained differences in income and population growth across countries may be attributed to the contrasting effect of international trade on industrial and non-industrial nations. Consistent with the evidence provided in section 2, their theory suggests that the expansion of international trade in the 19th century and its effect on the pace of individualization has played a major role in the timing of demographic transitions across countries and has thereby been a significant determinant of the distribution of world population and a prime cause of the 'Great Divergence' in income levels across countries in the last two centuries. International trade had an asymmetrical effect on the evolution of industrial and non-industrial economies. While in the industrial nations the gains from trade were directed primarily towards investment in education and growth in output per capita, a significant portion of the gains from trade in non-industrial nations was channeled towards population growth. ${ }^{155}$

In the second phase of the Industrial Revolution, international trade enhanced the specialization of industrial economies in the production of industrial, skilled intensive, goods. The associated rise in the demand for skilled labor has induced a gradual investment in the quality of the population, expediting a demographic transition, stimulating technological progress and further enhancing the comparative advantage of these industrial economies in the production of skilled intensive goods. In non-industrial economies, in contrast, international trade has generated an incentive to specialize in the production of unskilled intensive, non-industrial, goods. The absence of significant demand for human capital has provided limited incentives to invest in the quality of the population and the gains from trade have been utilized primarily for a further increase in the size of the population, rather than the income of the existing population. The demographic transition in these non-industrial economies has been significantly delayed, increasing further their relative abundance of unskilled labor, enhancing their comparative dis-

\footnotetext{
${ }^{153} \mathrm{An}$ alternative mechanism is explored by Berdugo, Sadik and Sussman (2003).

${ }^{154}$ Related to the unified paradigm, Pomeranz (2000) has suggested that the discovery of the New World enabled Europe, via Atlantic trade, to overcome 'land constraints' and to take-off technologically. The inflow of grain and other commodities as well as the outflow of migrants during the Nineteenth century may have played a crucial role in Europe's development. By easing the land constraint at a crucial point — when income per capita had begun to rise rapidly, but before the demographic transition had gotten under way - the "ghost acres" of the New World provided a window of time which allowed Europe to pull decisively away from the Malthusian equilibrium.

${ }^{155}$ In contrast to the recent literature on the dynamics of comparative advantage (e.g., Findlay and Kierzkowski (1983), Grossman and Helpman (1991) Matsuyama (1991), Young (1991), Mountford (1998), and Baldwin et. al (2001) the focus on the interaction between population growth and comparative advantage and the persistent effect that this interaction may have on the distribution of population and income in the world economy generates an important new insight regarding the distribution of the gains from trade. The theory suggests that even if trade affects output growth of the trading countries at the same rate, (due to the terms of trade effect) income per capita of developed and less developed economies will diverge since in less developed economies growth of total output will be generated primarily by population growth, whereas in developed economies it will be generated by an increase in output per capita.
} 
advantage in the production of skilled intensive goods and delaying their process of development. The research suggests, therefore, that international trade affected persistently the distribution of population, skills, and technologies in the world economy, and has been a significant force behind the 'Great Divergence' in income per capita across countries. ${ }^{156}$

The historical evidence described in section 2 suggests that the fundamental hypothesis of this theory is consistent with the process of development of the last two centuries. As implied by the trade patterns reported in Table 2.1, and the evolution of industrialization depicted in Figure 2.14, trade over this period induced the specialization of industrialized economies in the production of industrial goods whereas non-industrial economies specialize in the production of primary goods. The asymmetric effect of international trade on the process of industrialization of developed and less developed economies, as depicted in Figure 2.14, affected the demand for human capital as analyzed in section 2.3.3, and thus the timing of the demographic transition in developed and less-developed economies, generating a great divergence in output per capita as well as significant changes in the distribution of world population, as depicted in Figure 2.33. ${ }^{157}$

The diverging process of development of the UK and India since the 19th century in terms of the levels of income per capita and population growth is consistent with the theory of Galor and Mountford (2003) and provides an interesting case study. During the nineteenth century the UK traded manufactured goods for primary products with India. ${ }^{158}$ Trade with Asia constituted over $20 \%$ of UK total exports and $23.2 \%$ of total imports throughout the nineteenth century (Bairoch 1974). ${ }^{159}$ Consistent with the proposed hypothesis, as documented in Figure 2.14, industrialization in the UK accelerated, leading to a significant increase in the demand for skilled labor in the second phase of the Industrial Revolution, a demographic transition and a transition to a state of sustained economic growth.

For India, however, international trade played the reverse role. The period 1813-1850 was characterized by a rapid expansion in the volume of exports and imports which gradually transformed India from being an exporter of manufactured products - largely textiles - into a supplier of primary commodities (Chaudhuri 1983). Trade with the UK was fundamental in this process, with the UK supplying over two thirds of its imports for most of the nineteenth century and being the market for over a third of India's exports. As depicted in Figure 2.14, the rapid industrialization in the UK in the nineteenth century was associated with a decline in the per capita level of industrialization in India. ${ }^{160}$ The delay in the process of industrialization and consequently the lack of demand for skilled labor delayed the de-

\footnotetext{
${ }^{156}$ Consistent with the thesis that human capital has reinforced the existing patterns of comparative advantage, Taylor (1999) argues that human capital accumulation during the late Nineteenth Century was not a source of convergence even among the advanced ' Greater Atlantic' trading economies. The richer economies - U.S.A. and Australia - had greater levels of school enrollments than the poorer ones, Denmark and Sweden.

${ }^{157}$ Consistent with the viewpoint the trade has not been uniformly beneficial across time and regions, recent research by Rodriguez and Rodrik (2001) has indicated that the relationship between openness and growth changed in the last century. Moreover, Clemens and Williamson (2004) find a positive relationship between average tariff levels and growth for the period 1870-1913 and a negative relationship for the period 1970-1998. Similarly Vamvakadis (2002) finds a positive relationship between several measures of openness and growth after 1970 and some evidence of a negative relationship in the period 1870-1910.

${ }^{158}$ The colonial power of the UK may have encouraged the specialization of India in the production of primary goods beyond the degree dictated by market forces. However, these forces would have just reinforced the adverse effects described in this paper.

${ }^{159}$ In contrast, trade with Asia constituted only $5 \%$ or less of French, German or Italian exports and $12.1 \%$ of total imports of continental Europe.

${ }^{160}$ Furthermore, Bairoch (1974) found that industries that employed new technologies made up between 60 and 70 percent of the UK manufacturing industry in 1860 but less than 1 percent of manufacturing industries in the developing countries. This contrasts with the experience of the non-UK European economies which produced more of the 'new technology' goods and which traded with themselves to a greater extent, (Bairoch, 1974).
} 
mographic transition and the process of development. ${ }^{161}$ Thus, while the gains from trade were utilized in the UK primarily towards an increase in output per capita, in India they were channeled towards an increase in the size of the population. The ratio of output per capita in the UK relative to India grew from 3:1 in 1820 to 11:1 in 1998, whereas the ratio of India's population relative to the UK's population grew from 8:1 in 1870 to $16: 1$ in $1998 .^{162}$

\section{Concluding Remarks}

The transition from stagnation to growth and the associated phenomenon of the great divergence have been the subject of an intensive research in the growth literature in recent years. The discrepancy between of exogenous and endogenous neoclassical growth models and the process of development along most of human history, induced growth theorists to advance an alternative theory that captures in a single unified framework the contemporary era of sustained economic growth, the epoch of Malthusian stagnation that had characterized most of human history, and the fundamental driving forces of the recent transition between these distinct regimes.

The understanding of the contemporary growth process is fragile and incomplete unless growth theory would be based on proper micro-foundations that would reflect the qualitative aspects of the growth process in its entirety. Moreover, a comprehensive understanding of the hurdles faced by less developed economies in reaching a state of sustained economic growth would be futile unless the origin the transition of the currently developed economies into a state of sustained economic growth would be identified and their implications would be modified to account for the differences in the structure of less developed economies in an interdependent world.

Imposing the constraint that a single unified theory account for the entire intricate process of development in the last thousands of years is a discipline that enhances the viability of growth theory. A unified theory of economic growth reveals the underlying micro foundations that are consistent with the process of economic development along the entire spectrum of human history, rather than with the last century only, enhancing the confidence in the viability of growth theory, its predictions and policy implications, while improving the understanding of the sources of the recent transition from stagnation to growth and the associated phenomenon of the great divergence.

Unified growth theory suggests that the transition from stagnation to growth is an inevitable by-product of the inherent Malthusian interaction between population and technology and its ultimate impact on the demand for human capital and thereby on the onset of the demographic transition . Variations in the timing of the transition across countries and regions reflect initial differences in geographical

\footnotetext{
${ }^{161}$ Unlike the rise in the industrial demand for education in the UK, education was not expanded to a similar degree in India in the 19th Century. As noted by Aparna Basu (1974), during the nineteenth century the state of education in India was characterized by a relatively large university sector, aimed at producing skilled bureaucrats rather than industrialists, alongside widespread illiteracy of the masses. The literacy rate was very low, (e.g., 10\% in Bengal in 19178 ) but nevertheless, attempts to expand primary education in the twentieth century were hampered by poor attendance and high drop out rates, which may suggest that the rate of return to education was relatively low. The lack of broad based education in India can also be seen using the data of Barro and Lee (2000). Despite an expansion of education throughout the twentieth century Barro and Lee report that in 196072.2 percent of Indians aged 15 and above had "no schooling" compared with 2 percent in the UK.

${ }^{162}$ Another interesting case study providing supporting evidence for the proposed hypothesis is the economic integration of the Israeli and the West Bank economies in the aftermath of the 1967 war. Trade and factor mobility between the skilled abundant economy of Israel and the unskilled abundant economy of the West Bank shifted the West Bank economy toward further specialization in the production of primary goods, and possibly triggered the astonishing increase in crude births rates from 22 per 1000 people in 1968 to 42 per 1000 in 1990, despite a decline in mortality rates. The gains from trade and development in the West Bank economy were converted primarily into an increase in population size, nearly doubling the population in those two decades. Estimates of the growth rates of output per capita over this period are less reliable and suggest that the increase was about 30\%. Consistent with the proposed theory, the Palestinian uprising in the early 1990s and the gradual disintegration of the two economies resulted in the reduction in the crude birth rates.
} 
factors and historical accidents and their manifestation in variations in institutional, demographic, and cultural factors, trade patterns, colonial status, and public policy. 


\section{References}

[1] Abramowitz, M. (1993), "The Search of the Sources of Growth: Areas of Ignorance, Old and New", Journal of Economic History 53: 217-243.

[2] Abramovitz, M., and P.A. David, (2000), "American Macroeconomic Growth in the Era of Knowledge-Based Progress: The Long-Run Perspective", in: S.L. Engerman, and R.E. Gallman, eds., The Cambridge Economic History of the United States, Volume 2 (Cambridge University Press, New York).

[3] Acemoglu, D. P. Aghion and F. Zilibotti (2003), "Distance to Frontier, Selection, and Economic Growth," MIT.

[4] Acemoglu, D., S. Johnson and J. Robinson (2002), "Reversal of Fortune: Geography and Institutions in the Making of the Modern World Income Distribution", Quarterly Journal of Economics 117: $1231-1294$.

[5] Acemoglu, D., S. Johnson and J. Robinson (2003). "The Rise of Europe: Atlantic Trade, Institutional Change and Economic Growth", MIT.

[6] Acemoglu, D., and J.A. Robinson (2000), "Why Did the West Extend the Franchise? Democracy, Inequality and Growth in Historical Perspective", Quarterly Journal of Economics 115: 1167-1199.

[7] Acemoglu, D., and F. Zilibotti (1997), "Was Prometheus Unbound by Chance? Risk, Diversification, and Growth", Journal of Political Economy 105: 709-751.

[8] Aghion, P., and P. Howitt (1992), "A Model of Growth through Creative Destruction", Econometrica 60: 323-351.

[9] Alesina, A., A Devleeschauwer, W. Easterly, S. Kurlat and R. Wacziarg (2003), "Fractionalization," Journal of Economic Growth, 8; 155-194.

[10] Allen, R. (2000), "Economic Structure and Agricultural Productivity in Europe 1300-1800," European Review of Economic History, 1-25.

[11] Anderson, R. D. (1975), Education in France 1848-1870 (Clarendon Press, Oxford).

[12] Azariadis, C. (1996), "The Economics of Poverty Traps," Journal of Economic Growth," 1: 449486.

[13] Baldwin, R.E., M. Philippe and G.I.P. Ottaviano (2001), "Global Income Divergence, Trade and Industrialization: The Geography of Growth Take-Offs", Journal of Economic Growth 6: 5-37.

[14] Bairoch, P. (1974), "Geographical Structure and Trade Balance of European Foreign Trade From 1800-1970", Journal of European Economic History 3: 557-608.

[15] Bairoch, P. (1982), "International Industrialization Levels from 1750-1980", Journal of European Economic History 11: 269-333.

[16] Bairoch, P. (1988). Cities and Economic Development (The University of Chicago Press, Chicago).

[17] Barro, R.J., and G.S. Becker (1989), "Fertility Choice in a Model of Economic Growth", Econometrica 57: 481-501.

[18] Barro R.J., and J. Lee (2000), "International Data on Educational Attainment: Updates and Implications", Harvard University.

[19] Barro, R.J., and X. Sala-i-Martin (2003), Economic Growth (MIT Press, Cambridge).

[20] Basu, A. (1974), The Growth of Education and Political Development in India 1898-1920 (Oxford University Press, Oxford).

[21] Becker, G.S. (1981), A Treatise on the Family (Harvard University Press, Cambridge).

[22] Becker, G.S. H.G. Lewis (1973), "On the Interaction between the Quantity and Quality of Children", Journal of Political Economy 81: S279-S288. 
[23] Becker, G.S., K. Murphy and R. Tamura (1990),. "Human Capital, Fertility, and Economic Growth," Journal of Political Economy, October 98: S12-S37.

[24] Benabou, R. (2000), "Unequal Societies: Income Distribution and the Social Contract", American Economic Review 90: 96-129.

[25] Ben Porath, Y. (1967), "The Production of Human Capital and the Life Cycle of Earnings," Journal of Political Economy, 75: 352-65.

[26] Berdugo, B., J. Sadik and N. Sussman (2003) "Delays in Technology Adoption, Appropriate Human Capital, Natural Resources and Growth" Hebrew University.

[27] Berghahn, V. R. (1994), Imperial Germany, 1871-1914: Economy, Society, Culture and Politics (Berghahn Books,Providence).

[28] Bertocchi, G. (2003), "The Law of Primogeniture and the Transition from Landed Aristocracy to Industrial Democracy", CEPR Discussion Paper 3723.

[29] Bertocchi, G. and F. Canova (2002), "Did Colonization Matter for Growth? An Empirical Exploration into the Historical Causes of Africa's Underdevelopment," European Economic Review 46: 1851-1871.

[30] Bertocchi, G. and M. Spagat, (2004), "The Evolution of Modern Educational Systems: Technical vs. General Education, Distributional Conflict, and Growth," Journal of Development Economics, 73: 559-582.

[31] Bisin, A., and T. Verdier (2000), "Beyond the Melting Pot: Cultural Transmission, Marriage, and the Evolution of Ethnic and Religious Traits", Quarterly Journal of Economics 115: 955-988.

[32] Bloom, D. E., D. Canning, and J. Sevilla (2003), "Geography and Poverty Traps," Journal of Economic Growth 4, 355-378.

[33] Bloom, D. and J. G. Williamson (1998), Demographic Transition and Economic Miracles in Emerging Asia, World Bank Economic Review 12: 419-455.

[34] Boldrin, M. and L. Jones (2002), "Mortality, Fertility, and Saving in a Malthusian Economy," Review of Economic Dynamics 5: 775-814.

[35] Boserup, E., (1965). The Conditions of Agricultural Progress, (Aldine Publishing Company, Chicago).

[36] Boucekkine, R, D. de la Croix and O. Licandro.(2003), "Early Mortality Declines at the Dawn of Modern Growth," Scandinavian Journal of Economics, 105: 401-418.

[37] Bourguignon, F., and T. Verdier (2000), "Oligarchy, Democracy, Inequality and Growth", Journal of Development Economics 62: 285-313.

[38] Bowen, J. (1981), A History of Western Education. Vol. 3: The Modern West Europe and the New World (St. Martin's Press, New York).

[39] Bowles, S. (1998), "Endogenous Preferences: The Cultural Consequences of Markets and other Economic Institutions," Journal of Economic Literature 36: 75-111.

[40] Bowles, S., and H. Gintis (1975), "Capitalism and Education in the United States", Socialist Revolution 5: 101-138.

[41] Boyd, R., and P.J. Richardson (1985), Culture and the Evolutionary Process (University of Chicago Press, Chicago).

[42] Boyer, G. (1989), "Malthus was Right After All: Poor Relief and Birth Rates in South-Eastern England", Journal of Political Economy 97: 93-114.

[43] Brezis, E. S , P. R Krugman, and D. Tsiddon (1993). "Leapfrogging in International Competition: A Theory of Cycles in National Technological Leadership," American Economic Review, 83: 12111219. 
[44] Browning, M., L.P. Hansen and J.J. Heckman (1999), "Micro Data and General Equilibrium Models", in J. Taylor and M. Woodford (eds.),Handbook of Macroeconomics (North-Holland, Amsterdam).

[45] Caldwell, W. J, (1976), "Toward a Restatement of Demographic Transition Theory", Population and Development Review 2: 321-66.

[46] Caselli, F., (1999), "Technological Revolutions" American Economic Review 89: 78- 102.

[47] Caselli, F. and J. Coleman (2002), "The World Technological Frontier," Harvard University.

[48] Cavalcanti, T., and J. Tavares, (2003), "Women Prefer Larger Governments: Female Labor Supply and Public Spending," University Nova de Lisboa.

[49] Cavalli-Sforza, L.L., and M.W. Feldman (1981), Cultural Transmission and Evolution: A Quantitative Approach (Princeton University Press, Princeton).

[50] Cervellati, M. and U. Sunde (2003), "Human Capital Formation, Life Expectancy and the Process of Development," Iza.

[51] Chanda, A. and C.-J. Dalgaard (2003), "Dual Economies and International Total Factor Productivity Differences," University of Copenhagen

[52] Chaudhuri, K.N. (1966), "India's Foreign Trade and the Cessation of the East India Company's Trading Activities, 1828:40", Economic History Review 19: 345-363.

[53] Chaudhuri, K.N. (1983), "Foreign Trade and Balance of Payments (1757-1947)", in: D. Kumar, ed., The Cambridge Economic History of India (Cambridge University Press, Cambridge).

[54] Chesnais, J., (1992), "The Demographic Transition: Stages, Patterns and Economic Implications" (Clarendon Press, Oxford).

[55] Cipolla, (1969),. Literacy and Development in the West (Penguin Books, Harmondsworth, Middlesex)

[56] Clark, G. (1987), "Why Isn't the Whole World Developed?: Lessons from the Cotton Mills", Journal of Economic History 47: 141-174.

[57] Clark, G. (1991), "Labour Productivity in English Agriculture, 1300-1860", in: B.M.S. Campbell and M. Overton, eds., Agricultural Productivity in the European Past (Manchester University Press, Manchester).

[58] Clark (2001), "The Secret History of the Industrial Revolution." UC Davis.

[59] Clark, G. (2002), "Farmland Rental Values and Agrarian History: England and Wales, 1500-1912", European Review of Economic History 6: 281:308.

[60] Clark, G. (2003), "The Condition of the Working-Class in England, 1200-2000: Magna Carta to Tony Blair", UC Davis.

[61] Clark, G. and G. Hamilton (2003) "Survival of the Fittest? Capital, Human Capital, and Reproduction in European Society before the Industrial Revolution" UC Davis.

[62] Clemens, M.A., and J.G. Williamson (2004), "Why Did The Tariff-Growth Correlation Reverse After 1950?", Journal of Economic Growth, 9, 5-46.

[63] Coale, A.J., and R. Treadway (1986), "A Summary of the Changing Distribution of Overall Fertility, Marital Fertility, and the Proportion Married in the Provinces of Europe", in: A J. Coale and S. Watkins, eds., The Decline of Fertility in Europe (Princeton University Press, Princeton).

[64] Coatsworth, J. H. (1993), "Notes on the Comparative Economic History of Latin America and the United States." In Bernecker, W. and H. W. Tobler, Eds. Development and Underdevelopment in America (Walter de Gruyter, New York).

[65] Cody, M.L. (1966), "A General Theory of Clutch Size", Evolution 20: 174-184. 
[66] Connolly, M. and P. F. Peretto (2003), "Industry and the Family: Two Engines of Growth," Journal of Economic Growth 8: 115-148.

[67] Crafts, N.F.R (1985), British Economic Growth during the Industrial Revolution (Oxford University Press, Oxford).

[68] Crafts, N.F.R., and C.K. Harley (1992)), "Output Growth and the Industrial Revolution: A Restatement of the Crafts-Harley View", Economic History Review 45: 703-730.

[69] Craig, F.W.S. (1989), British Electoral Facts, 1832-1987 (Gower Press, Brookfield).

[70] Cressy, D. (1980), Literacy and the Social Order: Reading and Writing in Tudor and Stuart England, (Cambridge University Press, Cambridge).

[71] Cressy, D. (1981), "Levels of Illiteracy in England 1530-1730", in Graff H. J. ed. Literacy and Social Development in the West: A Reader, (Cambridge University Press, Cambridge).

[72] Cubberly, E.P. (1920), The History of Education.(Cambridge University Press, Cambridge).

[73] Dahan, M., and D. Tsiddon (1998), "Demographic Transition, Income Distribution, and Economic Growth", Journal of Economic Growth 3: 29-52.

[74] Dalgaard C-J., and C. T. Kreiner (2001), "Is Declining Productivity Inevitable?" Journal of Economic Growth, 6: 187-204.

[75] Darwin, C, (1859), On the Origin of Species by Means of Natural Selection (John Murray, London).

[76] Darwin, C. (1871), The Descent of Man, and Selection in Relation to Sex (John Murray, London).

[77] Dawkins, R. (1989), The Selfish Gene (Oxford University Press, Oxford).

[78] De la Croix D. and M. Doepke (2003), "Inequality and Growth: Why Differential Fertility Matters, "American Economic Review, 93: 1091-1113.

[79] Deninger K, and Squire, L (1998), "New Ways of Looking at Old Issues: Inequality and Growth", Journal of Development Economics, 57: 259-287.

[80] De Vries, J. (1984). European Urbanization, 1500-1800 (Harvard University Press, Cambridge).

[81] Diamond, J. (1997), Guns, Germs, and Steel: The Fates of Human Societies. (Norton, New York).

[82] Doepke, M. (2004), "Accounting for Fertility Decline During the Transition to Growth", Journal of Economic Growth 9:

[83] Doepke, M (2005) "Child Mortality and Fertility Decline: Does the Barro-Becker Model Fit the Facts?," Journal of Population Economics (forthcoming).

[84] Doepke, M. and F. Zilibotti (2003) "The Macroeconomics of Child Labor Regulation," IIES, Stockholm University.

[85] Doms, M., T. Dunne and K.R. Troske (1997), "Workers, Wages and Technology", Quarterly Journal of Economics 112: 253-290.

[86] Duffy, J., C. Papageorgiou and F. Perez-Sebastian, (2004), Capital-Skill Complementarity? Evidence from a Panel of Countries, Review of Economic and Statistics.

[87] Durham, W. (1982), "Interaction of Genetic and Cultural Evolution: Models and Examples", Human Ecology 10: 289-323.

[88] Durlauf, S. N. (1996), "A Theory of Persistent Income Inequality," Journal of Economic Growth, 1: $75-94$.

[89] Durlauf, S.N. and P. A. Johnson (1995), "Multiple Regimes and Cross-Country Growth Behavior," Journal of Applied Econometrics 10: 365-84."

[90] Durlauf, S.N. and D. Quah (1999), "The New Empirics of Economic Growth" in Handbook of Macroeconomics, J. B. Taylor and M. Woodford (eds.), (North-Holland, Amsterdam). 
[91] Dyson, T., and M. Murphy (1985), "The Onset of Fertility Transition", Population and Development Review 11: 399-440.

[92] Eckstein, Z., P. Mira and K. I. Wolpin.(1999), "A Quantitative Analysis of Swedish Fertility Dynamics:1751-1990." Review of Economic Dynamics 2: 137-165.

[93] Easterlin, R. (1981), "Why Isn't the Whole World Developed?", Journal of Economic History 41: $1-19$.

[94] Easterly, W. and R. Levine (1997), "Africa's Growth Tragedy: Policies and Ethnic Divisions," Quarterly Journal of Economics 111: 1203-1250.

[95] Easterly, W. and R. Levine (2003), "Tropics, germs, and crops: the role of endowments in economic development", Journal of Monetary Economics, 50: 3-39.

[96] Edlund, L. and N-P. Lagerlof (2002), "Implications of Marriage Institutions for Redistribution and Growth," Columbia University.

[97] Endler, J.A. (1986), Natural Selection in the Wild (Princeton University Press, Princeton).

[98] Engerman, S., and K.L. Sokoloff (2000), "Factor Endowment, Inequality, and Paths of Development Among New World Economies", UCLA.

[99] Erlich, I., and F. T. Lui (1991), "Intergenerational trade, Longevity, and Economic Growth," Journal of Political Economy 99: 1029-1059.

[100] Estavadeordal, A., B. Frantz and A.M. Taylor (2002), "The Rise and Fall of World Trade, 18701939", Quarterly Journal of Economics118: 359-407.

[101] Estavadeordal, A., and A.M. Taylor (2002), "A Century of Missing Trade", American Economic Review 92: 383-393.

[102] Estevo, G. (1983), The Struggle for Rural Mexico. (Bergin and Garvey, South Hadley, MA)..

[103] Feinstein, C.H. (1972), National Income, Expenditure and Output of the United Kingdom 18551965, (Cambridge University Press, Cambridge).

[104] Fernandez, R., A. Fogli and C. Olivetti (2004), "Mothers and Sons: Preference Formation and Female Labor Force Dynamics," Quarterly Journal of Economics 119.

[105] Fernandez, R., and R. Rogerson (1996): "Income Distribution, Communities, and the Quality of Public Education," Quarterly Journal of Economics, 111: 135-164.

[106] Fernandez-Villaverde J. (2003), "Was Malthus Right? Economic Growth and Population Dynamics", University of Pennsylvania.

[107] Feyrer, J. (2003), "Convergence by Parts," Dartmouth College.

[108] Fiaschi D. and A. M. Lavezzi (2003), "Distribution Dynamics and Nonlinear Growth," Journal of Economic Growth 4: 379-402.

[109] Field, A. (1976), "Educational Reform and Manufacturing Development in Mid-Nineteenth Century Massachusetts", Journal of Economic History 36: 263-266.

[110] Findlay, R., and H. Keirzkowsky (1983), "International Trade and Human Capital: A simple General Equilibrium Model", Journal of Political Economy 91: 957-978

[111] Findlay, R., and K.H. O'Rourke (2003), "Commodity Market Integration, 1500-2000", in: M.D. Bordo, A.M. Taylor and J.G. Williamson, eds., Globalization in Historical Perspective (The University of Chicago Press, Chicago).

[112] Flora, P., F. Kraus and W. Pfenning (1983), State, Economy and Society in Western Europe 1815-1975, Vol. I. (St. James Press, Chicago).

[113] Fogel, R. W.(1994), "Economic Growth, Population Theory, and Physiology: The Bearing of Long-Term Processes on the Making of Economic Policy," American Economic Review 84: 36995. 
[114] Foster, A.D., and M.R. Rosenzweig (1996), "Technical Change and Human-Capital Returns and Investments: Evidence from the Green Revolution", American Economic Review 86: 931-953.

[115] Galor, O. (1996), "Convergence?: Inferences from Theoretical Models," Economic Journal, 106: 1056-1069.

[116] Galor, O., and O. Moav (2000), "Ability Biased Technological Transition, Wage Inequality and Growth", Quarterly Journal of Economics 115: 469-498.

[117] Galor, O., and O. Moav (2002), "Natural Selection and the Origin of Economic Growth", Quarterly Journal of Economics 117: 1133-1192.

[118] Galor, O., and O. Moav (2003), "Das Human Kapital: A Theory of the Demise of the Class Structure", Brown University.

[119] Galor, O., and O. Moav (2004a), "From Physical to Human Capital Accumulation: Inequality and the Process of Development", Review of Economic Studies,

[120] Galor, O., and O. Moav (2004b), "Natural Selection and the Evolution of Life Expectancy," Hebrew University.

[121] Galor, O., O. Moav and D. Vollrath (2003), "Land Inequality and the Origin of Divergence and Overtaking in the Growth Process: Theory and Evidence," Brown University.

[122] Galor, O., and A. Mountford, (2003), "Trading Population for Productivity," Brown University.

[123] Galor, O., and D. Tsiddon (1997), "Technological Progress, Mobility, and Growth", American Economic Review 87: 363-382.

[124] Galor, O., and D.N. Weil (1996), "The Gender Gap, Fertility, and Growth", American Economic Review 86: 374-387.

[125] Galor, O., and D.N. Weil (1999), "From Malthusian Stagnation to Modern Growth", American Economic Review, 89: 150-154.

[126] Galor, O., and D.N. Weil (2000), "Population, Technology and Growth: From the Malthusian regime to the Demographic Transition", American Economic Review 110: 806-828.

[127] Galor, O., and J. Zeira (1993), "Income Distribution and Macroeconomics", Review of Economic Studies 60: 35-52.

[128] Gallup, J. L., J. D. Sachs, and A. D. Mellinger, "Geography and Economic Development," NBER Working Paper No. w6849, December 1998.

[129] Goldin, C. (1990), Understanding The Gender Gap: An Economic History of American Women. (Oxford University Press, New York)

[130] Goldin, C. (2001), "The Human Capital Century and American Leadership: Virtues of the Past", Journal of Economic History 61: 263-292.

[131] Goldin, C., and L.F. Katz (1998), "The Origins of Technology-Skill Complementarity", Quarterly Journal of Economics 113: 693-732.

[132] Goldin, C., and L.F. Katz (2001), "On the Legacy of U.S. Educational Leadership: Notes on Distribution and Economic Growth in the 20th Century", American Economic Review 91: 18-23.

[133] Goodfriend, M., and J. McDermott (1995), "Early Development", American Economic Review 85: $116-133$.

[134] Gould, E.D., O. Moav and A. Simhon (2003), "The Mystery of Monogamy," Hebrew University.

[135] Gould, S.J. (1977), Ever Since Darwin (Norton, New York).

[136] Grant, B.R., and P.R. Grant (1989), Evolutionary Dynamics of a Natural Population (University of Chicago Press, Chicago).

[137] Green, A. (1990), Education and State Formation (St. Martin's Press, New York). 
[138] Greenwood, J., and A. Seshadri (2002), "The U.S. Demographic Transition," American Economic Review 92: 153-159.

[139] Grossman, G.M., and E. Helpman (1991), Innovation and Growth (MIT Press, Cambridge).

[140] Grossman, H. I., and M. Kim (1999), "Education Policy: Egalitarian or Elitist?" Economics and Politics 15: 225-246.

[141] Gylfason T. (2001). "Natural Resources, Education, and Economic Development," European Economic Review 45: 847-859.

[142] Hansen, G., and E. Prescott (2002), "Malthus to Solow", American Economic Review 92: 12051217.

[143] Hansson, I., and C. Stuart (1990), "Malthusian Selection of Preferences", American Economic Review 80: 529-544.

[144] Hanushek, E.A. (1992), "The Trade-Off between Child Quantity and Quality", Journal of Political Economy 100: 84-117.

[145] Hassler, J., and J.V. Rodriguez Mora (2000), "Intelligence, Social Mobility, and Growth", American Economic Review 90: 888-908.

[146] Hazan, M., and B. Berdugo (2002), "Child Labor, Fertility and Economic Growth," Economic Journal, 112: 810-828.

[147] Hazan, M., and H. Zoabi (2004). "Does Longevity Cause Growth," Hebrew University.

[148] Hechter, M. (2001), Internal Colonialism Study: National Integration in the British Isles, 18511966 (Inter-University Consortium for Political and Social Research, Ann Arbor).

[149] Hernandez, D. J. (2000), Trends in the Well Being of America's Children and Youth. U.S. Bureau of the Census.

[150] U.S. Bureau of the Census, (1975), Historical Statistics of the United States: Colonial Times to 1970, Part 1, (Washington D.C.).

[151] Hibbs D. A., and O. Olson (2004), "Biogeography and Long-Run Economic Development", European Economic Review 48:

[152] Horrell, S., and J. Humphries (1995), "The Exploitation of Little Children": Child Labor and the Family Economy in the Industrial Revolution," Exploration in Economic History 32: 485-516

[153] Howitt, P., and D. Mayer-Foulkes (2002), "R\&D, Implementation and Stagnation: A Schumpeterian Theory of Convergence Clubs", Brown University.

[154] Hurt, J. (1971), Education in Evolution (Paladin, London).

[155] Iyigun, M. F. (2004), "Geography, Demography, and Early Development," Boulder.

[156] Jones C.I. (1997), "Convergence Revisited," Journal of Economic Growth, 2: 131-154.

[157] Jones C.I. (2001), "Was an Industrial Revolution Inevitable? Economic Growth Over the Very Long Run" Advances in Macroeconomics 1: 1-43.

[158] Jones, E.L. (1981), The European Miracle: Environments, Economies and Geopolitics in the History of Europe and Asia (Cambridge University Press, Cambridge).

[159] Kalemli-Ozcan, S. (2002), "Does the Mortality Decline Promote Economic Growth," Journal of Economic Growth 7: 411-439.

[160] Kalemli-Ozcan, S., H.E. Ryder and D. N. Weil (2000), "Mortality Decline,Human Capital Investment,and Economic Growth" Journal of Development Economics, 62: 1-23

[161] Kaplan, H.S. (1994), "Evolutionary and Wealth Flows of Fertility - Empirical Tests and new Models", Population and Development Review 20: 753-791.

[162] Kettlewell, H.B.D. (1973), The Evolution of Melanism (Clarendon Press, Oxford). 
[163] Knick, H.C. (1999), "Reassessing the Industrial Revolution: a Macro View ", in: J. Mokyr, ed., The British Industrial Revolution: an Economic Perspective (Westview Press, Boulder).

[164] Kogel, T., and A. Prskawetz. (2001), "Agricultural Productivity Growth and Escape from Malthusian Trap", Journal of Economic Growth 6: 337-357.

[165] Kohler, H., J.L. Rodgers and K. Christensen (1999), "Is Fertility Behavior in our Genes? Findings from a Danish Twin Study", Population and Development Review 25: 253-263.

[166] Komlos, J. and M. Artzrouni (1990), "Mathematical Investigations of the Escape from the Malthusian Trap", Mathematical Population Studies 2: 269-287.

[167] Kremer, M. (1993), "Population Growth and Technological Change: One Million B.C. to 1990," Quarterly Journal of Economics 108: 681-716.

[168] Kremer, M. and D. L. Chen (2002), "Income Distribution Dynamics with Endogenous Fertility," Journal of Economic Growth 7: 227-258

[169] Krugman, P., and A. Venables (1995), "Globalization and the inequality of nations", Quarterly Journal of Economics 90: 857-880.

[170] Kuhn, T.S., (1957), The Copernican Revolution, (Cambridge, MA)

[171] Kurian, G.T. (1994), Datapedia of the U.S. 1790-2000, America Year by Year (Bernan Press, Lonham).

[172] Kuznets, S. (1967), "Quantitative Aspects of the Economic Growth of Nations : X. Level and Structure of Foreign Trade: Long-Term Trends", Economic Development and Cultural Change 15: $1-140$.

[173] Kuzynski, R. R. (1969), The Measurement of Population Growth, (Gordon and Breach Science Publishers, New York).

[174] Lack, D. (1954), The Natural Regulation of Animal Numbers (Clarendon Press, Oxford).

[175] Lagerlof, N., (2003a), "From Malthus to Modern Growth: The Three Regimes Revisited", International Economic Review 44: 755-777.

[176] Lagerlof, N. (2003b), "Gender Equality and Long-Run Growth," Journal of Economic Growth, 8: 403-426.

[177] Landes, D.S. (1969), The Unbound Prometheus. Technological Change and Industrial Development in Western Europe from 1750 to the Present (Cambridge University Press, Cambridge).

[178] Landes, D. S. (1998), The Wealth and Poverty of Nations (Norton, New York).

[179] Lee, C. (1979), British Regional Employment Statistics,1841-1971 (Cambridge University Press, Cambridge).

[180] Lee, R.D. (1997), "Population Dynamics: Equilibrium, Disequilibrium, and Consequences of Fluctuations", in: O. Stark and M. Rosenzweig, eds., The Handbook of Population and Family Economics (Elsevier, Amsterdam).

[181] Levy-Leboyer, M., and F. Bourguignon (1990), The French Economy in the Nineteenth Century (Cambridge University Press, Cambridge).

[182] Lewis, W.A. (1954), "Economic Development with Unlimited Supply of Labor", The Manchester School 22: 139-191.

[183] Lindert, P.H., and J.G. Williamson (1976), "Three Centuries of American Inequality", Research in Economic History 1: 69-123.

[184] Livi-Bacci, M. (1997), A Concise History of World Population (Blackwel, Oxford).

[185] Livingston F, (1958), "Anthropological Implications of Sickle Cell Distribution in West Africa", American Anthropologist 60: 533-562. 
[186] Lucas, R.E. (2002), The Industrial Revolution: Past and Future (Harvard University Press, Cambridge).

[187] MacArthur, R.H., and E.O. Wilson (1967), The Theory of Island Biogeography (Princeton University Press, Princeton).

[188] Maddison, A. (2001), The World Economy: A Millennia Perspective (OECD, Paris).

[189] Maddison, A. (2003), The World Economy: Historical Statistics CD-ROM (OECD, Paris).

[190] Malthus, T.R. (1798), An Essay on the Principle of Population (printed for J. Johnson, in St. Paul's Church-Yard, London).

[191] Masters, W.E., and M.S. McMillan (2001), "Climate and Scale in Economic Growth," Journal of Economic Growth 6: 167-187.

[192] Matsuyama, K. (1992), "Agricultural Productivity, Comparative Advantage, and Economic Growth", Journal of Economic Theory 58: 317-334.

[193] Matthews, R.C., C.H. Feinstein and J.C. Odling-Smee (1982), British Economic Growth 1856-1973 (Stanford University Press, Stanford).

[194] McClelland, C.E. (1980), State, Society, and University in Germany: 1700-1914 (Cambridge University Press, Cambridge).

[195] McCloskey, D.N. (1981), "The Industrial Revolution, A Survey", in: R.C. Floud and D.N. McCloskey, eds., The Economic History of Britain Since 1700 Vol 1 (Cambridge University Press, Cambridge).

[196] McDermott, J. (2002), "Development Dynamics: Economic Integration and the Demographic Transition", Journal of Economic Growth 7:371-410.

[197] McEvedy, C., and R. Jones (1978), Atlas of World Population History (Penguin, London).

[198] Menchik, P., and M. David (1983), "Income Distribution, Lifetime Savings, and Bequests", American Economic Review 73: 672-690.

[199] Mitch, D. (1992), The Rise of Popular Literacy in Victorian England: The Influence of Private Choice and Public Policy (University of Pennsylvania Press, Philadelphia).

[200] Mitch, D. (1993), "The Role of Human Capital in the First Industrial Revolution", in: J. Mokyr, ed., The British Industrial Revolution: An Economic Perspective (Westview Press, Boulder).

[201] Mitch, D. (2001), "The Rise of Mass Education and Its contribution to economic Growth in Europe, 1800-2000", mimeo (University of Maryland Baltimore County).

[202] Mitchell, B. (1981), European Historical Statistics, 2nd ed., (New York).

[203] Moav, O. (2005), "Cheap Children and the Persistence of Poverty", Economic Journal, 114:

[204] Mokyr, J. (1985), Why Ireland Starved : A Quantitative and Analytical History of the Irish Economy, 1800-1850 (Allen and Unwin, London).

[205] Mokyr, J. (1990), The Lever of Riches (Oxford University Press, New York).

[206] Mokyr, J. (1993), "The New Economic History and the Industrial Revolution,” in: J. Mokyr, ed., The British Industrial Revolution: an Economic Perspective (Westview Press, Boulder).

[207] Mokyr, J. (2001), "The Rise and Fall of the Factory System: Technology, Firms, and Households since the Industrial Revolution", Carnegie-Rochester Conference Series On Public Policy 55: 1-45.

[208] Mokyr, J. (2002), The Gifts of Athena: Historical Origins of the Knowledge Economy (Princeton University Press, Princeton).

[209] Mookherjee, D., and D. Ray (2003), "Persistent Inequality", Review of Economic Studies 70: 369-393. 
[210] Morrisson, C., and W. Snyder (2000), "Income Inequalities in France from the Early Eighteenth Century to 1985", Revue Economique 51: 119-154.

[211] Mountford, A., (1998) "Trade, Convergence and Overtaking," Journal of International Economics, 46: $167-182$.

[212] Muller, D.K. (1987), "The Process of Systematization: the Case of German Secondary Education", in: D. Muller, F. Ringer and B. Simon, eds., The Rise of the Modern Educational System (Cambridge University Press, Cambridge).

[213] Neher, A.P. (1971), "Peasants, Procreation and Pensions," American Economic Review 61: 380389.

[214] Nelson, R.R., and E.S. Phelps (1966), "Investment in Humans, Technological Diffusion, and Economic Growth", American Economic Review 56: 69-75.

[215] North, D. C. (1981), Structure and Change in Economic History, (W.W. Norton \& Co., New York).

[216] O'Rourke, K.H., A.M. Taylor and J.G. Williamson (1996), "Factor Price Convergence in the Late Nineteenth Century", International Economic Review 37: 499-530.

[217] O'Rourke, K.H., and J.G. Williamson (1999), Globalization and History (MIT Press, Cambridge).

[218] O'Rourke, K.H., and J.G. Williamson (2003), "Malthus to Ohlin," Harvard University.

[219] Parente, S., and E.C. Prescott (2000), Barriers to Riches (MIT Press, Cambridge).

[220] Pereira, A.S. (2003), "When Did Modern Economic Growth Really Start? The Empirics of Malthus to Solow." UBC.

[221] Persson, T., and G. Tabellini (1994), "Is Inequality Harmful for Growth?", American Economic Review 84: 600-621.

[222] Pollard, S. (1963), "Factory Discipline in the Industrial Revolution", Economic History Review 16: 254-271.

[223] Pomeranz, K. (2000), The Great Divergence: China, Europe and the Making of the Modern World Economy (Princeton University Press, Princeton).

[224] Pritchett, L.(1997),. "Divergence, Big Time,". Journal of Economic Perspectives 11: 3-17.

[225] Przeworski, A. (2003), "The Last Instance:Are Institutions the Primary Cause of Economic Development?" Department of Politics, New York University.

[226] Psacharopoulos, G. and H. A. Patrinos (2002), "Returns to Investment in Education: A Further Update September 1, 2002," World Bank.

[227] Quah, D. (1996), "Convergence Empirics Across Economies with (some) Capital Mobility," Journal of Economic Growth, 1: 95-124.

[228] Quah, D. (1997), "Empirics for Growth and Distribution: Stratification, Polarization, and Convergence Clubs," Journal of Economic Growth, 2: 27-61.

[229] Razin, A., and U. Ben-Zion (1975), "An Intergenerational Model of Population Growth," American Economic Review, 65: 923-933.

[230] Ringer, F. (1979), Education and Society in Modern Europe (Indiana University Press, Bloomington).

[231] Robson, A.J. (2001), "The Biological Basis of Economic Behavior", Journal of Economic Literature 39: 11-33.

[232] Robson A.J., and H. S. Kaplan (2003), "The Evolution of Human Longevity and Intelligence in Hunter-Gatherer Economies," American Economic Review 93: 150-169. 
[233] Rodgers, J.L., and D. Doughty (2000), "Genetic and Environmental Influences on Fertility Expectations and Outcomes Using NLSY Kinship Data", in: J.L. Rodgers, D.C. Rowe and W.B. Miller, eds., Genetic Influences on Human Fertility and Sexuality (Kluwer, Boston).

[234] Rodgers, J.L., K. Hughes, H. Kohler, K. Christensen, D. Doughty, D.C. Rowe and W.B. Miller (2001a), "Genetic influence helps explain variation in human fertility: Evidence from recent behavioral and molecular genetic studies", Current Directions in Psychological Science 10: 184-188.

[235] Rodgers, J.L., H. Kohler, K. Ohm Kyvik, and K. Christensen (2001b), "Behavior Genetic Modeling of Human Fertility: Findings from a Contemporary Danish Twin Study", Demography 38: 29-42.

[236] Rodriguez R. and D. Rodrik (2001), "Trade Policy and Economic Growth: A Skeptic's Guide to the Cross-National Evidence," NBER Macroeconomics Annual eds. B. Bernanke and K. S. Rogoff, (MIT Press, Cambridge).

[237] Rodrik D., A. Subramanian and F. Trebbi (2004), "Institutions Rule: The Primacy of Institutions over Geography and Integration in Economic Development, Journal of Economic Growth 9.

[238] Rosenzweig, M.R., and K. I. Wolpin (1980), "Testing the Quantity-Quality Fertility Model: the use of Twins as a Natural Experiment", Econometrica 48: 227-240.

[239] Saint-Paul, G. (2003), "On Market and Human Evolution" CEPR Discussion Paper No. 3654.

[240] Sala-i-Martin, X. (2002), The Disturbing "Rise" in World Income Distribution," NBER Working Paper.

[241] Sanderson, M. (1995), Education, Economic Change and Society in England 1780-1870 (Cambridge University Press, Cambridge).

[242] Schofield, R. S. (1973) "Dimensions of Illiteracy, 1750-1850," Explorations in Economic History 10: $437-454$.

[243] Schultz, T.W. (1964), Transforming Traditional Agriculture (Yale University Press, New Haven).

[244] Schultz, T.W. (1975), "The Value of the Ability to Deal with Disequilibria", Journal of Economic Literature 8: 827-846.

[245] Simon, B. (1987), "Systematization and Segmentation in Education: the Case of England", in: D. Muller, F. Ringer and B. Simon, eds., The Rise of the Modern Educational System (Cambridge University Press, Cambridge).

[246] Smith, A. (1776), The Wealth of Nations (Modern Library, New-York, 1937).

[247] Smith, D. (2001), "International evidence on how income inequality and credit market imperfections affect private saving rates", Journal of Development Economics 64: 103-127.

[248] Soares, R. R. (2003), "Mortality Reductions, Educational Attainment, and Fertility Choice," University of Maryland.

[249] Spree, R. (1977), Die Wachstumszyklen der deutschen Wirtschaft von 1840 bis 1880 (Dunker \& Humboult, Berlin).

[250] Stokey, N. (2001), "A Quantitative Model of the British Industrial Revolution, 1780-1850. Carnegie-Rochester Conference Series on Public Policy 55: 55-109.

[251] Stone, L., (1969), "Literacy and Education in England 1640-1900," Past and Present 42: 69-139.

[252] Tamura, R.F. (2002), "Human Capital and the Switch From Agriculture to Industry", Journal of Economic Dynamics and Control 27: 207-242.

[253] Taylor, A. M. (1999), "Sources of Convergence in the Late Nineteenth Century", European Economic Review 9: 1621-45.

[254] U.S. Bureau of the Census, (1975), Historical Statistics of the United States: Colonial Times to 1970 (part 1) Series D 830-844, p.172. 
[255] Voth, H-J., (2003) "Living Standards During the Industrial Revolution: An Economist's Guide," American Economic Review, 93: 221-226.

[256] Voth, H-J., (2004) "Living Standards and the Urban Environment," in Paul Johnson and Roderick Floud,eds., The Cambridge Economic History of England. (Cambridge University Press, Cambridge).

[257] Weil, D.N. (2004), Economic Growth, (Addison Weseley, Boston).

[258] Weisdorf, J. L. (2004) "From Stagnation to Growth: Revisiting Three Historical Regimes." Journal of Population Economics (forthcoming).

[259] Weisenfeld, S.L. (1975), "Sickle Cell Trait in Human Biological and Cultural Evolution", Science 157: $1135-1140$.

[260] West, E.G. (1985), "Literacy and the Industrial Revolution", in: J. Mokyr, ed., The Economics of the Industrial Revolution (Rowman and Littlefield).

[261] Williamson, J.G. (1985), Did British Capitalism Breed Inequality? (Allen \& Unwin, Boston).

[262] Wilson, E.O. (1975), Sociobiology (The Belknap Press of Harvard University Press, Cambridge).

[263] Wolthuis, J. (1999), Lower Technical Education in the Netherlands 1798-1993: the Rise and Fall of a Subsystem. Netherlands.

[264] Wrigley, E.A. (1969), Population and History (McGraw-Hill, New York).

[265] Wrigley, E.A., and R.S. Schofield (1981), The Population History of England 1541-1871: A Reconstruction (Harvard University Press, Cambridge).

[266] Yates, P.L. (1959), Forty Years of Foreign Trade: A Statistical Handbook With Special Reference to Primary Products and Underdeveloped Countries (Allen \& Unwin, London).

[267] Young, A. (1991), "Learning by Doing and the Dynamic Effects of International Trade," Quarterly Journal of Economics, 106 369-405. 